\title{
Identifying infestation probabilities of Emerald Ash Borer (Agrilus planipennis, Fairmaire) in the Mid-Atlantic region
}

\author{
William D. Ayersman \\ West Virginia University
}

Follow this and additional works at: https://researchrepository.wvu.edu/etd

\section{Recommended Citation}

Ayersman, William D., "Identifying infestation probabilities of Emerald Ash Borer (Agrilus planipennis, Fairmaire) in the Mid-Atlantic region" (2010). Graduate Theses, Dissertations, and Problem Reports. 2948. https://researchrepository.wvu.edu/etd/2948

This Thesis is protected by copyright and/or related rights. It has been brought to you by the The Research Repository @ WVU with permission from the rights-holder(s). You are free to use this Thesis in any way that is permitted by the copyright and related rights legislation that applies to your use. For other uses you must obtain permission from the rights-holder(s) directly, unless additional rights are indicated by a Creative Commons license in the record and/ or on the work itself. This Thesis has been accepted for inclusion in WVU Graduate Theses, Dissertations, and Problem Reports collection by an authorized administrator of The Research Repository @ WVU. For more information, please contact researchrepository@mail.wvu.edu. 


\title{
Identifying Infestation Probabilities of Emerald Ash Borer (Agrilus planipennis, Fairmaire) in the Mid-Atlantic Region
}

\author{
William D. Ayersman
}

Thesis submitted to the Davis College of Agriculture, Natural Resources and Design at West Virginia University in partial fulfillment of the requirements for the degree of

\author{
Master of Science \\ in \\ Forestry
}

\author{
Michael Strager, Ph.D., Chair \\ John Brooks, Ph.D. \\ Yong-Lak Park, Ph.D.
}

Division of Forestry and Natural Resources

Morgantown, West Virginia

2010

Keywords: emerald ash borer, predictive modeling, maximum entropy, Mid-

Atlantic region, management strategies 


\title{
Abstract \\ Identifying Infestation Probabilities of Emerald Ash Borer (Agrilus planipennis, Fairmaire) in the Mid-Atlantic Region
}

\author{
William D. Ayersman
}

Emerald Ash Borer (EAB) impacts all species of North American ash trees, and has caused several million dollars (U.S.) in damage to trees across the affected region. EAB is primarily spread through the movement of trees and wood products, such as nursery stock and firewood. This thesis assessed the potential risk of EAB introduction in the Mid-Atlantic region of the U.S., where the species has not yet been as widely reported. Using a Geographic Information Systems-based approach, a risk prioritization framework was developed to assess and rank various mapped factors for EAB introduction. Results indicated high risk areas throughout the study region with approximately 30 counties being cited for potential risk. From an analysis of risk versus ash basal area for all counties, three management strategies were derived; quarantine, plan harvest, public outreach and monitoring. 


\section{Acknowledgements}

I wish to thank all my committee members for their assistance and guidance while working on my thesis. All the knowledge I've gained through this experience will be invaluable to me in the future. This project would not have been possible without each of your contributions. I would like to especially thank Dr. Strager for all advice throughout my graduate career, and without him, I would be truly overwhelmed.

I would also like to thank Rick Turcotte and Ann Steketee from the USDA Forest Service in Morgantown, WV, for their project funding and suggestions throughout the entire process. Without their expertise and funding, this Masters degree would not have been possible.

I also wish to thank all my friends for their support throughout this endeavor. You all have stuck with me through the good times and bad. Somehow, all my friends managed to keep me sane during the stressful times.

Lastly, I appreciate the utmost support from my family, who all encouraged me to pursue a graduate level education and to always do the best I could. Without their endless support and love, I could have never achieved this goal. To my mom, dad, granddad, and my sister, I love you all more than you can imagine. 


\section{Table of Contents}

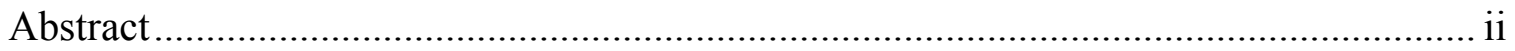

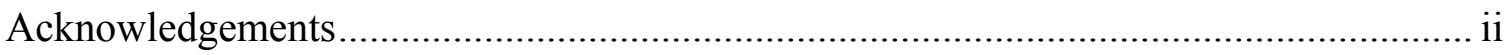

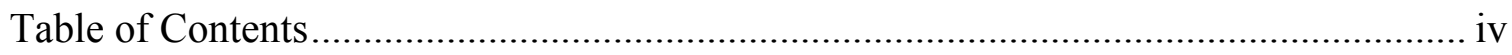

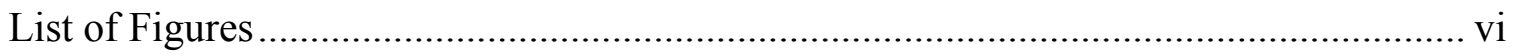

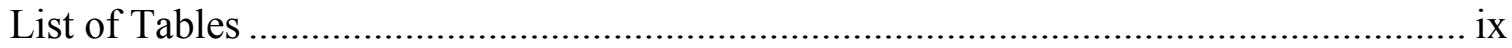

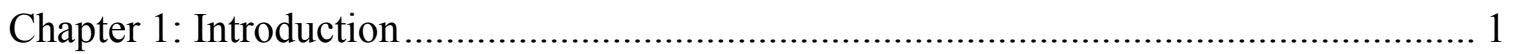

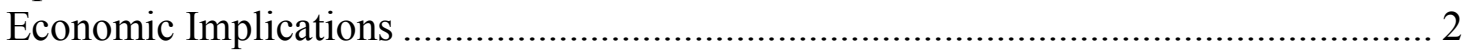

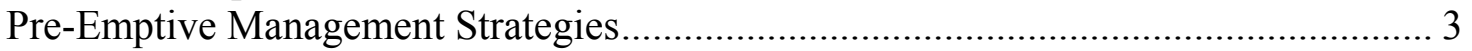

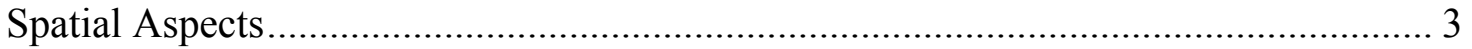

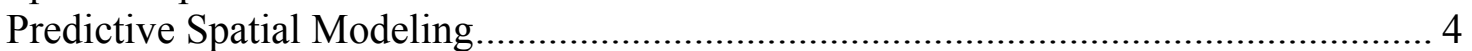

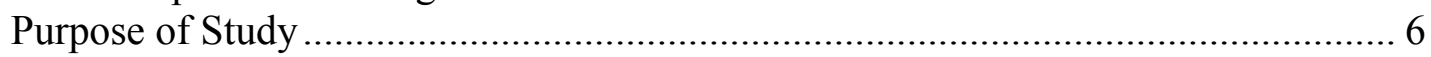

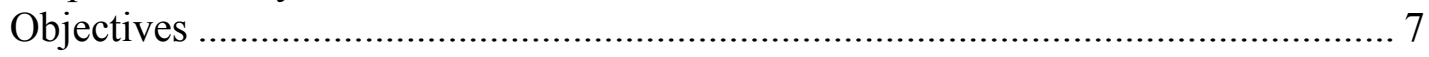

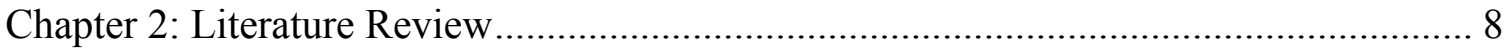

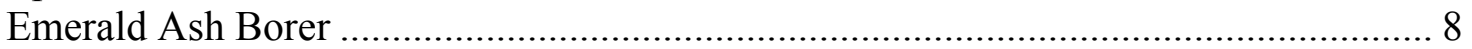

Emerald Ash Borer: The Arrival and Spread....................................................... 8

Invasive Insects and the Urban Ecosystem............................................................. 9

Native Ranges and Natural Enemies of Emerald Ash Borer .................................... 11

Impacts from the Emerald Ash Borer .................................................................... 12

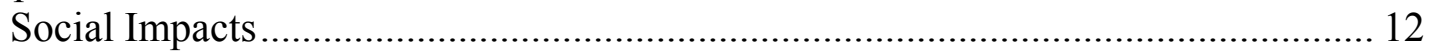

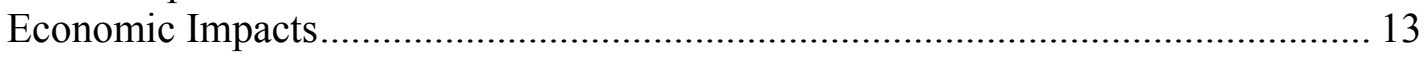

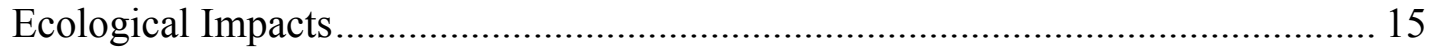

Ash Abundance in the Mid-Atlantic .................................................................. 16

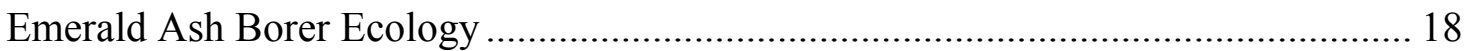

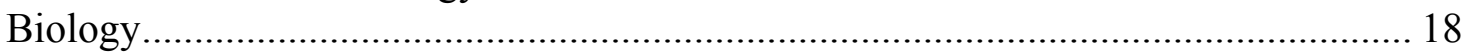

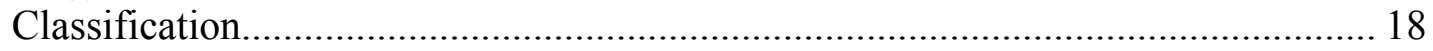

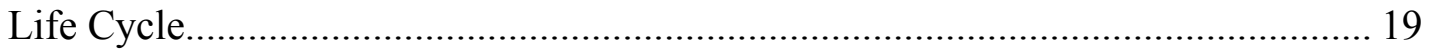

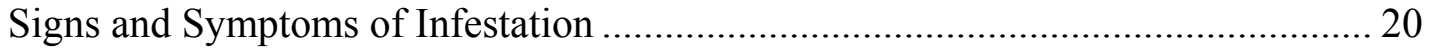

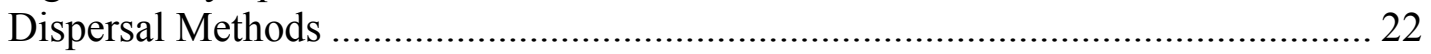

Current Options for Monitoring and Treatment........................................................ 23

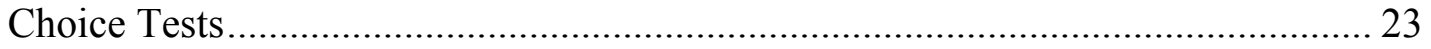

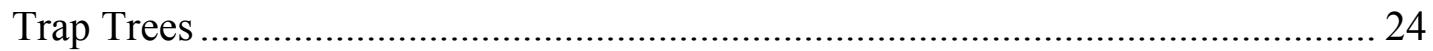

Treatment Procedures .................................................................................. 24

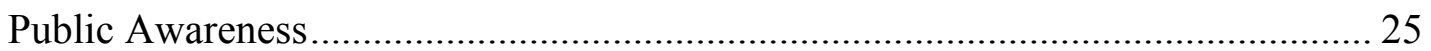

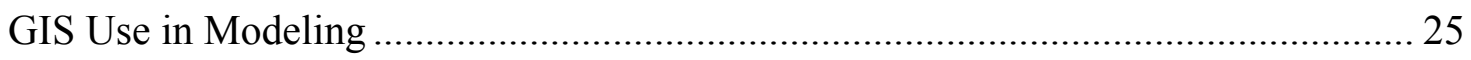

Using GIS Data in Risk Modeling ..................................................................... 27

Previous GIS Studies Involving Emerald Ash Borer............................................. 28

Review of Maximum Entropy .......................................................................... 32 


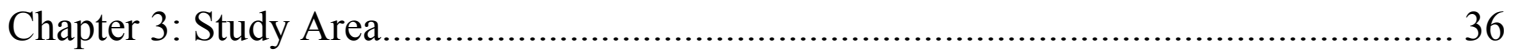

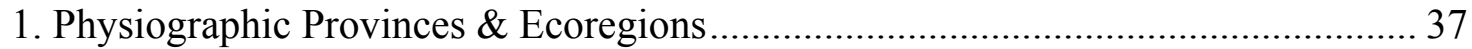

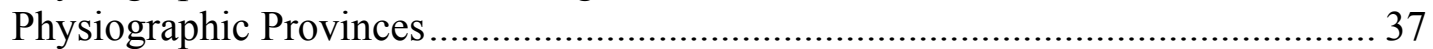

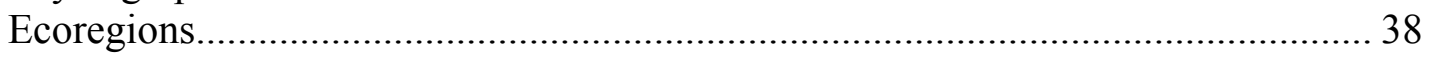

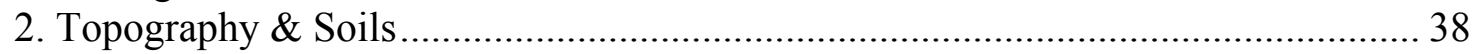

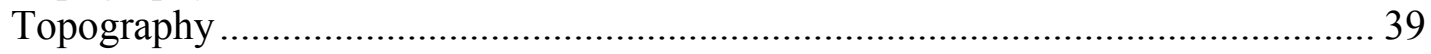

Soils

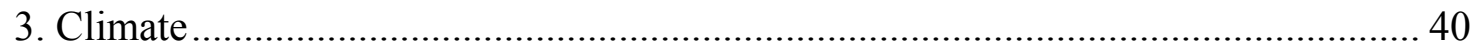

4. Prior Invasive Species and Disease Outbreaks .................................................... 41

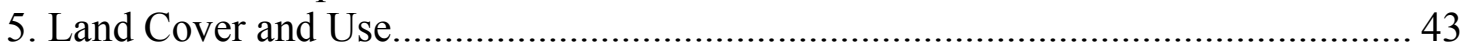

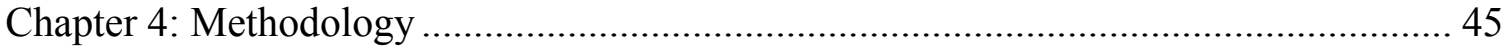

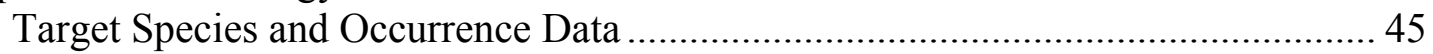

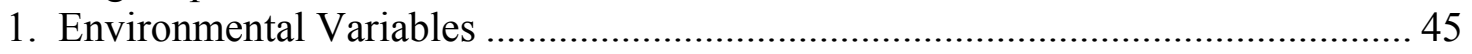

1.1 Campground, Nursery, and Sawmill Density Grids ......................................... 46

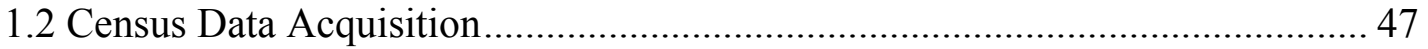

1.3 Road Intersection and Rest Area Dataset Creation............................................ 48

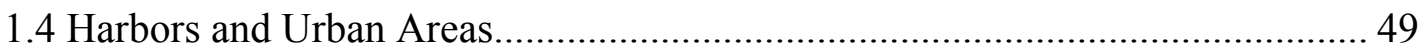

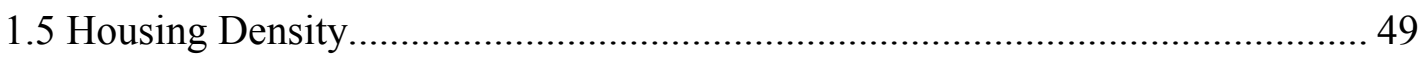

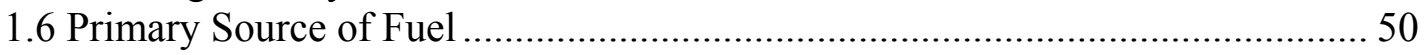

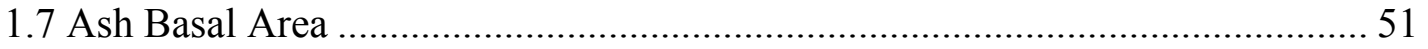

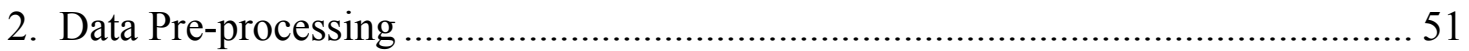

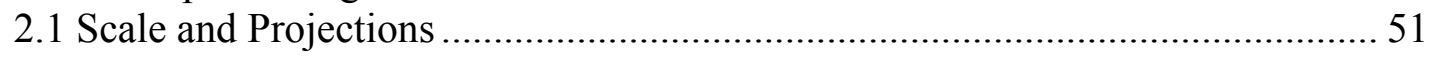

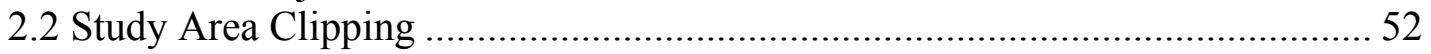

2.3 Creation of ASCII Grids ........................................................................... 52

3. Maximum Entropy Model Parameters.................................................................. 53

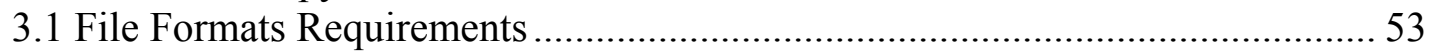

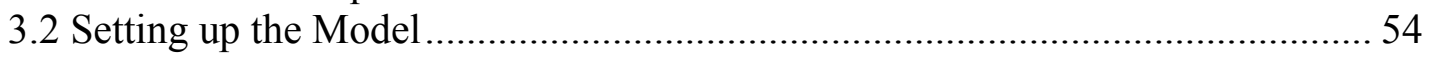

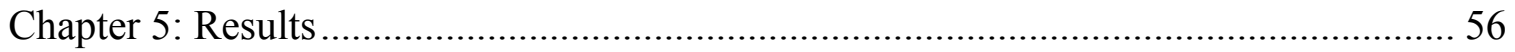

Analysis of Predictive Power and Error................................................................. 56

Predictive Probability of Presence Map................................................................ 59

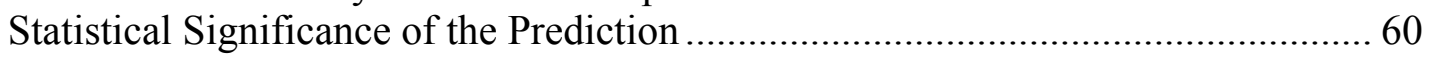

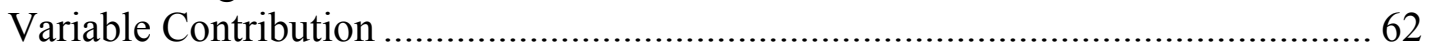

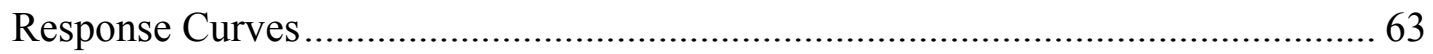

Jackknife Analysis of Environmental Variables..................................................... 75

Chapter 6: Discussion and Conclusions......................................................................... 79

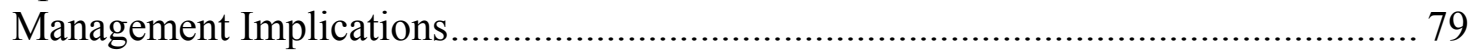

Contiguous High Risk Areas …………………………................................... 79

Ash Basal Area versus High Risk Areas............................................................. 80

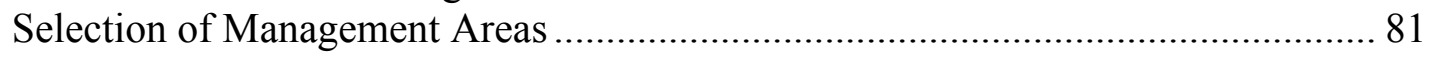

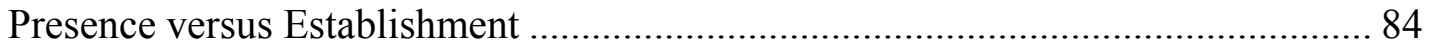

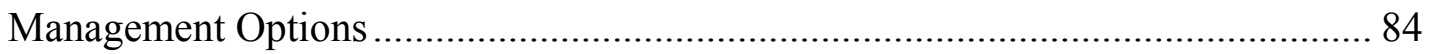

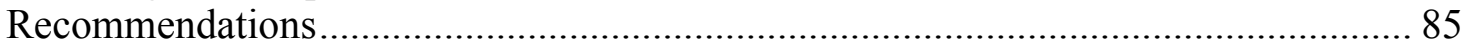

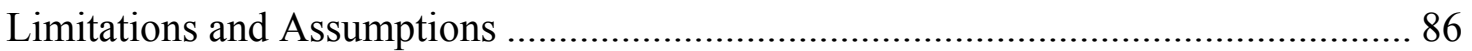




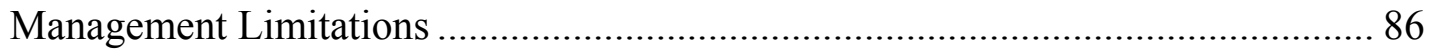

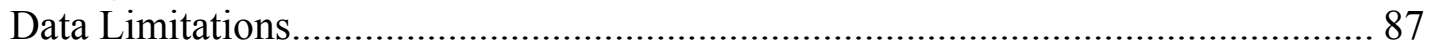

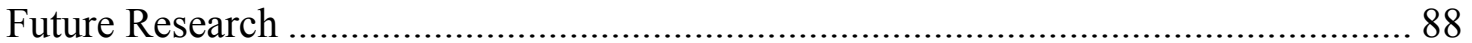

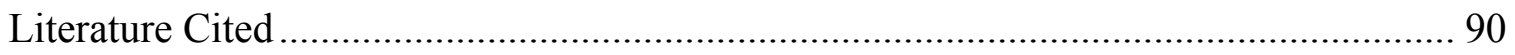

\section{List of Figures}

Figure 1. Damages associated with EAB. Photo by Steven Katovich, USDA Forest

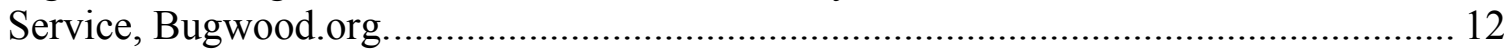

Figure 2. Tree mortality associated with EAB damages. Photo by Daniel Herms, The

Ohio State University, Bugwood.org.......................................................................... 15

Figure 3. Native range of green ash (left) and white ash (right). Photo taken from Burns

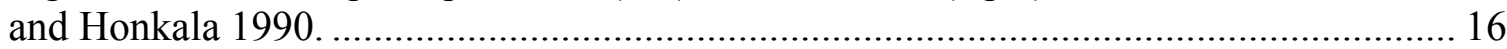

Figure 4. Emerald Ash Borer. Photo by David Cappaert, Michigan State University,

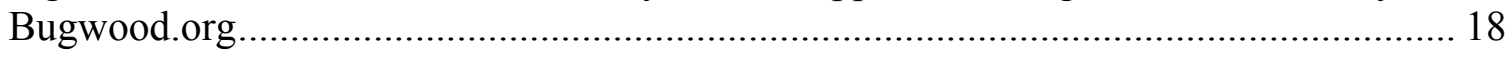

Figure 5. EAB adult. Photo by David Cappaert, Michigan State University, Bugwood.org

Figure 6. EAB larvae. Photo by David Cappaert, Michigan State University,

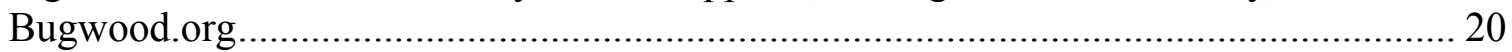

Figure 7. D-shaped exits holes associated with emerging EAB adults. Photo by Daniel Herms, The Ohio State University, Bugwood.org ..................................................... 20

Figure 8. Epicormic branching. Photo by Michigan Department of Agriculture,

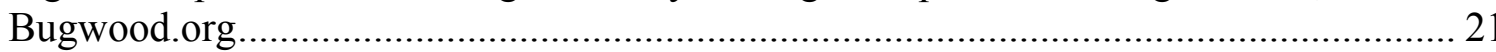

Figure 9. Trap tree used to lure EAB adults. Photo by Pennsylvania Department of Conservation and Natural Resources - Forestry Archive, Bugwood.org......................... 24

Figure 10. Diagram of fundamental and occupied niches explaining species distributions in geographical and environmental space. Taken from Pearson (2007)........................ 35

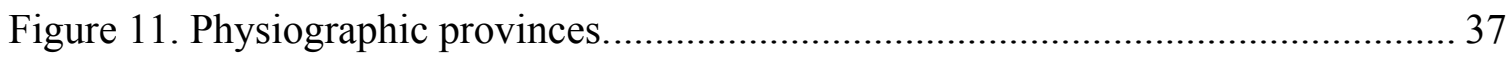

Figure 12. Ecoregions in the Mid-Atlantic....................................................... 38

Figure 13. Elevation above sea level (meters) ..................................................... 39

Figure 14. NRCS map of soil orders for the Mid-Atlantic .......................................... 40 
Figure 15. Climate zone map acquired from howtotravelamerica.com............................ 41

Figure 16. NLCD land cover image for the emerald ash borer study area...................... 44

Figure 17. Omission and commission errors in Maxent model for EAB. ....................... 57

Figure 18. Receiver operating curve (ROC) representing area under the curve (AUC) justifying the model's predictive power for probability of EAB presence. ....................... 58

Figure 19. Predicted potential probability of presence for EAB in the Mid-Atlantic....... 60

Figure 20. Common threshold values from one simulation of the replications for the Maxent EAB model.

Figure 21. Response curves for ash basal area grid for the Maxent EAB model. The left curve represents the marginal response curve and the corresponding variable curve located on the right. The $\mathrm{x}$-axis represents the amount of basal area while the $\mathrm{y}$-axis is probability of presence.

Figure 22. Response curves for campground density for the Maxent EAB model. The left curve represents the marginal response curve and the corresponding variable curve located on the right. The $\mathrm{x}$-axis represents density within a five mile search radius using kernel density. The y-axis is probability of presence.

Figure 23. Response curves for the distance to harbors grid for the Maxent EAB model. The left curve represents the marginal response curve and the corresponding variable curve located on the right. The $\mathrm{x}$-axis represents distance (meters) from the closest harbor. The $y$-axis is probability of presence.

Figure 24. Response curves for the distance to urbanized areas grid for the Maxent EAB model. The left curve represents the marginal response curve and the corresponding variable curve located on the right. The $\mathrm{x}$-axis represents distance (meters) from the urban area boundary. The y-axis is probability of presence.

Figure 25. Response curves for the housing density grid in the Maxent EAB model. The left curve represents the marginal response curve and the corresponding variable curve located on the right. The $\mathrm{x}$-axis represents housing units per square kilometer. The yaxis is probability of presence.

Figure 26. Response curves for the human population for the Maxent EAB model. The left curve represents the marginal response curve and the corresponding variable curve located on the right. The $\mathrm{x}$-axis represents the total human population per block group from the 2000 census. The $y$-axis is probability of presence.

Figure 27. Response curves for the major (i.e. interstates and U.S. highways) road intersections and rest areas for the Maxent EAB model. The left curve represents the 
marginal response curve and the corresponding variable curve located on the right. The $\mathrm{x}$-axis represents the distance (meters) from each intersection or rest area. The y-axis is probability of presence.

Figure 28. Response curves for the seasonal homes for the Maxent EAB model. The left curve represents the marginal response curve and the corresponding variable curve located on the right. The $\mathrm{x}$-axis represents the total number of seasonal homes (secondary homes) per block group from the 2000 census. The y-axis is probability of presence

Figure 29. Response curves for tree production (nurseries) density within a five mile radius for the Maxent EAB model. The left curve represents the marginal response curve and the corresponding variable curve located on the right. The $\mathrm{x}$-axis represents the density of tree production. The y-axis is probability of presence.

Figure 30. Response curves for the wood transportation (i.e. sawmills, logging, and firewood) density with a search radius of 50 miles for the Maxent EAB model. The left curve represents the marginal response curve and the corresponding variable curve located on the right. The $\mathrm{x}$-axis represents the density of available businesses that transport wood. The $y$-axis is probability of presence.

Figure 31. Response curves for the homes that use firewood by county for the Maxent EAB model. The left curve represents the marginal response curve and the corresponding variable curve located on the right. The $\mathrm{x}$-axis represents the total homes per county. The y-axis is probability of presence.

Figure 32. Results of jackknife evaluations of relative importance of environmental variables for EAB Maxent model using training data. For non abbreviated variables reference Table 2

Figure 33. Results of jackknife evaluations of relative importance of environmental variables for EAB Maxent model using test data. For non abbreviated variables reference Table 2.

Figure 34. Results of jackknife evaluations of relative importance of environmental variables for EAB Maxent model using AUC data. For non abbreviated variables reference Table 2

Figure 35. Spatial distribution of counties that have high risk or that could potentially be affected by EAB 83

Figure 36. Scatter plot of management options for the EAB study area. The green marks indicate all counties within the study area while the yellow dots indicate the counties that are currently quarantined. 85 


\section{List of Tables}

Table 1. NLCD 2001 land cover area (in $\mathrm{km}^{2}$ ) and percentage for the EAB study region.

Table 2. ArcMap corner coordinates for the EAB study area......................................... 52

Table 3. Selected environmental variables and their percent contribution (average of 10 simulations) in Maxent model for EAB in the Mid-Atlantic study region................63

Table 4. Counties by state that contain at least $26 \mathrm{~km}^{2}$ ( $\sim 6500$ acres) of high risk area

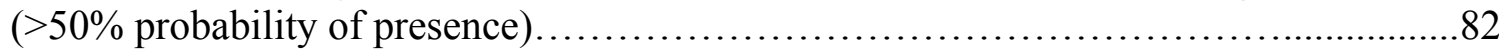

Table 5. Potential counties to be at risk for EAB. These counties have tens of thousands of acres with probabilities ranging from $25-50 \%$.........................................................83 


\section{Chapter 1: Introduction}

Invasive, or exotic species, frequently receive great attention from researchers and natural resource agencies due to the potential for rapid spread and widespread damage. They pose challenges to indigenous life forms because they use valuable resources, have no known natural enemies, and thrive in environments suitable for their survival. One invasive species, in particular, that has quickly arisen as a major threat in the United States is the emerald ash borer (Agrilus planipennis, Fairmaire: Coleoptera: Buprestidae). The emerald ash borer (EAB) was introduced sometime in the mid 1990s in Detroit, Michigan (Siegart et al. 2008) and first reported in July 2002 (Poland and McCullough, 2006). Since that time, EAB has spread to several states throughout the upper Mid-West and Mid-Atlantic regions (USDA APHIS, 2008).

For over 10 years, the EAB has been killing ash (Fraxinus spp.) trees throughout the upper Mid-West and Mid-Atlantic Regions of the United States. To date, the EAB has collectively killed over 20 million ash trees within these regions with no sign of slowing down. It takes roughly 2-3 years, after infestation, before tree mortality occurs. Through its numerous vectors (firewood, nursery stock, flight, etc), EAB is spreading without much resistance.

With tree mortality and its rapid spread, total costs associated with the EAB are hard to quantify. Monetary figures such as tree removal, tree replacement, and timber damage can be derived, but it's difficult to obtain a dollar amount for loss of non-market items such as an aesthetic value or reduced wildlife habitat associated with tree mortality. In addition, limited monetary resources are available for treatment procedures so eradication efforts cannot be blindly established. Currently, each state, with a significant ash population, has a written reaction plan for $\mathrm{EAB}$ identifying how to treat and monitor its presence. Interstate rest areas are targeted sites for sampling traps because of the high volume of human traffic. Visual surveys are 
also conducted to monitor spread but are not extremely effective, especially in new areas of contamination, since symptoms do not normally occur for one to three years. Trap trees and artificial traps are generally unreliable due to weak responses and recognition of them by the insect.

\section{Economic Implications}

Given that ash is a valuable hardwood species in the US, economic impacts are at high risk. It is estimated that there are more than 8 billion ash trees in the US, of which more than 700 million occur in Michigan, 280 million in Ohio, and 150 million in Indiana (Mastro et al. 2007; Wei et al. 2007). Wisconsin currently has approximately 720 million ash trees with black and green being the most prevalent (Perry et al. 2008). Wide-range establishment of EAB could have substantial impacts on the landscape of the upper Mid-West and Mid-Atlantic regions because of lost timber value, wildlife habitat, and depletion of urban shade trees. Damages could result in a total loss of millions of board feet of ash sawlogs and veneer. Totals in Michigan alone reach upwards of 307 million board feet with a compensatory value as high as $\$ 18.9$ billion (Poland and McCullough, 2006; Mastro et al. 2007; Wei et al. 2007). In addition, the total impact of the losses will include the loss in landscape value, the cost of tree removal, including stumps, and the cost of replacement trees. For example, in Ohio, the total loss for removal and replacement could range from $\$ 1.8$ to $\$ 7.8$ billion alone (Sydnor et al. 2007).

By examining the losses in Michigan and Ohio, potential damages could result in billions of dollars in damages throughout the rest of the Mid-Atlantic region. The West Virginia Department of Agriculture EAB Action Plan indicates that the EAB could potentially affect 3090 million trees having a value of $\$ 20-60$ billion. The nursery industry could also be in jeopardy, as ash stock accounts for \$100-140 million in revenue annually. In Michigan alone, 
eradication efforts have cost over $\$ 328$ million as of 2003 and continue to increase with infestations spreading rapidly (Poland and McCullough, 2006).

\section{Pre-Emptive Management Strategies}

Protecting and saving ash trees should be one of the main priorities when dealing with EAB spread. Infected ash trees and products cannot be sold on the market, rendering them as wasted material. A solution for urban landowners, and others with small property holdings, is to pre-treat ash trees giving them a better chance of survival. Many chemical treatments such as basal applicators, systemic injections, soil injection, and foliar applications are available for use (Herms et al. 2009). Landowners should take initiative and protect their ash trees and save money in the future.

An alternate solution for landowners and managers with large woodlots of contiguous ash is to harvest that timber in advance of EAB establishment and mortality to avoid serious loss. This provides a better solution where it is not applicable or economically feasible to apply chemical treatments to protect trees. Pre-emptive harvesting utilizes ash timber without waste making it a good treatment option while providing a source of income for the landowner.

\section{Spatial Aspects}

Studies ranging from bio-control treatments to risk modeling with Geographic Information Systems (GIS) have been ongoing in order to learn as much as possible about this curious new insect and the outcomes associated with pest outbreaks. In the past decade, GIS has proven to be a powerful tool for analyzing spatial problems. Utilization of GIS allows users to collect, manage, and analyze large amounts of data that can be linked to spatial locations within the given study region (Ward and Johnson, 2007). Using GIS to model invasive species will aid 
in the process of understanding their dispersal, distributions, and habitats. Defining where a species may survive depends heavily on being able to determine its existing or potential habitat (Holcombe et al. 2007).

GIS has been applied in many applications dealing with indigenous and non-indigenous forest pests. Wolter et al. (2008) used Landsat data to map the abundance of the host species for the spruce budworm for future planning and modeling of outbreaks. Additional GIS applications in research studies include the development of a hazard rating system for pine beetles (Cook et al. 2007), predicting the spread of forest pathogens (Hunter et al. 2008) and monitoring landscape classification (Mora and Iverson, 2002).

Exclusive EAB studies have involved capturing ash decline using hyperspectral technologies by predicting forest health with an emphasis on ash species in areas that are currently being impacted by EAB (Pontius et al. 2008). In another study, BenDor et al. (2006) spatially modeled EAB spread with anthropogenic criteria and modeled the spread while only using natural movement of EAB. Tests from that study showed that EAB spread was accelerated when anthropogenic factors were included in the model. The Minnesota Dept. of Agriculture took this a step further by incorporating human vectors (campgrounds, nurseries, wood producers, population data, etc.) into their modeling approach. Their findings suggest that weights should be applied for each of the vectors because the likelihood of spread is not consistent throughout all vectors. In addition, their model was one of the first spatial models to predict the risk of EAB introduction with urban areas and human population.

\section{Predictive Spatial Modeling}

Predictive models of spatial distribution of species are valuable in numerous ecological and conservation applications (Phillips and Dudik, 2008). Examples of predictive modeling 
includes mapping suitable locations for threatened and endangered species (Kumar \& Stohlegren, 2009), predicting fungal distribution patterns (Wollan et al. 2008), and spread of invasive insects (Thuiller et al. 2005). However, the vast majority of these models depend on the availability of presence and absence data (Phillips and Dudik, 2008). Research is beginning to shy away from the requirement to provide absence data when creating predictive models, especially since the amount of absence data is rare (Phillips et al. 2006). The lack of systematic sampling is the most likely reason as to why this occurs (Elith et al. 2006). Use of presence-only data certainly has its advantages, but some of the data collection methods can be biased toward individual studies (Elith et al. 2006). Ecological (or niche) modeling with presence-only data has been gaining recognition in the last few years (Peterson et al. 2007). Species modeling using presence data needs to have environmental criteria to produce the suitability for the species in question (Phillips et al. 2006). Environmental criteria (variables) can include but are not limited to: topographic, climatic, edaphic, and remotely sensed data. A number of models can predict distributions from presence and absence data such as Genetic Algorithm for Rule Set Production (GARP), Classification and Regression Trees (CART), Greater Linear Models (GLM), and Greater Additive Models (GAM). A relatively new predictive modeling approach, maximum entropy, allows for only presence data to be used when modeling which is convenient for users because it does not involve the hassle of collecting absence data.

Maximum entropy (Maxent) is described as a general purpose method for making predictions using incomplete information. Maxent models probability distributions well with few occurrence points which makes it an excellent choice for this study. The model design uses prior information and follows the basic principal of agreeing with what is proven to be known while carefully avoiding assumptions to anything that is unknown (Jaynes, 1957). Avoided 
assumptions allow the model to produce more accurate results than the other predictive models which enforces why Maxent is the selected model for this study. Since Maxent is built upon a Bayesian statistical model, the model has the ability to predict not only current infestation distributions but also has the predictive power to find new potential areas where EAB has the greatest risk of introduction through interpolation.

\section{Purpose of Study}

The purpose of this study is to develop a predictive model that can be used to identify areas most susceptible to EAB in efforts to slow or contain the spread through human mediated criteria. These criteria are described as any human interaction variables that could be associated with EAB spread. This study attempts to model the susceptibility of future spreading for areas not yet affected by EAB within the six-state study area of DE, MD, NJ, OH, PA, WV and the District of Columbia. This study will look to build upon past EAB models by introducing the idea of recently urbanized growth, housing density, land use changes, and by including homes that use firewood as the main source of fuel. This mapping and modeling effort to locate new susceptible areas should increase recognition about EAB in the Mid-Atlantic region and will hopefully prevent future destructive impacts.

Currently, land managers are taking a reactive approach to the EAB spread. Timelines begin when infestations are first found, and then extensively monitor sites often resulting in regulatory action otherwise known as quarantine boundaries. Regulatory restrictions usually begin on a county-wide level, prohibiting the movement of any ash from within the boundaries in a desperate attempt to slow spreading, and then, migrate to state quarantines. Treatments are a likely approach but they are not economically feasible after approximately $50 \%$ of the canopy has died (Herms et al. 2009). Instead, all trees are cut down within a certain distance of the 
infestation. Eradication distance varies greatly based on how extensively the area was monitored and size of the infestation. So far, these measures have yielded unsuccessful results, largely due to people unknowingly moving EAB through quarantined boundaries.

This research seeks to give land managers a proactive approach to EAB spread. By creating this model, land managers will be able to monitor areas deemed to have the highest probability of presence based on current EAB locations and human spread factors from past research. Implementation of monitoring and treatment methods can be established before EAB colonies are found, which increases survival success of ash trees and possibly saving millions of dollars in eradication processes in the future.

\section{Objectives}

The objectives of this study are to;

1) create spatial data layers related to spread and establishment of EAB through anthropogenic criteria

2) implement an appropriate modeling framework in order to utilize these data layers using GIS, and

3) map and identify new high risk areas for EAB for management and monitoring. 


\section{Chapter 2: Literature Review}

\section{Emerald Ash Borer}

Regarded as one of the most destructive invasive pests in North America, the emerald ash borer (Agrilus planipennis, Fairmaire) has quickly made a profound impact on the United States (Haack et al. 2002; Cappaert et al. 2005; Poland and McCullough, 2006; Mastro et al. 2007; Wei et al. 2007). Within the first five years of inception (1998 to 2003), the core area of infestation by EAB had increased 170-fold (Siegart et al. 2008). Even EAB outlier populations have spread more rapidly than first predicted (Cappaert et al. 2005; Iverson et al. 2006; Heimlich et al. 2008). Currently, EAB infestation has resulted in rapid mortality of ash (Fraxinus spp.) of various sizes and habitats (Pontius et al. 2008). While EAB has had adverse impacts on forest biodiversity, it also creates problems in urban ecosystems because ash resources are not only widely distributed in forested ecosystems but also planted as shade trees and ornamentals (Lui and Bauer, 2008).

\section{Emerald Ash Borer: The Arrival and Spread}

First reports of EAB came from Detroit in the summer of 2002. In July 2002, EAB was discovered to be the causal agent of decline and mortality of ash throughout the city of Detroit (Poland and McCullough, 2006). Soon after, population density surveys were conducted in areas where tree mortality had occurred (Poland and McCullough, 2006). In an unrelated study, a cross-dating analyses of the area suggested that $\mathrm{EAB}$ was originally established in the WestlandGarden City vicinity of Michigan in 1997-1998 (Siegart et al. 2008). It is believed that EAB made its entry into the United States nestled in solid wood packaging material from Asia (Cappaert et al. 2005). 
Spreading from Michigan became apparent and soon after it was discovered in Ohio in 2003. Since then, EAB has spread to 39 counties throughout the state with five other counties quarantined (Ohio Dept. of Agriculture, 2009). In Maryland, EAB was found in a Prince George County nursery in August 2003 from infested nursery stock and was quickly eradicated by March 2004 (Maryland Dept. of Agriculture, 2008). The Maryland Dept. of Agriculture also indicated that EAB larvae were found in the same vicinity in August 2006 which led to the area being quarantined once again. In 2007, EAB spread into the neighboring states of Pennsylvania and West Virginia. Pennsylvania implemented a quarantine area in the western part of the state in June of 2007 containing Allegheny, Beaver, Butler, and Lawrence counties (Pennsylvania DCNR, 2008). Most recently, EAB was confirmed in Clinton County, PA in early March 2009 (Rick Turcotte, personal communication). In West Virginia, EAB was discovered from a trap tree in Fayette County in October 2007 and is believed to be introduced by the movement of firewood (West Virginia Division of Forestry, 2008). In May 2009, a positive EAB sample was found Morgan County making it the second county in West Virginia to be identified with additional finds in Morgan and Roane counties (Yong-Lak Park, personal communication). EAB has also been confirmed in other surrounding states that include Wisconsin, Indiana, Illinois, Missouri, and Virginia by means of firewood movement and infested nursery stock (USDA APHIS, 2008).

\section{Invasive Insects and the Urban Ecosystem}

Industrial cities are often a major arrival and breeding ground for invasive insects (Poland and McCullough, 2006). Cities, such as Detroit, have numerous ports, highways, and airports for transporting various materials which facilitates spread of invasive species through a variety of different vectors (Crowl et al. 2008). All of these factors equate to an advantageous entry 
method for invasive insects because of the amount of human activity that flows to and from urban areas.

Upon arriving at a new destination, invasive insects must have suitable habitat in order to survive. Insects need food, proper temperatures, and habitable areas for reproduction to maintain a steady and increasing population (Keena, 2006). Unfortunately, the eastern United States has the proper elements needed for EAB survival. EAB thrives on green ash (F. pennsylvanica), white ash (F. americana), and black ash (F. nigra) species which are all native to the United States (Poland and McCullough, 2006). Having these native ash species as a suitable host enables EAB population growth and ultimately, with time, enables spread. In large urban areas, green and white ash are used mainly for aesthetic purposes. City landscapers often plant ash along streets and in parks as a valuable resource of shade for the public during hot summer months. In addition to aesthetics, street trees provide shade to houses, air pollution removal, and reduce storm water runoff making them extremely beneficial (Walton et al. 2008).

Urban trees are frequently planted in unfavorable sites such as parking lots, where they experience stresses from pollution, soil compaction, and damage due to human activities (Ward and Johnson, 2007; Barnd et al. 2008). Trees in natural forest settings generally experience less stress than those located along roadsides, in plantations, or city parks because they are not exposed to these harmful conditions (Lui et al. 2008). Factors such as the exposure to concrete and asphalt, shallow and compacted soils, toxic emissions, and lack of essential nutrients all have the potential to hinder tree health (Flint, 1985; Nowak et al. 2006; Ward and Johnson, 2007). These physiological stresses can weaken a tree's natural defense to diseases and insect outbreak making them vulnerable to infestation. Such stressful conditions could possibly predispose trees 
to insect or pathogen attacks increasing the chance that non-indigenous pests will increase establishment success (Poland and McCullough, 2006).

\section{Native Ranges and Natural Enemies of Emerald Ash Borer}

Due to the presence of natural enemies, EAB is only considered a minor pest in China (Lui et al. 2008). Found elsewhere in surrounding countries, EAB is also native to Taiwan, Korea, Russia, Mongolia and Japan (Haack et al. 2002; Smith et al. 2003). In Asia, ash species have rapid growth, attractive crowns, high wood quality and are resistant to most pests which makes them a desirable timber and ornamental tree species (Lui et al. 2008). In recent decades, the introduction of North America ash species to these countries have thrust EAB into pest status in some areas as well as increasing its distribution to additional locations in northern China (Lui et al. 2008). During the 1960s, in the Heilongjiang and Liaoning Provinces of China, EAB outbreaks were common in the Nearctic white ash plantings (Liu et al. 2008). The outbreak in the Liaoning Providence subsided in the late 1960s after all the white ash trees in the city of Shenyang died.

Much of the bio-control research has been done in China because EAB is native to that region. After initial studies were completed, three specific insects were found to be natural enemies of EAB which include: Spathius agrili (Hymenoptera: Braconidae), Oobius agrili (Hymentoptera: Encyrtidae) and Tetrastichus planipennisi (Hymenoptera: Eulophidae) (USDA APHIS, 2008). Since EAB is still a recent discovery in the United States, indigenous natural enemies may be somewhat slow to react to the newly introduced species. If eradication or containment of EAB cannot be obtained from resources within the United States, the introduction of Chinese natural enemies could be considered (Liu et al. 2008). For instance, in the summer of 2007, Spathius agrili was determined to have no significant impact on North 
American fauna (Strazanac et al. 2008). To test its effectiveness on EAB, three sites in Michigan were selected for Spathius agrili release for a monitoring and impact study with results still pending at this time (Strazanac et al. 2008). The introduction of these natural enemies are possible; however, more studies are needed before their use could be enacted due to environmental regulations.

\section{Impacts from the Emerald Ash Borer}

\section{Social Impacts}

Outbreaks of EAB are devastating to urban and naturally forested areas because of the

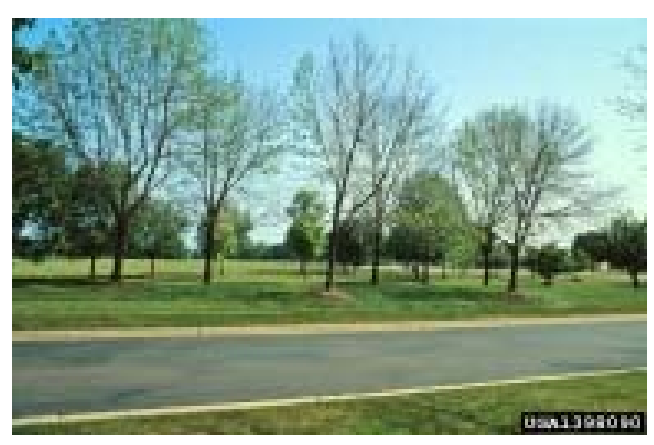

Figure 1. Damages associated with EAB. Photo by Steven Katovich, USDA Forest Service, Bugwood.org. potential to create adverse social, economic, and ecological impacts. In Detroit and many other major cities, ash is a landscape tree found in urban settings (Fig. 1). An impact of this magnitude can leave people emotionally distraught with feelings of unsatisfaction and displeasure because millions of Americans benefit

physiologically from the presence of urban trees (Nowak et al. 2006). Such drastic outcomes can result in neighborhoods being barren and having unattractive streets if outbreaks reach the point where trees must be removed. If removal is necessary, planting small trees will take years to reach the mature size of most trees that are currently being eradicated. Schroeder and Ruffolo (1996) noted that the single largest factor in determining the attractiveness of street scenes was the size of trees. Larger trees are more attractive according to homeowners.

One example of this situation is a study that was conducted in Toledo, Ohio, by Heimlich et al. (2008). His research tried to pinpoint different attitudes that were prominent when the 
removal of ash trees was ordered by the city. Currently, all of Toledo's approximately 5,000 ash street trees are scheduled for removal (Heimlich et al. 2008). From his report, many residents were eager to see the events taking place outside their homes and even offered suggestions and responses on how to handle the epidemic. Since it was apparent that residents wanted to be involved in the ash replacement strategy, the city of Toledo offered a survey for people to provide ideas for the project. Results of the study concluded that the people of Toledo wanted replacement trees planted (no particular species indicated) because it makes the streets more aesthetically appealing.

\section{Economic Impacts}

Ash is a valuable hardwood species in the United States which has great economic impact from loss. Ash wood is used for many different applications such as flooring, furniture, sports equipment and tool handles (USDA APHIS, 2008). Of the 16 native ash species (Cappaert et al. 2005), white, green, and black ash are more valuable than other ash species because of their practical uses. It is estimated that there are more than 8 billion ash trees in the US, of which more than 700 million occur in Michigan, 280 million in Ohio, and 150 million in Indiana (Mastro et al. 2007; Wei et al. 2007). The numbers in these three states are alarming because one-seventh of the ash trees located in the United States are present in this region. Another example is in Wisconsin where ash is a staple tree species. Ash is found throughout Wisconsin but is most abundant in the northern part of the state. Currently, Wisconsin has approximately 720 million ash trees with black and green being the most prevalent (Perry et al. 2008). With such a substantial amount of ash, EAB impacts in Wisconsin, and the rest of the US, are projected to match the devastation of Dutch elm disease and chestnut blight (Perry et al. 2008). 
EAB has already become widely established in Michigan and Ohio resulting in a total loss of millions of board feet of ash sawlogs and veneer. Totals in Michigan alone reach upwards of 307 million board feet with a compensatory value as high as $\$ 18.9$ billion (Poland and McCullough, 2006; Mastro et al. 2007; Wei et al. 2007). The total impact of the losses include the decline in landscape value, the cost of tree removal (including stumps), and the cost of replacement trees. In Ohio, the total losses for removal and replacement could range from $\$ 1.8$ to $\$ 7.8$ billion alone (Sydnor et al. 2007). Diminished landscape values include a variety of fiscal and environmental factors such as increased heating and cooling costs, reduced property values, increased storm water runoff, and reduced wildlife habitat as well as reduced aesthetic quality (Sydnor et al. 2007).

The fiscal impacts that are expected to occur in the state of Ohio are described by Sydnor et al. (2007). One aspect of the fiscal impacts is predicated on landscape value. This aspect represents an individual tree's contribution to the environment. The landscape value is calculated using the tree diameter, monetary values for size/species, and the tree's location on the landscape. From the report, a street tree's value was estimated to be roughly $\$ 800$ for a 12 -in diameter tree. Park trees were a bit lower (\$642). In aggregate, the potential loss in landscape value for the state of Ohio is projected to be $\$ 0.8$ to $\$ 3.4$ billion. The study compared tree removal costs as well as tree replacement costs. Tree removal costs are similar to landscape values and range from $\$ 0.7$ to $\$ 2.9$ billion and will most likely need to be covered by public and private budgets. Tree replacement costs are lower than landscape values and tree removal costs, but still range from $\$ 0.3$ to $\$ 1.3$ billion and will also need to be covered by public and private budgets. Total costs, including landscape, removal, and replacement costs, are $\$ 1.7$ billion at 
best. In a worst case scenario, grand totals yield a loss of $\$ 7.5$ billion as a result of EAB, which is a staggering amount for a single pest in a single state (Sydnor et al. 2007).

\section{Ecological Impacts}

In Michigan, as well as numerous other states, many landscapers and city organizations plant monocultures (single species) to reduce costs. Infestations in these monocultures will likely have a disastrous outcome when epidemics arrive because of lack of diversity (Whitesell et al. 1992). When invasive outbreaks affect cities, rapid spread usually occurs which can create the potential for disaster. Monocultures make it difficult to contain or eradicate pests because every tree within a given radius is susceptible to infection. For instance, a similar situation has occurred before in Detroit when the American elm population was destroyed by Dutch elm disease

in the 1950s and 1960s (Poland and McCullough, 2006). Once

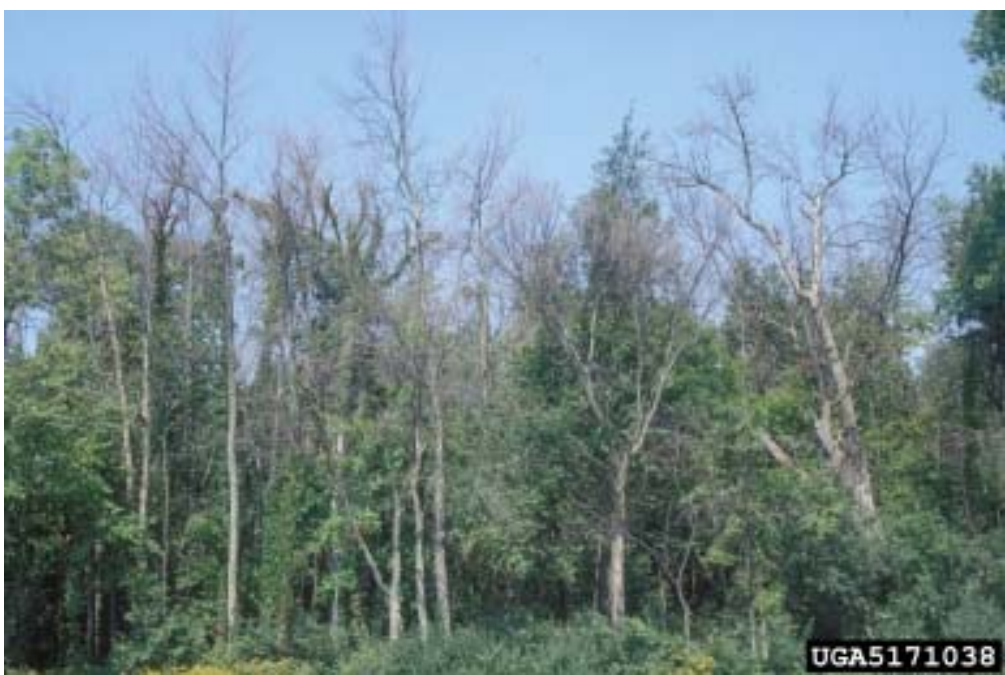

Figure 2. Tree mortality associated with EAB damages. Photo by Daniel Herms, The Ohio State University, Bugwood.org.

all elms were cleared from the city, ash was planted to re-inhabit the decimated areas.

Natural forest ecosystems are at just a high risk as the urban ecosystems from EAB infestations (Fig. 2). In 2003, the Federal Register estimated that the United States contains roughly 8 billion ash trees, the vast majority of which are growing throughout our forest landscapes. According to Poland and McCullough (2006), EAB impacts are difficult to quantify, ecologically, but could be profound in the long-term. For example, the loss of ash could affect 
certain wildlife populations because ash trees provide browse, thermal cover, and protection for a variety of wildlife species (Heyd, 2005). Seeds, which are often produced in abundance, are consumed by song and game birds, small mammals, and insects. Without this source of food and shelter, some wildlife species could have trouble adapting to the extenuating circumstances.

\section{Ash Abundance in the Mid-Atlantic}

Naturally, ash grows in a variety of the 26 known forest cover types with white ash, green ash, and black ash being the most abundant in volume. White ash prefers rich, moist, welldrained soils with high nitrogen content and a moderate to high calcium content which can be found throughout eastern United States (Burns and Honkala, 1990). Green ash is the most widely distributed of all the American ashes (Fig. 3) and generally grows on moist bottom land or stream bank sites (Burns and Honkala, 1990). Because green ash is resistance to most insects and disease, it is a very popular ornamental tree. Black ash can be found in mixed stands but most often grows in poorly drained sites such as bogs
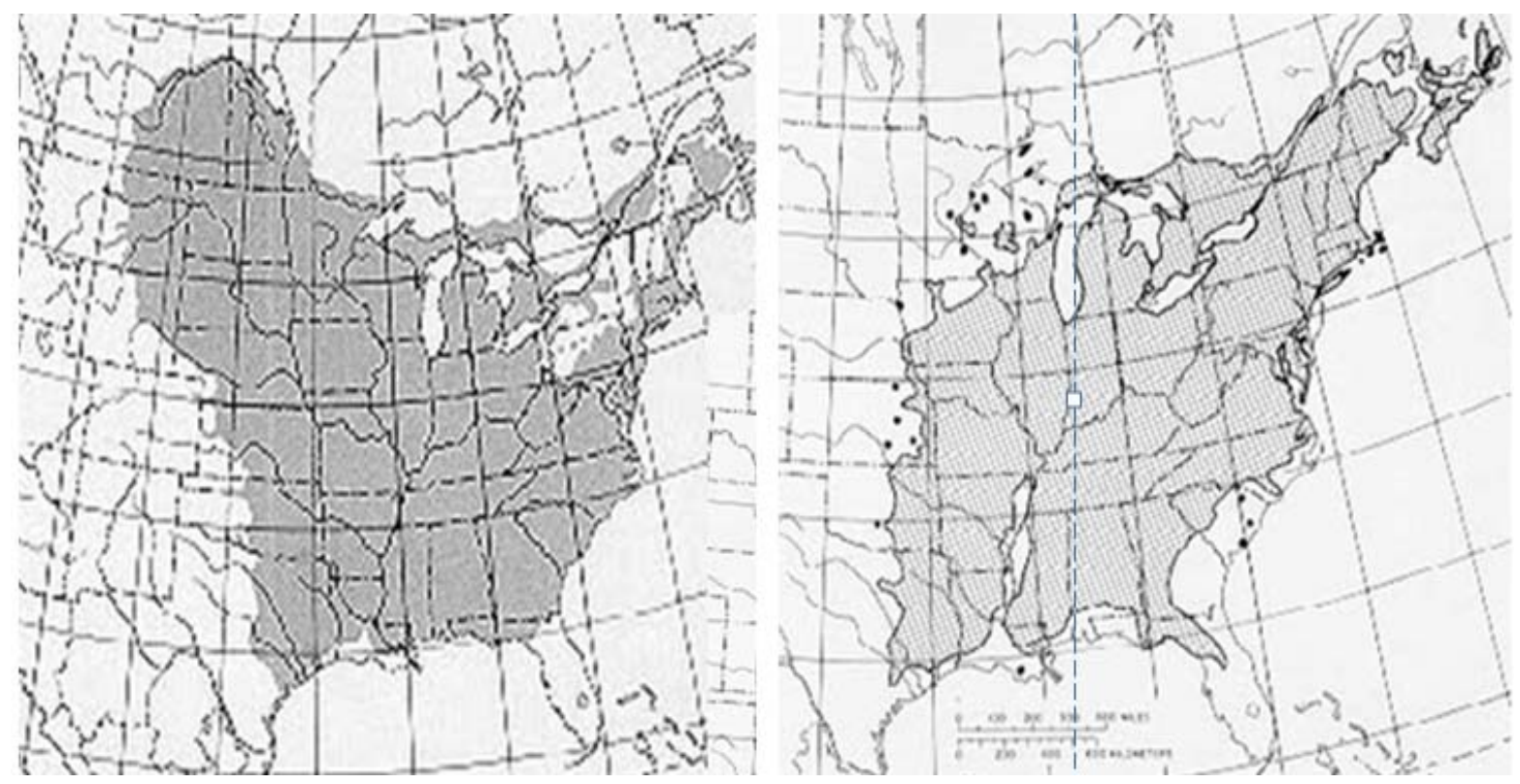

Figure 3. Native range of green ash (left) and white ash (right). Photo taken from Burns and Honkala 1990. 
and swamps (Burns and Honkala, 1990). Pure stands of black ash are common in the northern Great Lakes region and Canada (Poland and McCullough, 2006). Many aspects of black ash are unknown because it has never been commercially important; however, it has been used for basket making because the wood is craftable (Burns and Honkala, 1990).

In the Mid-Atlantic region, ash resources are present but not as abundant as in the Upper Mid-West states such as Wisconsin and Michigan. Pennsylvania contains approximately 5\% ash with no spatially distinct area of abundant growth (McWilliams et al. 2007). Ash resources in Delaware are mostly confined to the northern part of the state, planted in cities, and are not common throughout the rest of the state (Nowak et al. 2009). New Jersey's landscape is dominated by pine and oaks with a very low amount of ash; however, the total volume of ash has increased by 13\% since 1987 (Widmann, 2005). From the last documented forest resources report in 1986, the volume of ash in Maryland is also minimal (Frieswky and DiGovanni, 1988). Throughout West Virginia, ash grows sporadically throughout the forest landscape comprising a mere $3 \%$ of the total volume of trees growing in the state (Griffith and Widmann 2003). Ohio has a younger age distribution of ash and has become more abundant within the last few decades (Griffith et al. 1993). Even though the amount of ash in this region is low, there is still the potential for ecological impacts. If EAB continues to invade urban and forest ecosystems, it could possibly change the structure of the forest of the eastern United States creating a significant ecological change to the region (Poland and McCullough, 2006). 


\section{Emerald Ash Borer Ecology}

\section{Biology}

\section{Classification}

Emerald ash borer is classified in the Coleopteran order in taxonomy. One of the most distinctive features of

Coleopterans is their wing structure. EAB adults have four wings with the front pair being hard and brittle (elytra) and the hind wings being membranous (Fig. 4). The membranous hind wings are used for flight and are folded under the elytra for

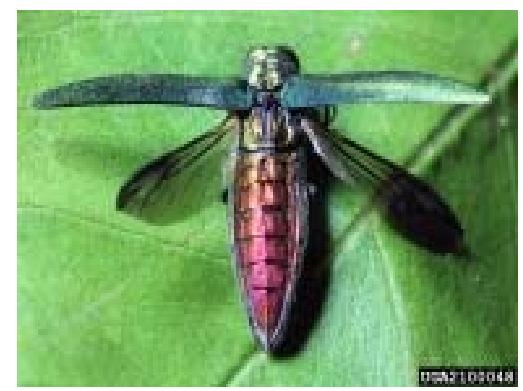

Figure 4. Emerald Ash Borer. Photo by David Cappaert, Michigan State University, Bugwood.org protection when not in use. Even though EAB beetles have wings, they are not known to be sufficient flyers and, therefore, not their primary means of long-range dispersal (Bauer et al. 2003b; Cappaert et al. 2005). However, short-range dispersal can be done by flying (Yong-Lak Park, personal communication). In addition to their two different pairs of wings, EAB adults have chewing mouthparts and well-developed mandibles which give them the ability to consume ash leaves as their food source. EAB undergoes complete metamorphosis to transform from their larvae to adulthood. The life cycle of EAB can vary in length but normally has one generation per year.

EAB adults belong to a family of insects known as the flat-headed wood borer, also known as Buprestidae (Poland and McCullough, 2006; Wei et al. 2007; Wisconsin DNR, 2008; USDA APHIS, 2008). Buprestids are one of the most common families of beetles with approximately 675 known families in the United States. Many adult buprestids are attracted to dead or dying trees and the foliage of trees and shrubs, such as the case with EAB. Buprestid larvae have the distinct characteristic to bore underneath the bark into the wood of living trees or 
newly cut or dying logs (Ueckert and Wright, 1974). Once hatched, they tunnel under the bark making serpentine galleries that are used for pupation.

\section{Life Cycle}

EAB adults are dark metallic green in appearance (Fig. 5). Adults are observed to be 7.5 to $13.5 \mathrm{~mm}$ long with their bodies elongated and slender (McCullough and Katovich, 2004). The life span of adults varies depending on sex. On average, females live roughly one to two weeks longer than males (USDA APHIS, 2008) with most adults living from three to six weeks (Poland and McCullough, 2006). Adults are most active during the day because they favor warm, sunny weather while feeding (Wisconsin DNR, 2008).

Adults prefer feeding on foliage in direct sunlight generally feeding on the leaf

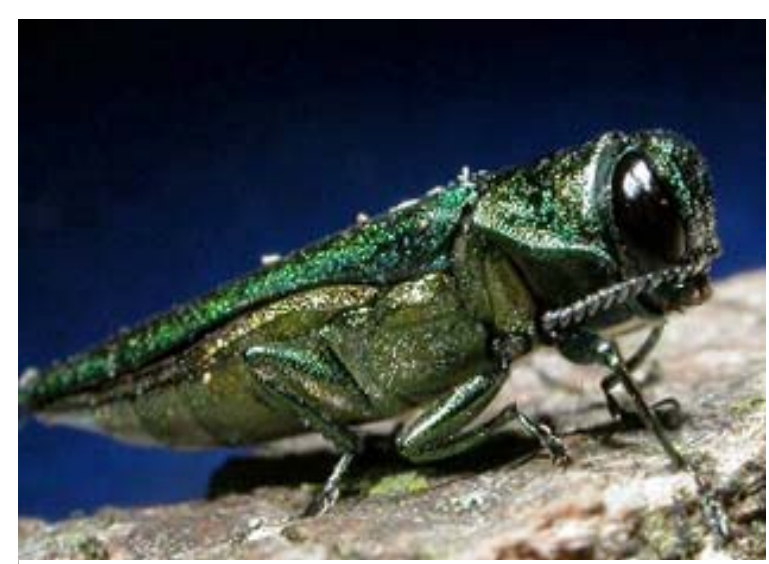

Figure 5. EAB adult. Photo by David Cappaert, Michigan State University, Bugwood.org margins (Wisconsin DNR, 2008; McCullough and Katovich, 2004). Females lay roughly 60-90 eggs throughout their lifetime (USDA APHIS, 2008) with eggs approximately $1 \mathrm{~mm}$ in diameter. Eggs gradually change from a light to dark tint after being laid on the bark (Bauer et al. 2003a) and hatch generally within 7-10 days. Once hatched, the first instar larvae chew their way through the bark and into the cambial region which contains live tissue and phloem (Wisconsin DNR 2008).

As the larvae feed (Fig. 6), they wind back and forth creating characteristic serpentineshaped galleries beginning in the phloem and extending into the xylem layers (Bauer et al. 2003a). As larvae mature and complete their feeding, they excavate a pre-pupal chamber in the 


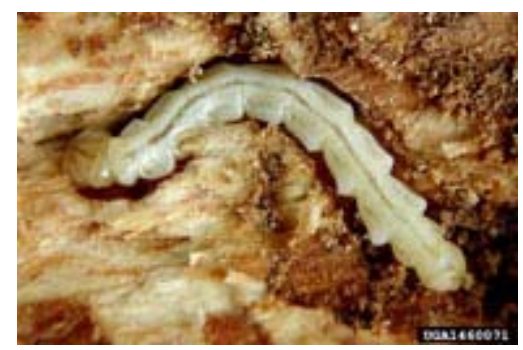

Figure 6. EAB larvae. Photo by David Cappaert, Michigan State University, Bugwood.org outer sapwood where they stay and continue their life cycle over winter (McCullough and Katovich, 2004). Pupation occurs while in this chamber the following spring which completes the life cycle (Poland and McCullough, 2006). However, not all

EAB larvae complete their lifecycle in one year; scientists have found that larvae can require an additional year of feeding prior

to adult emergence (Cappaert et al. 2005). These larvae with extended feeding periods are typically observed in healthy or lightly infested ash trees whose defenses are more effective at decreasing larval growth rate and increasing larval mortality (Poland and McCullough, 2006).

\section{Signs and Symptoms of Infestation}

Common signs left by EAB are serpentine galleries beneath the surface of the bark, eggs in deep bark crevices, presence of larvae, and D-shaped emergence holes (Fig. 7) (Wisconsin DNR, 2008; Wilson and Rebek, 2005; Pennsylvania DCNR, 2008). Symptoms of EAB are common to those of any stressed tree. Often, rapid crown dieback in the top third of the tree will be the first symptom of an attack (Wilson and Rebek, 2005) and persist until significant dieback

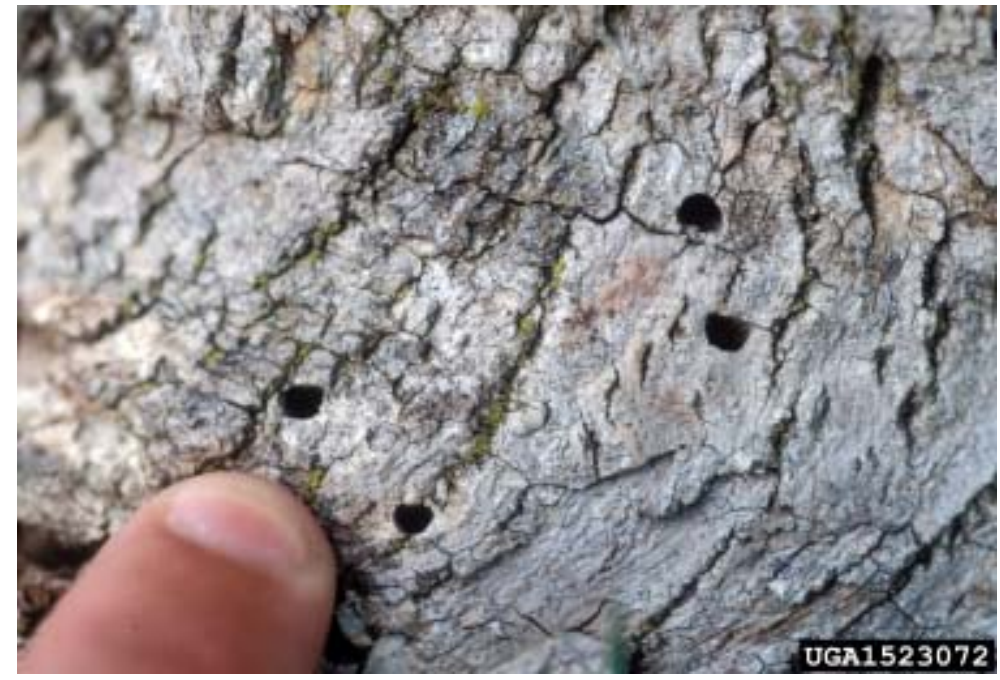

Figure 7. D-shaped exits holes associated with emerging EAB adults. Photo by Daniel Herms, The Ohio State University, Bugwood.org

throughout the rest of the crown has been fatal. As with most stressed trees, epicormic branching is common with EAB infections (USDA APHIS, 2008). Other symptoms such as bark splitting 
and increased woodpecker activity have also been noted (McCullough and Katovich, 2004; Wisconsin DNR, 2008). These signs and symptoms are an effective way to identify an EAB outbreak, but when these signs occur, infestation has already taken place and not much can be

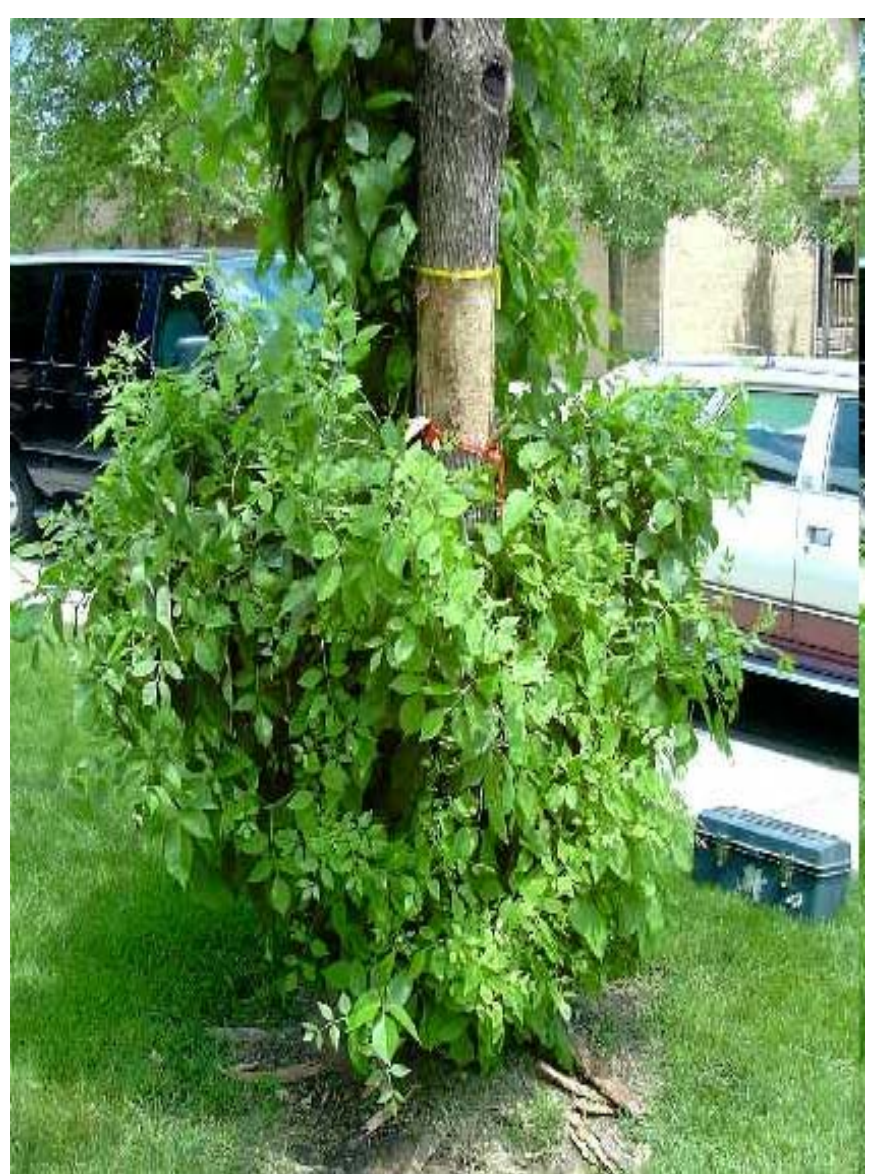

Figure 8. Epicormic branching. Photo by Michigan Department of Agriculture, Bugwood.org done to prevent the spread of EAB in that general area. Unfortunately, signs and symptoms usually do not appear until sometime after infestation (Timms et al. 2006). By that time, significant tree mortality can occur in 1-3 years (Poland and McCullough, 2006).

\section{EAB Impacts on Individual Trees}

Since $\mathrm{EAB}$ is an invasive species, indigenous ash trees are not adapted and have not evolved with natural defenses to ward off an attack. Once eggs have hatched from the bark crevices, they bore their way into the cambial layer and the sapwood

(Bauer et al. 2003a). After numerous larvae have fed on the cambium and sapwood, they, in essence, girdle the tree. Once the cambial layer is destroyed, trees cannot transport vital nutrients through the phloem which will hinder growth of the crown and leaves. Eventually, adults will emerge and start feeding on the foliage. This, too, has a traumatizing effect and stresses the tree even further. By feeding on leaves, photosynthetic activities will decline with the decrease in leaf area. The barrage of attacks from different areas interrupts all abilities a tree 
needs to survive. It is very common for stressed trees to respond by producing epicormic branches (Fig. 8) as a last ditch effort to receive the vital nutrients they need to survive (Pontius et al. 2008). Generally, trees die within five years of an EAB attack (USDA APHIS, 2008).

\section{Dispersal Methods}

The EAB is known to have flight potential - upwards of 5,200m in 40 hours (Bauer et al. 2003b), but is thought to spread more rapidly through the movement of firewood, nursery stock, and freight including wood pallets. In many states, such as Ohio, where EAB has been found are now quarantined and movement of wood is illegal (Goebel et al. 2008). Natural resource agencies have restricted the movement of firewood as precautionary measures to slow the spread and prevent new areas of development. To restrict movement, states are requiring a permit before any logs, firewood, pulpwood and other wood products can be moved across quarantined borders. For example, it is illegal to transport ash products such as trees, logs, branches, wood chips, bark, and other non-coniferous firewood out of Ohio's quarantined areas (Goebel et al. 2008). While these materials can move freely within the boundaries of the quarantined area, they cannot leave without an Ohio Department of Agriculture compliance agreement or permit that meets current federal requirements (Goebel et al. 2008).

A case study done in 2003 by McCullough et al. (2003) recorded EAB spread from infested firewood pile in Tipton, Michigan. The firewood was brought from an EAB infested area in southwestern Michigan. To analyze the movement from the woodpile, 235 ash trees were marked and recorded up to a distance of $400 \mathrm{~m}$ away from the infested wood. Samples were taken from a selected amount of marked trees. From these trees, a section of bark was removed from the trunk, lower, middle and canopy of the tree. Once it was confirmed that galleries were found at the boundary of the $400 \mathrm{~m}$ survey area, another survey was conducted. This time, 
samples were taken as far away as $850 \mathrm{~m}$ from the infested woodpile. After analyzing both surveys, it was determined that $70 \%$ of galleries occurred within $100 \mathrm{~m}$ of the woodpile and greatly decreased as distance from the woodpile increased with no apparent preference on tree size (McCullough et al. 2003). The farthest gallery was observed $750 \mathrm{~m}$ away. To neutralize the problem, all ash trees within a radius of $800 \mathrm{~m}$ were destroyed by the Michigan Department of Agriculture.

\section{Current Options for Monitoring and Treatment}

\section{Choice Tests}

Choice tests are used by entomologists to test for preferences of a particular insect. For instance, through a series of choice test studies, entomologists have discovered that EAB could be attracted to purple colored objects by comparing them with many other color options. Putting this to good use, these purple traps have been placed near high traffic areas (human activity) to monitor EAB distributions and find new areas of infestation. Choice tests can also be used to determine trap selection apparatuses, ash leaf volatiles, and alternate host potential. By combining all these factors, the data could be used as part of other studies to test factors that are unknown or have limited information. For example, a study done in 2004 by Anulewicz et al. (2007) put the alternate host potential theory to the test. This study was designed to test if EAB females would oviposit on species other than ash. Four common ash species (green, white, black, and blue) and three alternate hosts American elm (U. americana), black walnut (J. nigra), and Japanese tree lilac (S. reticulate) were selected for the study. Analysis of nursery stems from dissection showed that galleries had formed on ash stems and virtually no galleries were found on lilac or walnut stems (Anulewicz et al. 2007). Looking deeper into the results, $65 \%$ of the 
galleries were found on green ash trees with rough bark. Overall, their study revealed that EAB females will oviposit on alternate species, but early development and feeding was drastically impaired when compared to the early development on ash trees.

\section{Trap Trees}

A study conducted from 2003 to 2005 by Storer et al. (2007) looked into the detection and monitoring of EAB populations by using trap trees (Fig. 9). In their study, they intentionally girdled thousands of ash trees across Michigan to monitor outlier populations and to evaluate its distribution throughout the state. Adult EAB may be trapped on a sticky surface on the tree, or larvae may be detected by peeling the tree

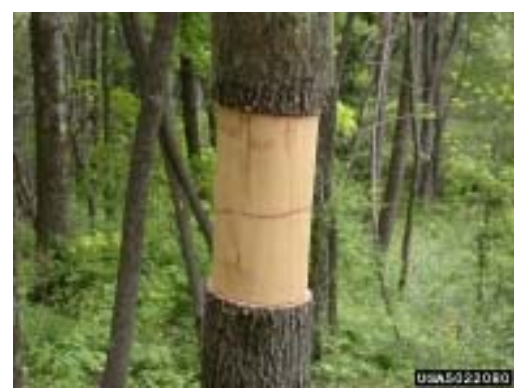

Figure 9. Trap tree used to lure EAB adults. Photo by Pennsylvania Department of Conservation and Natural Resources - Forestry Archive, Bugwood.org

after possible exposure to adults (Storer et al. 2007). Findings from their study show that EAB lands more frequently on ash trees than any other species with girdled ash trees being much more attractive than ungirdled ash trees. Because stressed trees emit volatiles by girdling, this makes trap trees much more effective way to monitor EAB. In the same document, the Michigan Dept. of Agriculture conducted a girdling study in 2004 and 2005 with a similar trap tree process. Accounts of that study are described to be similar to Storer et al. (2007).

\section{Treatment Procedures}

Biocontrol options have been studied extensively due to their popularity and effectiveness in controlling other invasive species. The use of entomopathogenic fungi such as Beauveria bassiana (Balsamo) Vuillemin and Metarhizium anisopliae (Metschnikoff) Sorokin have been used in other pest situations to manage outbreaks of locusts, Colorado potato beetle, 
and diamondback (Lui and Bauer, 2008). Whether or not they will be effective against EAB is undetermined as studies are still ongoing. However, with the recent accounts of Lui and Bauer (2008), EAB shows some susceptibility to these strands of entomopathogenic fungi. When in contact with B. bassiana, a fungal trunk spray, EAB adults were infected and killed. The fungi also had positive effects on EAB larvae because it increased their mortality. Sub-lethal effects even showed shortened adult longevity and prolonged larval development.

Chemical treatments such as imidacloprid sprays that are applied to the trunk have been known to severely reduce EAB emergence (Nzokou et al. 2006). Trunk injections like Imicide/Mauget and Bidrin/Mauget have had little success slowing EAB reproduction (US Forest Service 2009). Other tests using bifenthrin and permethrin were found to reduce concentration of EAB (US Forest Service 2009).

\section{Public Awareness}

EAB is believed to be distributed primarily by the movement of firewood, nursery stock and by human transportation such as vehicles (Cappaert et al. 2005). Raising awareness to the public is a very important step to slowing the spread of this invasive insect. Outreach activities have been used to alert the public and educate them on the consequences of firewood movement. Within the last few years, many campaigns, brochures, bulletins, and announcements have been created to reach the public sector stressing the urgency of containment. The most important step in damage mitigation by the $\mathrm{EAB}$ is implementation and strict law enforcement of firewood quantities (BenDor et al. 2006).

\section{GIS Use in Modeling}


Geographic Information System (GIS) is a geospatial technology used for handling geographic data in digital form (Goodchild, 1993). GIS has the ability to preprocess and store large quantities of data while performing spatial operations (Goodchild, 1993). GIS allows users to collect, manage, and analyze data that can be linked to spatial locations geographically (Ward and Johnson, 2007). In addition, GIS makes data easy to view and manipulate in a variety of ways (Holcombe et al. 2007). Digital data layers and maps have significant value in decision making and assessments because they can aid in solving natural resource problems such as the relationship between a species and their environment (McRoberts et al. 2006). GIS has also been used in predicting the spatial distribution of exotic species since spatial analyses results are important for developing and implementing early warning and prevention systems (Hao et al. 2007). GIS users can enhance social and ecological benefits by identifying new areas of development and management to increase connectivity between social and ecological aspects (Carreiro and Zipperer, 2008).

Today, invasive species frequently receive great attention due to the potential for rapid spread and widespread damage. Invasive species pose challenges to indigenous life forms because they use valuable resources, have no known natural predators, and thrive in environments suitable for their survival. Using GIS to model invasive species will aid in the process of understanding their dispersal, distributions, and habitats. Defining where a species may survive depends heavily on being able to determine its existing or potential habitat (Holcombe et al. 2007). Since locations of infested trees can be mapped individually (Sharma et al. 2008), visual representations of spatial patterns can be accurately depicted and treatment areas can be designated. 


\section{Using GIS Data in Risk Modeling}

In the past few years, GIS has emerged as an extremely powerful tool and is being used to analyze risks in areas of natural disasters and outbreaks invasive species. In addition, the software is used for other research such as the development of a hazard rating system for pine beetles (Cook et al. 2007), predicting the spread of forest pathogens (Hunter et al. 2008) and monitoring landscape classification (Mora and Iverson, 2002). In conjunction with remote sensing and photogrammetry, GIS can be used to identify these types of hazards and/or risks. When assessing risk, many different definitions can be composed but most would define the two key components of susceptibility and vulnerability as part of the structure (Krist et al. 2006). These areas of interest are studied by researchers using GIS to analyze satellite images, aerial photos and field survey data. One example of risk modeling is a study approach to early detection over a large area that involves remote sensing technology. Narrow-band hyperspectral instruments have the capability to identify early signs of stress in vegetation and trees and, in some cases, even when symptoms are not visible to the human eye (Pontius et al. 2008).

Applications of GIS provide several opportunities to model outbreaks, assess ecological impacts, and visualize outcomes (Hunter et al. 2008). Model design and behavior, when understood, will yield more realistic estimates and predictions (Gustafson et al. 2002). Predicting natural resource data can be assessed within an acceptable range if historic and location data is specific enough. Ultimately, this type of research and data acquisition can be used to model future populations, climates, and pest outbreaks. Because of the adaptability and wide range of GIS uses, many agencies, emergency services and businesses utilize GIS to plan and organize their geographic data to make their daily activities more efficient. 


\section{Previous GIS Studies Involving Emerald Ash Borer}

A study done by Iverson et al. (2006) modeled the susceptibility and potential spread of EAB across the eastern United States, in Michigan and Ohio, using Forest Inventory and Analysis (FIA) data to account for ash distributions and abundance at a 20 X $20 \mathrm{~km}$ resolution. When combining the maps of percent forest cover, they were able to estimate the availability of the ash resource to EAB. In Ohio, a spatially explicit cell-based model was used to consider insect flight characteristics (Insect Flight Model) as well as external factors that enable the insects to travel passively (Insect Ride Model) (Iverson et al. 2006). From their study, the insect flight model would calculate probabilities of colonization in each cell based on the basal area of ash abundance and EAB abundance by assuming an 11-year cycle starting with initial colonization of a site and ending when all ash at the site are dead. The Insect Ride Model was then used to weight the road networks, wood products, population density, and campground information in a GIS and calculate an ash abundance multiplier that alters the ash abundance input to the Insect Flight Model. The modeled EAB colonization probability yields a map of colonization potential. Results from their study suggest that when the actual EAB detection spots were overlaid to determine the accuracy of predicted spread, $83 \%$ of the infections fell within a zone of high probability of colonization. In addition, $69 \%$ of the EAB finds (20042007) in the outlier zone, the zone beyond the immediate infestation front, occurred within $2 \mathrm{~km}$ of major Ohio roads. Campgrounds and wood products that were located farther from major roads experienced more EAB positive detections beyond the immediate vicinity $(2-10 \mathrm{~km})$ of the major roads. These results show that the potential sources of infection are more likely to contribute to EAB finds from roads. It should be noted that no significant relationship was found 
between ash basal area and EAB positive detections in either the occupied or the outlier zones. The same procedures are being used in Michigan but results are still pending.

Another study done by Pontius et al. (2008) captures ash decline in EAB infested areas using hyperspectral technologies. Because of the increase chance of spread, early detection of $\mathrm{EAB}$ is important in terms of management. The use of wavelength indices (or band ratios) pairs stress-sensitive wavebands in combination with relatively stress-insensitive bands to correct for variation in irradiance, leaf orientation, and shading. The result is a variable that is optimized for detection of plant stress (Carter, 1994). The majority of plant stress indices are sensitive to foliar chlorophyll content. Stress-induced changes in reflectance have been directly linked to foliar chlorophyll content in numerous studies (Rock et al. 1988; Vogelmann et al. 1993; Gitelson and Merzlyak, 1996; Pontius et al. 2008). When plants are subjected to stress, reductions in photosynthetic activity, inhibition of chlorophyll formation, and an increasing breakdown of the chlorophyll molecule commonly occurs. These criteria can be analyzed using remote sensing applications. For their study, image data and ground truth data (chlorophyll fluorescent measures, transparency, live crown ratio, crown vigor, twig dieback, and infestation symptoms) were collected. The field-based decline rating system developed for this study was able to capture and summarize the full range of ash decline that existed within the study areas. These data were used in conjunction with hyperspectral remote sensing imagery to create continuous coverages of predicted forest health with an emphasis on ash species in areas that are currently being impacted by EAB infestation. Compared to traditional decline classification, this hyperspectral based predictive model differentiated 5 decline classes with 97\% accuracy (Pontius et al. 2008). This represents an improvement in both accuracy and detail over more common multi-spectral remote sensing assessments of forest health. However, the extent to which these 
techniques can be used to monitor forest health is still unclear due to high costs, limited availability, and complex processing requirements (Pontius et al. 2008). With time, competition in the private sector and currently planned satellite sensors will eventually make this technology available to a wider audience. Utilizing these capabilities will be essential to identification and management of current and future pests (Pontius et al. 2008).

Another example of a project using GIS for EAB research was done by the Minnesota Department of Agriculture (MDA). This project was completed in December 2006 by the Plant Protection Division with the purpose of optimizing the placement of new EAB detection trees throughout Minnesota. To map the risk of EAB, they assembled GIS data layers for the state which included: campgrounds, seasonal homes, urban areas, sawmills, firewood dealers, nurseries, and accessibility. Campground, firewood, nursery and sawmill data can be obtained from natural resources agencies while seasonal homes and urban areas were derived from census data (Minnesota Dept. of Agriculture, 2006). From their study, campgrounds rated as the most likely sites for $\mathrm{EAB}$ introduction due to the potential for infested firewood to be brought to the campground. The mapped campgrounds contained records from all ownership types which include Federal, State, County, Municipal, and Private (Minnesota Dept. of Agriculture, 2006). Urban areas, sawmills, nurseries ranked high on the list of factors that could induce spread from the movement of wood and large human populations. Of the data obtained for sawmills, 493 of 626 mills were coded high risk because of three factors: 1) volume of wood processed; 2) if ash is used; 3) if logs are imported with bark attached (Minnesota Dept. of Agriculture, 2006). With all the datasets, input layers were additively combined to produce the introduction risk map. Once all the equations were applied, the map grid was smoothed using statistical kriging interpolation to create a more interpretable surface. Completion of the map yielded profound 
areas of risk that are easy to identify and was used to plan new areas to place trap trees, which were surveyed in 2007 and 2008. No information on those trees is available at this time. 


\section{Review of Maximum Entropy}

Maxent has been used extensively for species modeling within the past five years. The model utilizes environmental data coupled with presence points for the species being modeled. Probabilities are then created for the study area based on the combination of these data. For this project, Maxent provides an excellent modeling tool because EAB positive sites are currently known and environmental variables can be collected for the region. Results of the model can clearly define new areas of high probability other than those close to the presence-only point locations.

Statistically, entropy is defined as a measure of uncertainty when associated with a random variable. The principle of maximum entropy states that the probability distribution that best represents the current state of knowledge is the one with the largest entropy, in other words, closest to a uniform distribution (Phillips et al. 2006). Approximating unknown distributions is the best described by Jaynes (1957):

"The best approach is to ensure that the approximation satisfies any constraints on the unknown distribution that we are aware of, and that subject to those constraints, the distribution should have maximum entropy."

Basically, the maximum entropy principle agrees with what has proven to be known without assuming anything that is not known. The constraints mentioned in the above quote refer the environmental variables or features (Phillips and Dudik, 2008). The probability estimation from maximum entropy resides from Bayesian statistics using prior probabilities and a Maximum Likelihood method (Phillips et al. 2006). For an extensive review and explanation of maximum 
entropy associated functions see Phillips et al. (2006), Shamilov et al. (2008), Phillips and Dudik (2008) and Jaynes (1957).

The Maxent modeling approach utilizes the known presence-only data when predicting spatial distributions without the use of absence samples. Applying a maximum entropy model provides a method for making inferences from incomplete data information (Jaynes, 1957). Most species distribution models are very sensitive to sample size which can have effects on the model results (Kumar and Stohlegren, 2009). Maxent, on the other hand, is able to predict probability distributions/habitat suitability with a small amount of sample points (Wollen et al. 2008). Maxent's capability to utilize a machine learning method to evaluate current species locations and their interaction with the associated environmental variables is what sets it apart from other predictive models (Wollan et al. 2008). In fact, when compared to other modeling methods such as GLM and GAM, Maxent has been found to perform the best and provide the most accurate results in numerous comparison studies (Kumar \& Stohlegren, 2009).

Advantages to using Maxent are numerous. Over-fitting models can lead to inaccurate results. The Maxent design has the ability to not over-fit the model when using the presenceonly data but careful consideration must be taken when selecting variables (Phillips et al. 2006; Wollan et al. 2008). It also utilizes continuous and categorical data types and can represent probability distributions based on deterministic algorithms and mathematical definitions. In addition, Maxent is being accepted in many areas of research because of its ability to utilize a machine learning function as part of the predictive modeling procedure. However, since Maxent is still a relatively new modeling procedure, it does have some drawbacks. Fewer guidelines and methods for estimating error are not as defined as GLM and GAM (Phillips et al. 2006). Overfitting also requires more research to avoid error in variable selection, and, in general, Maxent is 
currently not used in standard statistical software packages because it has its own stand-alone program (Phillips et al. 2006).

Maxent has been used for a variety of different applications that have included: spatial distribution of wildlife species habitat (Yost et al. 2008, Thorn et al. 2009), threatened and endangered species modeling (Tinoco et al. 2009, Williams et al. 2009), and climate change (Fitzpatrick et al. 2008, Loarie et al. 2008). The versatility of Maxent illustrates its usefulness for modeling complex ideas with accuracy. Compared to previous modeling methods mentioned earlier, Maxent, more times than not, produces better results. The power and effectiveness of using maximum entropy proves that it can be used across multiple fields and still be capable of generating models to suit the user's needs.

Theoretically, predictive modeling revolves around the fundamental concepts of geographical versus environmental space as well as estimating niches and distributions (Pearson, 2007). The concept of environmental space pertains to the foundations of a "fundamental niche" which is defined by Hutchinson (1957) as a set of environmental conditions within which a species can survive and persist. Figure 10 displays the concept of these niches in respect to geographical or environmental space. If the actual distribution of the species occurs in the environmental space, then that part of the environmental space is occupied by the species (Pearson, 2007). This is referred to as an "occupied niche." If the environmental conditions located within the fundamental niche are displayed in the geographical space, then this could be considered the potential species distribution (Pearson, 2007). 


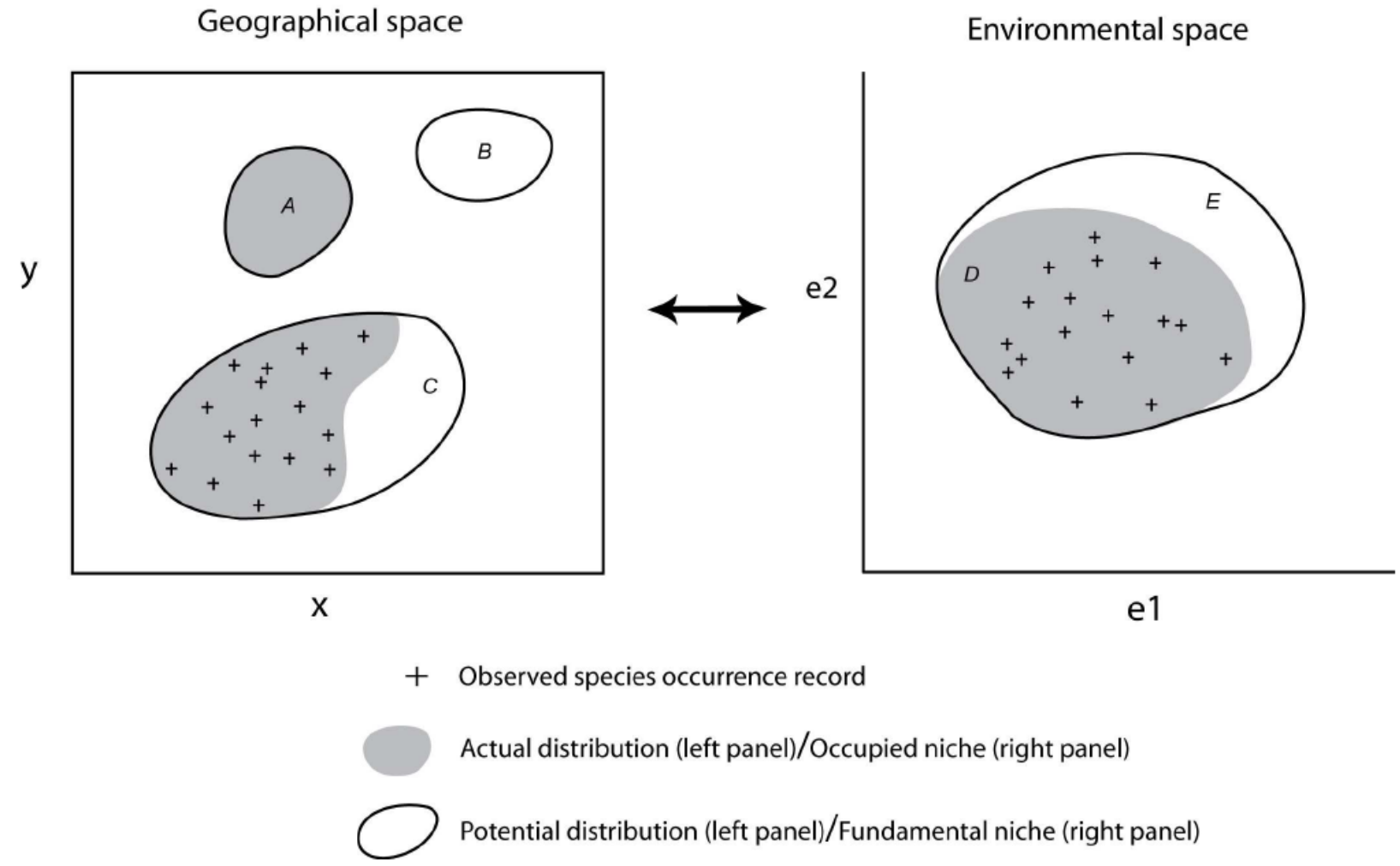

Figure 10. Diagram of fundamental and occupied niches explaining species distributions in geographical and environmental space. Taken from Pearson (2007). 


\section{Chapter 3: Study Area}

The study area for this research project is the Mid-Atlantic region of the United States which includes six states: Delaware, Maryland, New Jersey, Ohio, Pennsylvania, and West Virginia and the District of Columbia. This location was selected because it is currently on the fringe of the EAB infestation. Presently, EAB is highly concentrated in western Ohio with satellite populations in three other states (Maryland, Pennsylvania, and West Virginia).

Delaware and New Jersey have yet to report positive EAB sites. In order to better understand the general characteristics of the study area, this chapter provides information about physiographic regions, topography, soils, climate, past disease and outbreaks, and land cover and use.

This study area contains many diverse elements such as urban development, contiguous and fragmented forests, and major elevation changes. Elevation and climatic conditions are essential to EAB reproduction. Warmer climates offer more suitable habitat and increased growth rates. Urban development and forest fragmentation provide easily accessible breeding grounds for EAB establishment and colonization because of their anthropogenic interaction and stressed urban trees. Soils provide information as to where ash may or may not grow limiting the area of potential EAB spread. Physiographic provinces and ecoregions may contain useful information (about the location current EAB infestations and potential sites in the future) through similar environmental characteristics. Knowing the history of disease and insects outbreaks could affect how EAB is managed by studying past invasive problems. Since this study only models human spread criteria, environmental data should also be mentioned as it, too, may have an effect on EAB spread. 


\section{Physiographic Provinces \& Ecoregions}

\section{Physiographic Provinces}

Physiographic regions are defined as broad scale subdivisions based on geologic structure and history, rock type, and terrain identity (USGS, 2003). Regions with flatter surfaces could be more inclined to spread EAB based on easier accessibility rather than navigating mountainous terrain.

The study area extends across many physiographic provinces including: the Coastal Plain, Piedmont, Ridge and Valley, Appalachian Plateaus, and the Central Lowlands (Herlihy et al. 1998). Other provinces such as the Blue Ridge, New England, and Interior Low Plateaus are located within the study area but make up only three percent of the total (Fig. 11). The Appalachian Plateaus make up the greatest portion covering 51\% of the area with the Central Lowlands (17\%) and Ridge \& Valley (14\%) as the other dominant provinces.

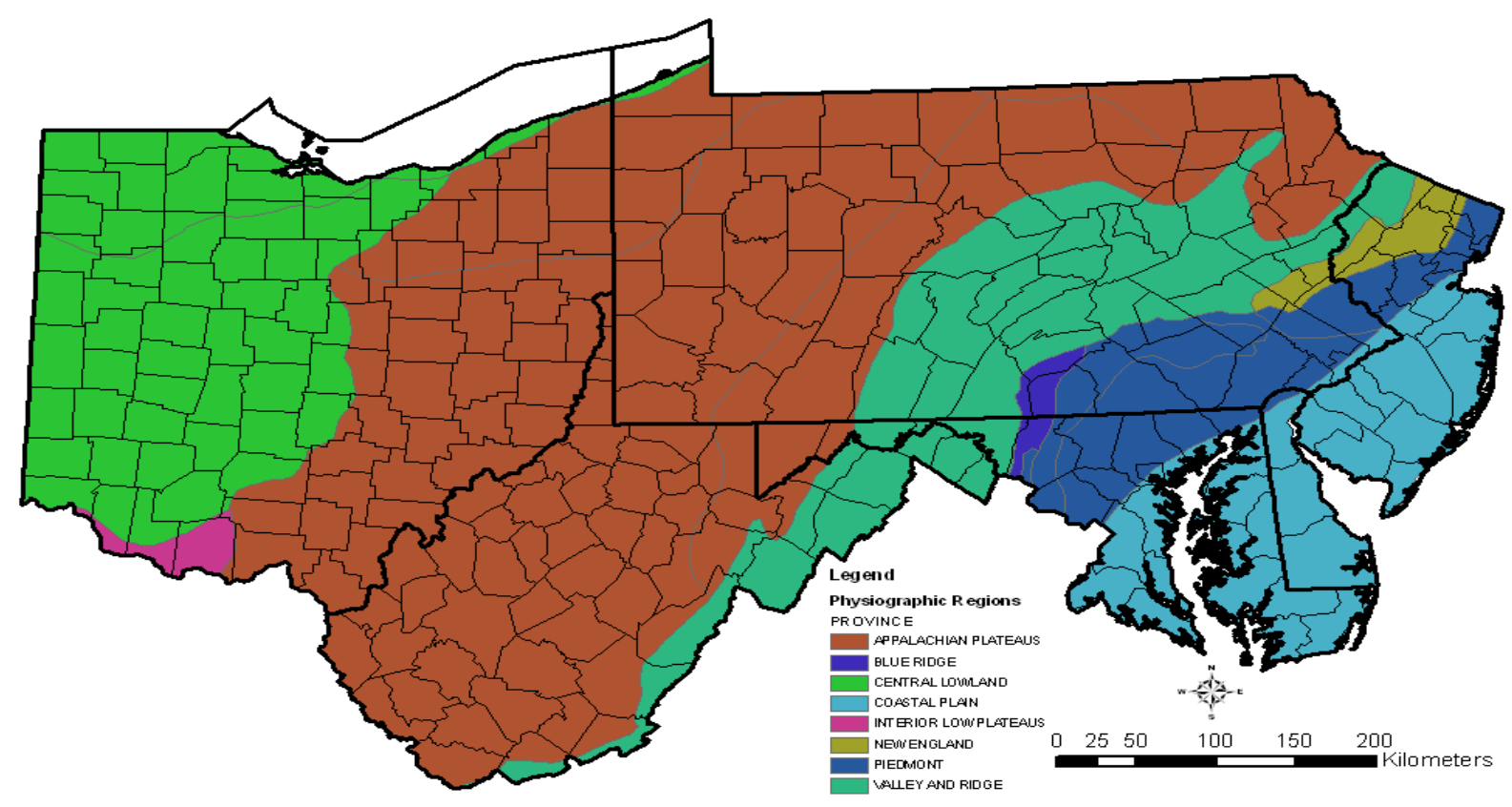

Figure 11. Physiographic provinces. 


\section{Ecoregions}

Ecoregions, or ecological regions, are areas of land or water that contain common characteristics which are geographically distinct from other areas around them (Omernik and Bailey, 1997). An ecoregion contains natural communities and/or species that are unique to its defining region; similar to an ecosystem except on a much larger scale. The study area contains 18 different ecoregions (Fig. 12) dominated by the southern unglaciated Allegheny plateau section, located in eastern Ohio, southwest Pennsylvania and the western part of West Virginia, encompassing $22 \%$ of the study area. The northern ridge and valley ecoregion contains another $15 \%$, and the central till plains, beech-maple section contributes $11 \%$.

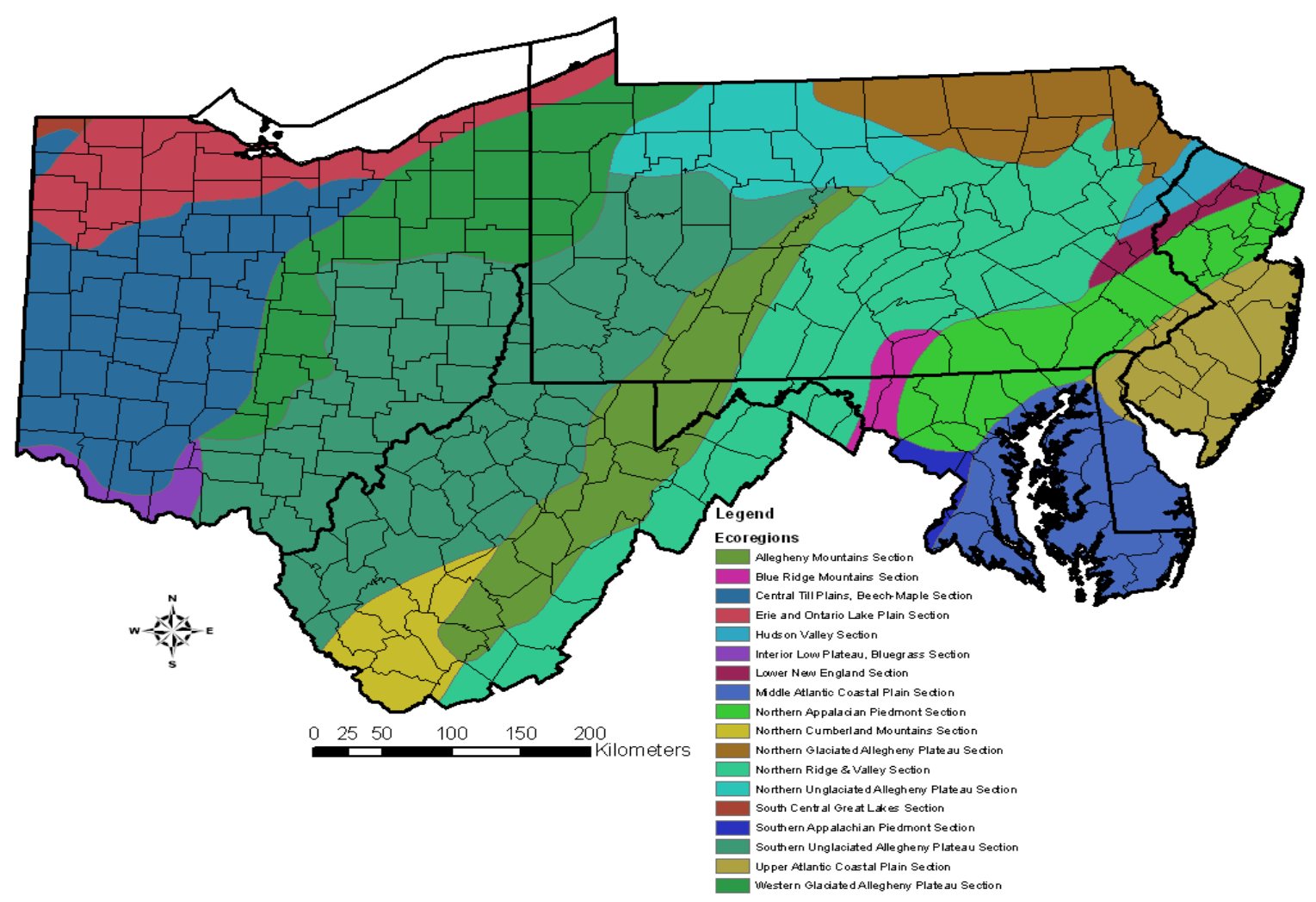

Figure 12. Ecoregions in the Mid-Atlantic.

\section{Topography \& Soils}




\section{Topography}

Elevation within the region varies greatly from sea level in Delaware, Maryland, and New Jersey to the highest point at Spruce Knob [1428m ( 4850ft)] in West Virginia (Fig. 13). The study area encompasses an array of different terrain attributes such as steep slopes, narrow valleys, plateaus, and coastal plains. Delaware, New Jersey, and eastern Maryland are relatively flat compared to the rest of the study area with elevations less than 118 meters.

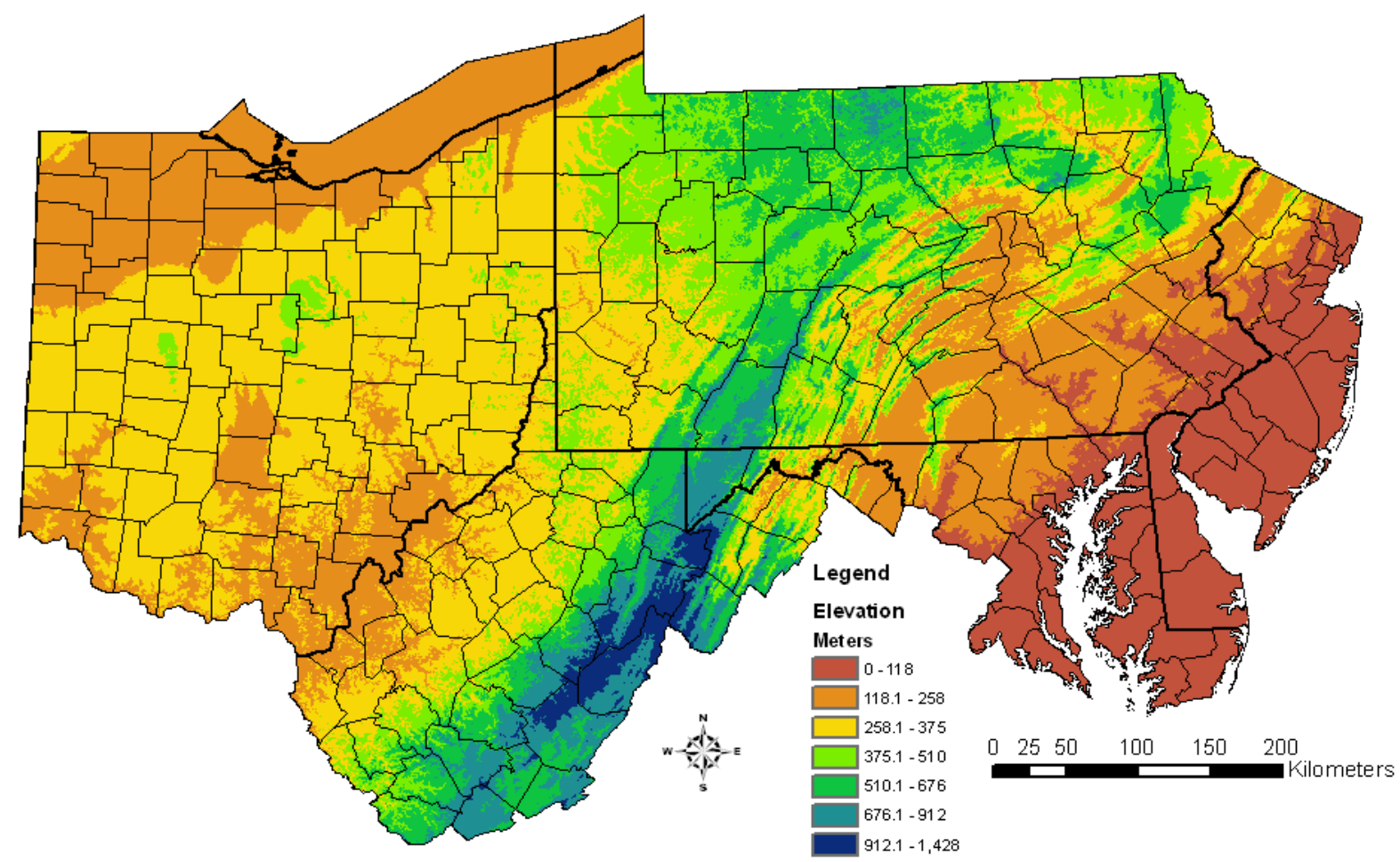

Figure 13. Elevation above sea level (meters).

\section{Soils}

Soil maps are commonly used for land assessment, environmental protection, and land evaluation. Depending on the scale, soil maps can be very general or extremely detailed, especially when accompanied by a soil survey report and soil attributes. For this study area, a generalized image of soil orders is used to represent the spatial distribution (Fig. 14). Inceptisols 
and Ultisols dominate throughout Delaware, Maryland, New Jersey, Pennsylvania and West Virginia while Alfisols are present throughout the Ohio landscape. Inceptisols are the most abundant, occurring mostly in forested environments. Alfisols represent one of the most important soil orders because of their productivity for food and fiber. These soil orders are important for ash species because of increased growth and production on these sites.

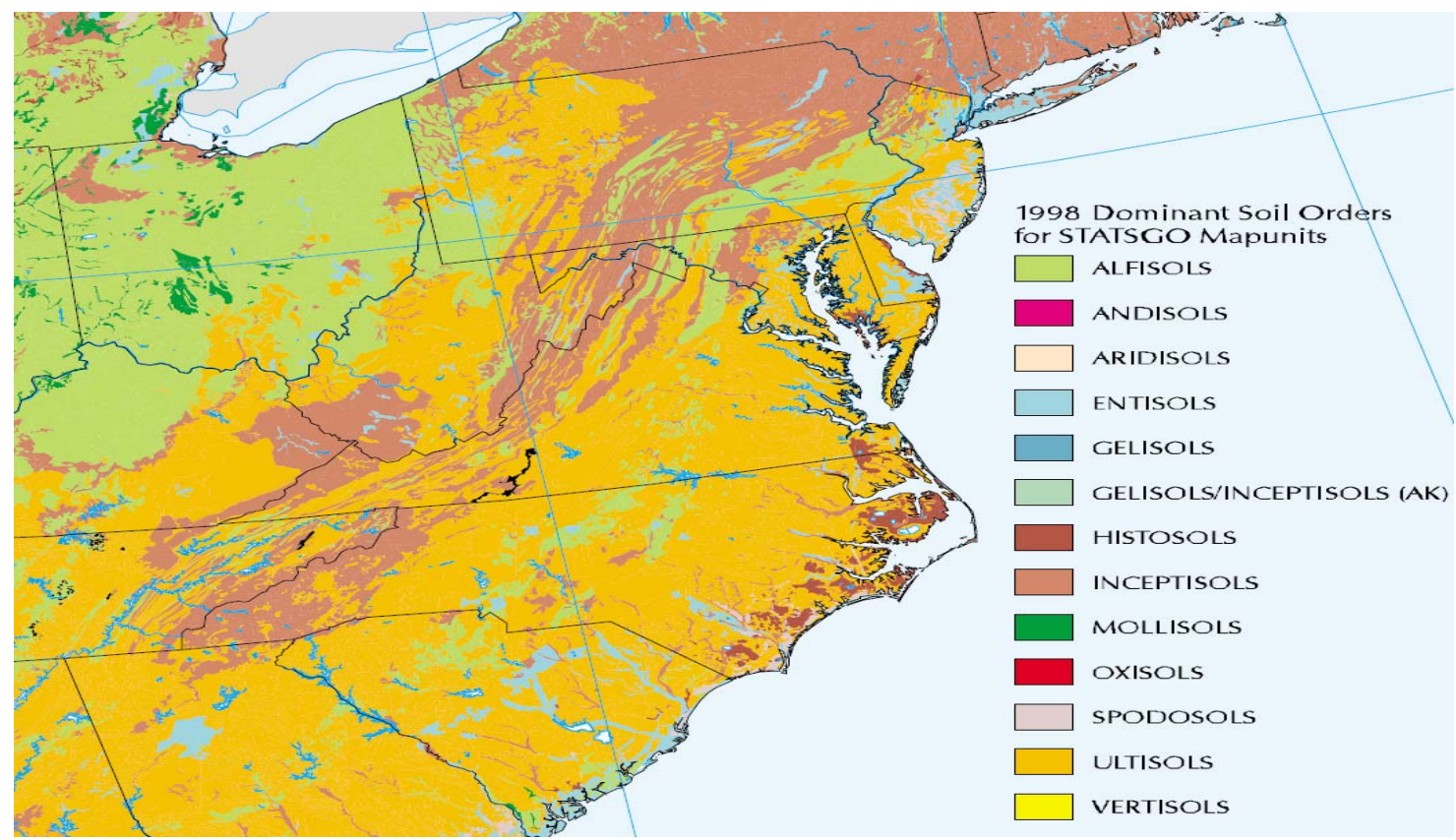

Figure 14. NRCS map of soil orders for the Mid-Atlantic

\section{Climate}

Although climate is not directly related to EAB survival, it does serve as a determinant for ash growth. The vast majority of the study area is classified as a humid continental climate (Fig. 15). This climate type undergoes variable weather patterns and large seasonal temperature variances. Summers are warm and humid with reoccurring thunderstorms while winters can be quite cold and snowy. Differences in elevation will effect winter precipitation as most snowfall 
will occur in the higher elevations. Snow cover does not generally last long in valleys and plains. Temperatures during the summer can be very hot at times with high humidity levels.

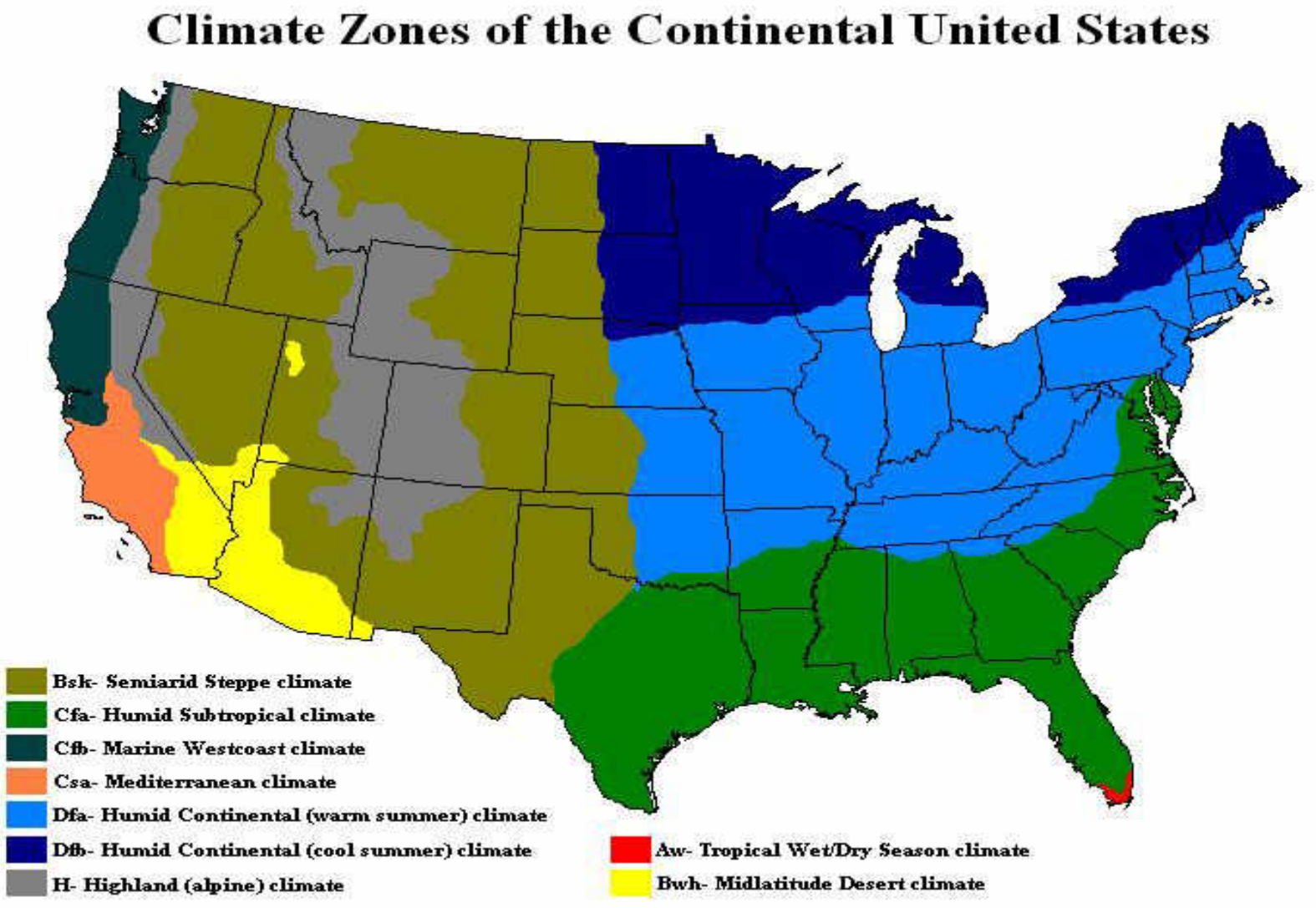

Figure 15. Climate zone map acquired from howtotravelamerica.com

Growing seasons for this region vary but generally begin during late April to early May and end roughly mid-October to early November. Depending on the location, the area has an approximate range of 140 to 200 growing days. Some growing seasons are much shorter like in north-central Pennsylvania where the growing season runs from late May to late September. Annual precipitation totals range from 50 to $125 \mathrm{~cm}$ (20-50 inches) which includes rain and snowfall. Some areas will receive over $150 \mathrm{~cm}$ (60 inches).

\section{Prior Invasive Species and Disease Outbreaks}


Invasive species are common to the study area. Invasive insect outbreaks such as hemlock woolly adelgid (A. tsugae) and gypsy moth (L. dispar) have greatly affected hemlock and oak species in this region. Asian longhorn beetle (A. glabripennis) is another harmful invasive that is a serious threat to hardwood species because it has no known natural predators (USDA APHIS, 2006). Non-indigenous plant species such as tree-of-heaven (A. altissima), garlic mustard (A. petiolata), Japanese stiltgrass (M. vimineum), and Kudzu (P. lobata) have also established in great numbers (Swearingen et al. 2002). Current regulations prohibit the transportation of infested host materials beyond quarantine areas in eradication attempts for all invasive insects (USDA APHIS, 2006). In some cases, monetary fines are given to citizens moving wood outside the designated boundaries. Constant monitoring and public outreach continues to be done by APHIS and the US Forest Service to raise awareness about the impacts invasives species can have on the forest.

In addition to invasives, disease pathogens such as Dutch elm disease (Ophiostoma spp.), chestnut blight (C. parasitica) and beech bark disease (C. fagisuga - the beech scale) have plagued the study region in years past by inflicting widespread damage and mortality. In fact, a disease such as chestnut blight, which became widespread in the early 1900s, has completely eradicated any chestnut component left in the forest today. Chestnut blight was originally found in New York in 1904 and within 40 years the entire range of American chestnut from Maine to Mississippi was determined to be infected (Griffin, 2000). To this date, chestnut trees rarely become larger than pole size. Much like chestnut blight, Dutch elm disease quickly spread throughout the US in the first half of the 1900s except this pathogen was disseminated by elm bark beetles as its primary source of dispersal (Gibbs, 1978) rather than relying on reproductive spores and wind. 


\section{Land Cover and Use}

According to the National Land Cover Dataset (NLCD) 2001 classification, deciduous forests dominate the study region making up approximately $44 \%$ of the land cover (Table 1 ). The main forest species include: oaks (Quercus spp), hickories (Carya spp.), maples (Acer spp.) and yellow-poplar (L. tulipifera) with components of hemlock (T. canadensis), white pine ( $P$. strobus), beech (F. grandifolia), black cherry (P. serotina), ash (Fraxnis spp.), and other various commercial and non-commercial species. The deciduous forest is prominent throughout the Table 1. NLCD 2001 land cover area (in $\mathrm{km}^{2}$ ) and percentage for the emerald ash borer study region.

\begin{tabular}{lll} 
Land Cover Classification & km $^{\mathbf{2}}$ & Percentage \\
\hline & & \\
Open Water & 15933.68 & $4.58 \%$ \\
Developed, Open Space & 22189.49 & $6.37 \%$ \\
Developed, Low Intensity & 11532.92 & $3.31 \%$ \\
Developed, Medium Intensity & 4706.85 & $1.35 \%$ \\
Developed, High Intensity & 1827.61 & $0.52 \%$ \\
Barren Land & 1712.51 & $0.49 \%$ \\
Deciduous Forest & 153975.86 & $44.21 \%$ \\
Evergreen Forest & 9581.33 & $2.75 \%$ \\
Mixed Forest & 9732.20 & $2.79 \%$ \\
Shrub, Scrub & 1632.87 & $0.47 \%$ \\
Herbaceous & 3239.59 & $0.93 \%$ \\
Hay/Pasture & 42270.72 & $12.14 \%$ \\
Cultivated Crops & 62640.45 & $17.99 \%$ \\
Woody Wetlands & 4880.64 & $1.40 \%$ \\
Emergent Herbaceous Wetlands & 2418.55 & $0.69 \%$ \\
Total & $\mathbf{3 4 8 , 2 7 5 . 2 7}$ & $\mathbf{1 0 0 . 0 0 \%}$ \\
\hline
\end{tabular}

mountainous regions of West Virginia and Pennsylvania. Another combined 30\% of the study area is classified as Hay/Pasture and Cultivated Crops (Fig. 16). Cultivated Crop land is restricted mainly in western Ohio while Hay/Pasture land is concentrated in Delaware, Maryland and Pennsylvania. 


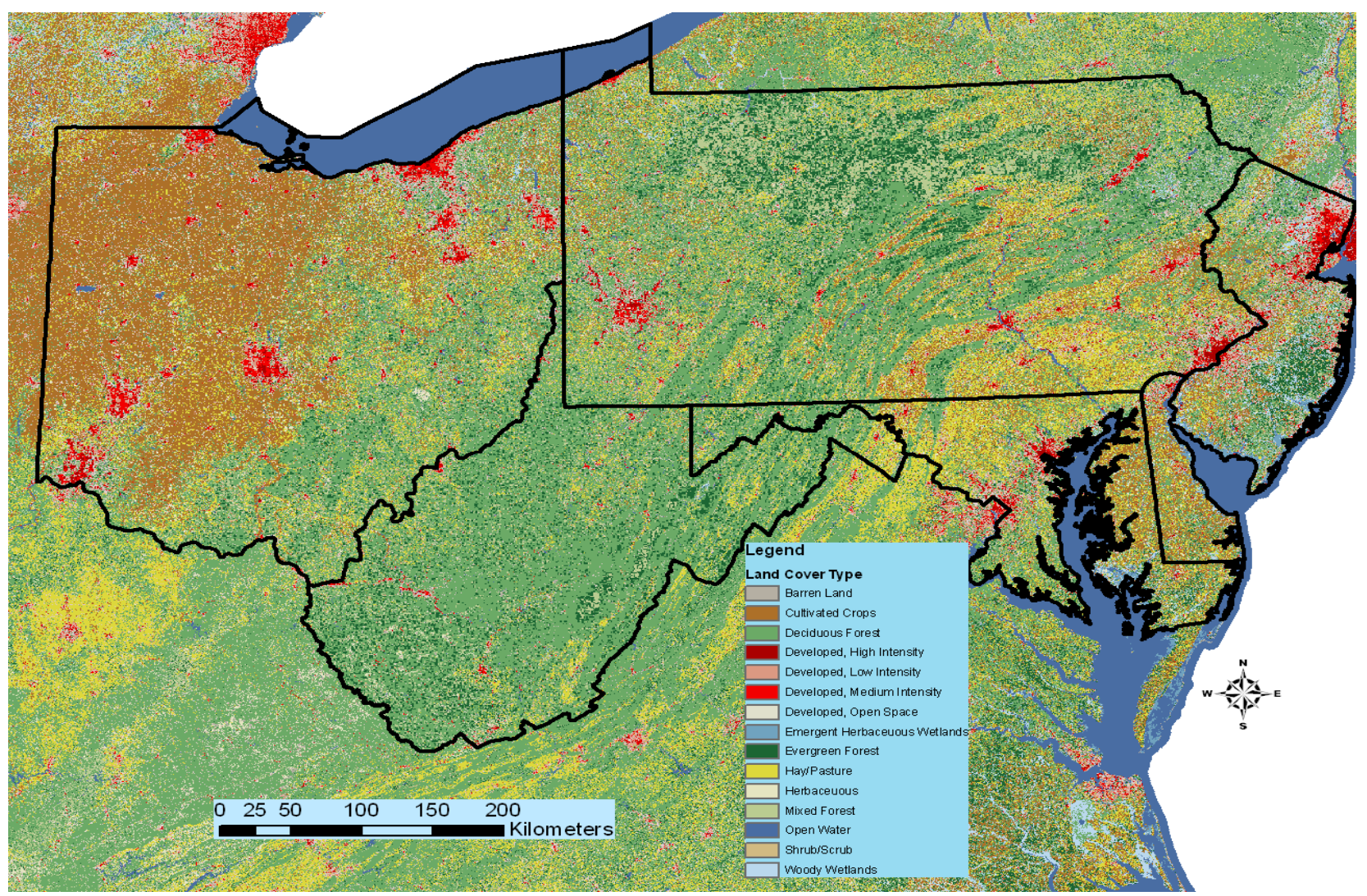

Figure 16. NLCD land cover image for the emerald ash borer study area.

Urban areas and major cities, which are a facilitator of EAB spread, are located within in the region (Iverson et al. 2006; Poland and McCullough, 2006). In terms of area, the developed land cover makes up $11.5 \%$ across all intensities, of which $6.4 \%$ is classified as open space.

Developed lands are dispersed around the major cities, such as Columbus, Cleveland, Pittsburgh, Philadelphia, Baltimore, and Washington DC. 


\section{Chapter 4: Methodology}

This project compiled spatial data layers that are important to the spread and establishment of emerald ash borer. The goal was to develop and assemble a modeling procedure in order to utilize data layers using GIS. These objectives were accomplished by developing spatial datasets using mostly human causal vectors combined with a maximum entropy modeling approach to predict probability distributions. The development of spatial data layers were completed using ArcMap Version 9.2 (ESRI, 2003) for analysis and dataset creation.

\section{Target Species and Occurrence Data}

Occurrence records of EAB were obtained from Department of Agriculture offices in each respective state where EAB has been positively identified as of December 2009 ( $n=982)$. No records from Delaware or New Jersey exist to date. These records indicate where EAB has been located by coordinate points. The range of EAB is not yet fully known in the United States so it is assumed that EAB can and will survive throughout the Mid-Atlantic study region as long as ash is the host species. Climatic factors affecting EAB survival are also unknown, but the climate of the northeastern U.S rivals its native range in Asia.

\section{Environmental Variables}

Fifteen environmental variables were considered as potential predictors of EAB spread and distribution. These variables were selected based on human spread mechanics and past modeling studies. All variables are associated with anthropogenic spread vectors with the exception of an ash basal area grid. All datasets were assembled using ESRI ArcGIS version 9.2 (ESRI, 2003). All environmental layers were resampled to $90 \mathrm{~m}$ spatial resolution to correspond 
for efficiently running Maxent while still properly representing ground resolution. As a result of preliminary analysis, some initial variables were omitted because they over represented certain areas which biased some urban areas. In all, eleven environmental variables were used for the final simulations. Final data types included: point features, line features, census data, and raster grids. This project used many different types of spatial data compiled from various sources. The following subsections describe how each data layer in the final model was collected and the justification for each variable.

\subsection{Campground, Nursery, and Sawmill Density Grids}

Human vector datasets are considered very important in modeling the spread of emerald ash borer. Firewood is often brought into campgrounds from long distances by travelers (Iverson et al. 2006), which creates a problem of EAB spreading and establishing satellite populations. EAB has also been noted to be spread through nursery stock and sawmill (firewood) movement (Iverson et al. 2006). EAB is often transported in live or dead wood materials which makes it difficult to detect. In order to model these variables, business locations were identified and density grids for each vector were created.

RefUSA, which is an online business database, was used to find business locations within the study region. RefUSA contains business information including business name, street address, city, state, zip, phone number, XY coordinates, and a NAICS code describing type of business. Each business was tabulated in an Excel spreadsheet. The information was then uploaded into ArcGIS to create the shapefiles for each layer.

Density grids were calculated from each of these variables for final analysis using the Kernel density function in Arc Toolbox. Kernel density was chosen because it provides a dynamic output that fits a smooth curve over each point. This is a better representation than 
using a Simple density calculation because it avoids the bulls-eye effect around each point. Cell size for the density grids was set at $90 \times 90$ meters for this study which represents roughly two acres per cell. This cell size was chosen to lessen computational time and still produce accurate results. For sawmill density, the search radius was set at $80,460 \mathrm{~m}$ (50 miles) because it is not economically feasible to transport ash timber much further. Ash is rarely of veneer quality which is why it is not a huge part of the timber market. Campground and nursery densities were calculated with a search radius of $8,046 \mathrm{~m}$ ( 5 miles) which was the same value used by the Minnesota Department of Agriculture for their EAB risk map. This is a conservative estimate of how far EAB could spread within one year. Since EAB has a low probability of spreading through firewood in campgrounds, the risk is much lower than sawmills because wood transport can cover a much larger area for each individual mill.

\subsection{Census Data Acquisition}

Census data was used to analyze the total population and the amount of seasonal homes within the study area. Total population is defined by the U.S Census as the sum of all individuals occupying a given census boundary. Research shows that higher human population density can lead to incidental EAB transport (Iverson et al. 2006). Seasonal homes are also defined by the U.S Census as residences for seasonal, recreational, or occasional use such as cottages and hunting cabins. In 2006, the Minnesota Department of Agriculture implemented an EAB spread model that included seasonal homes since these types of homes are more likely to transport (and store) firewood as a source of fuel in large quantities.

Population and seasonal home data was prepared using Census Data for 1990 and 2000. Using the National Historic Geographic Information System (NHGIS) database website, searches were conducted for both years in an effort to monitor change detection from 1990 to 
2000. The website provided shapefiles for census boundaries down to block level. However, due to the amount of missing data from the block level, block group level shapefiles and databases were used for this project. Total population and occasional use tables (which includes seasonal home data per block group) were the main emphasis of the searches for both years.

Detecting change from 1990 to 2000 was not feasible because many new census boundaries were created between the two years. Instead, the 2000 census data for population and seasonal homes were used in the final analysis due to that year being the most updated.

\subsection{Road Intersection and Rest Area Dataset Creation}

A dataset of roads was obtained from the ArcGIS 9.2 Data and Maps Media Kit for the study region. Invasive insects disperse/propagate through highways and rest areas because of the amount of human activity is higher (Koch \& Smith, 2008). Using the roads dataset, a distance to roads grid was derived. Rest areas and major highway/interstate intersections were also calculated. Distance from the roads was set at a threshold of $1 / 8$ mile, while the distance from intersections and rest areas was one mile. One mile represents a feasible distance that EAB can naturally disperse and begin colony establishment in a short amount of time (Taylor et al. 2005). The three grids were then weighted with rest areas being weighted the most and distance from roads weighted the least, then, additively combined to produce the final raster grid. Since these three variables are connected, weights were assigned to differentiate risk. Rest areas were deemed more suitable for EAB introduction because they generally have a park-like setting and because travelers congregate around them. Major roads and intersections were treated the same way except they usually do not have stopping points next to wooded areas so they were weighted much lower than rest areas. Roads were considered to have a very small chance of introducing EAB. Constant human traffic could cause an incidental EAB colony, but the risk is very low. 


\subsection{Harbors and Urban Areas}

Distance grids are important because of their spatial locations from important EAB spread vectors. Important variables used in this research included shipping harbors and urban areas. Shipping harbors were used due to the risk of insects being moved long distance or the introduction of new infestations by wood crating and packaging, such in this case of EAB being imported from Asia (Haack, 2002). Urban areas have more human activity than other rural communities which increases the probability of EAB establishment (Poland and McCullough, 2006; Minnesota Dept. of Agriculture, 2006). Trees in urban areas are generally more stressed due the environmental conditions, which makes them more susceptible to attack (Iverson et al. 2006).

The shipping harbors dataset was created by coordinate input since a feasible dataset was not attainable. To create this data layer, port addresses were entered from the World Port Source (www.worldportsource.com/states.php). The website provides a combination of satellite photographs (Imagery 2009 Digital Globe, GeoEye, U.S. Geological Survey) and Google maps for addressing. Additional information about each port is also available on the website such as its address, port type, size, coordinates and some websites. Using the coordinates and aerial photography, a shapefile was created using ArcCatalog. Urban areas for the project area were extracted from National Transportation Atlas Database 2009 Bureau of Census. The distance grids were calculated using Straight Line distance.

\subsection{Housing Density}

Housing density is another key variable because it correlates with human population and urban areas. As urban sprawl continues to increase, urban areas are become larger due to the construction of additional housing and business sectors. New development means land 
disturbances are occurring, which causes a transformation of land cover. Invasive species often thrive in disturbed areas making these new developments a point of emphasis. To study the housing change, housing density data was downloaded from the University of Wisconsin housing density statistics page (http://www.silvics.forest.wisc.edu/maps.asp). This dataset tracks housing density (units per $\mathrm{km}^{2}$ ) from 1940 to 2030. Housing density was projected from 20102030 using the prediction model from Hammer et al. (2004). The definition of a "housing unit" is strictly defined by the census bureau as a house, an apartment, a mobile home, a group of rooms, or a single room that is occupied (or if vacant, is intended for occupancy) as separate living quarters. Separate living quarters are those in which the occupants live and eat separately from any other persons in the building and which have direct access from the outside of the building or through a common hall. Zip files for each state were downloaded from their database provided on the website (see above website). Upon unzipping the data, the interchange file must be converted to a coverage file before ArcMap can read it properly.

After the conversion, the attribute table will be available to calculate percent change. For this study, percent change from 2000-2010 was selected because those years coincide with the years when EAB became prevalent. Since this density grid is still considered a shapefile, a raster conversion is needed with the percent change column as the point of reference for the new raster grid.

\subsection{Primary Source of Fuel}

Many homes owners in the Mid-Atlantic region use wood as a primary source of fuel to heat their house during the winter months. As a fuel source, wood is generally transported and stored while waiting to be burned. Stored firewood, especially unused firewood, could allow EAB ample amount of time to emerge, reproduce, and establish a new colony. The 2000 Census 
was used to provide an estimate of how many people in the Mid-Atlantic region use firewood throughout the winter as their primary heat source. Data was obtained on a county-level and the number of homes per county was identified.

\subsection{Ash Basal Area}

Ash is one of the most important factors of EAB modeling because an absence of ash means that EAB cannot survive without its host species. Tree basal area grids can be found and downloaded from the USDA Forest Service Forest Health Technology Enterprise Team (FHTET) website (http://www.fs.fed.us/foresthealth/technology/nidrm.shtml). The ash basal area grid displays the presence of ash throughout the study area determined from Forest Inventory Analysis (FIA) data.

\section{Data Pre-processing}

Data pre-processing was conducted in three steps: re-projection, clipping the study area boundary, and creation of ASCII grids for the Maxent model. All datasets were converted to raster grids with the same $90 \mathrm{~m}$ pixel size. Geographic dimensions for all layers must match exactly for the Maxent model to run.

\subsection{Scale and Projections}

Map scale is an important part of any spatial analysis. In GIS terms, map scale is defined as the relationship existing between a distance on a map and the corresponding distance on the earth. The terms "large-scale" and "small-scale" are common delineations of maps in reference to their size. These two delineations are often confused. Large-scale maps are very detailed over a small area (i.e. city maps) while small-scale maps are not as detailed and cover large areas (i.e. 
North America). This level of detail is called resolution for digital maps. Scale can greatly affect resolution which alters map accuracy.

Projections are also another very important part of GIS modeling, especially for large study areas that stretch hundreds of miles. Projections are used to account for the curvature on the earth's surface. Without them, calculations would assume that the earth's surface is flat causing drastic errors in mathematical functions. For this project, the standard projection was chosen to be North American Datum (NAD) 1983 Universal Transverse Mercator (UTM) Zone 17 coordinate system. This projection was selected because it was centralized to the study area. Original projections for downloaded data differed for almost every layer. Re-projection of these datasets to the standard projection was done before sub-setting the data.

\subsection{Study Area Clipping}

The states in the study area were clipped from a larger dataset from the ArcGIS 9.2 Data and Maps Media Kit. The coordinates for the corners are given in Table 2.

Table 2. ArcMap corner coordinates for the EAB study area.

\begin{tabular}{ccc} 
Corner & $X($ UTM) & Y(UTM) \\
\hline Upper Left & 169747.78 meters & 4707195.32 meters \\
Lower Right & 1097901.82 meters & 4117579.51 meters \\
\hline
\end{tabular}

\subsection{Creation of ASCII Grids}

All raster datasets were clipped to the aforementioned coordinates and saved as new raster grids. The grids were transformed to Integer format during the clip. The raster datasets were then, converted to ASCII format using the "Raster to ASCII" option in ArcToolbox. 


\section{Maximum Entropy Model Parameters}

Maxent software version 3.3.1 was available for free download and used for modeling (http://www.cs.princeton.edu/ sschapire/maxent/). Based on the current occurrence points, this model generates an estimate of probability of presence for EAB that varies logistically from 0 to 1 , where 0 is the lowest and 1 is the highest. The 982 locations and 11 environmental predictors were implemented in Maxent to model the potential areas at risk for EAB.

Testing and validation is required for any predictive model. Testing model performance should ideally have independent data, but some cases arise where this will not be available. In such cases, it is common to use an approach that partitions data randomly into "training" and "test" datasets (Kumar \& Stohlegren, 2009). Executing this creates a quasi-independent data for model testing (Kumar \& Stohlegren, 2009). Maxent has the ability to do this internally. In addition, Maxent allows modelers to use a jackknife procedure that tests each variable in the model separately, and then combines them for the final output. This allows for variable analysis to determine which variables had the most contribution to the model. However, it is important to note that all variables are still considered "significant." Otherwise, they should have not been included.

\subsection{File Formats Requirements}

Maxent works best for presence-only (or known location) data. For this project, a list of current EAB positive locations was used as presence data. This file must be in CSV format and contain three essential columns: species, longitude, and latitude. The column headings must match for the model to run. If the headings are not labeled correctly, the Maxent program will not recognize the CSV file appropriately resulting in an error. It is possible to have other 
information include in the file, but Maxent will not recognize these data. Extra data will not affect the outcome of the model. The environmental layers must be in ASCII format.

\subsection{Setting up the Model}

The environmental layers window is where the ASCII grids are placed for analysis. The boxes for create response curves, make picture of predictions, and jackknife to measure variable importance can be checked before the model is run to provide material for additional analysis. Output formats can be selected as Logistic, Cumulative, or Raw. Logistic formats are most common as they are the most intuitive when displaying probabilities since values range from 0 to

1. Auto features is the default setting and should remain checked unless the user wants to experiment with different response curves. Leaving auto features checked will instruct the model to search for all constraints based on the number of presence records available. Other feature types are based on the number of sample points which is explained within the Maxent Help menu.

The Settings tab allows for Maxent parameters to be set. The newest versions of Maxent have three tabs for defining parameters. Running the model with all default setting is "acceptable" but to produce more refined output, the user can utilize these parameters. The Basic tab represents the most basic features of the Maxent model but some of the most important too. Some notable features in this tab are random seed, random test percentage, regulation multiplier, backgrounds points, number of replicates and the replicate run type. Random seed is important for users who are running multiple replications of their model and want to use different sets of background points and test/training data partitions. If the random seed is not desired, random test percentage will suffice for partitioning test/training data by selecting a certain percent of sample points to set aside for testing, which is required to do the statistical 
tests for variable importance. A set test percentage is not currently defined, but $25-40 \%$ is common based on most existing studies. Regularization multiplier functions act much like a confidence interval. As the multiplier increases, the output distributions become wider which can be considered a conservative approach. When the multiplier is less than one, the output display becomes more defined and could be classified as a liberal approach. Generally, the default setting is used unless the user wants to be more conservative or more liberal. Background points collect environmental information in order to train the model. The default number of points is generally selected here as well, but larger study areas may want to increase this number. Replications indicate how many times the model is run. The outputs, when selecting multiple replications, are averaged and standard deviation is calculated to explain the variance within the replications. Replication run type indicates the type of sampling (with or without replacement) and includes crossvalidate, bootstrap, and subsample. If crossvalidate is selected, multiple replications must be used because each replicate provides its own set of test data.

The Advanced and Experimental tabs offer very in depth parameters that are only recommended for advanced Maxent users. The newer versions of Maxent provide very detailed features but currently, their contribution to model accuracy is not clearly evident at this time. For these tabs, default settings are almost always selected. 


\section{Chapter 5: Results}

The Maxent model produced some promising results. This section reports the outcomes of the Maxent model based on an average of 10 replications. Predictive power, error, and analysis of variable importance using response curves and jackknifes were recorded in this section.

\section{Analysis of Predictive Power and Error}

Assessing a model's outputs for error and predictive power can be somewhat daunting. However, Maxent's internal statistical features allows for model interpretation to be achieved with relative ease. Initially, it analyzes omission and commission errors, then, produces a receiver operating curve (ROC) to assess area under the curve (AUC). Through these analyses, figures are produced for interpretation. The first analysis result is to assess the diagram for omission and commission errors (Fig. 17). This image displays the test omission rate and predicted area as a function of cumulative threshold. The black line that splits the graph represents the predicted omission rate and is straight by the definition of the cumulative output format (Phillips et al. 2006). If the model is a "good" match to the predicted omission, the turquoise line (test data) will be above the predicted omission line. Although in some cases, the test data omission line will be below the predicted omission line. This does not necessarily mean that the model is invalid, but just explains that the test data and the training data are not independent. Spatially auto-correlated occurrence data will produce this type of result. In theory, if the training and test data were independent, the test data line would be above the predicted line. If the omission error of the test data was shifted further to the right in Fig. 17, then that would be a cause for concern because it implies a high amount of error. The dark band surrounding the test data line represents the standard deviation of the 10 model replications. As 
shown, the standard deviation is minimal indicating that the average is low for this model which indicates low variance among simulations.

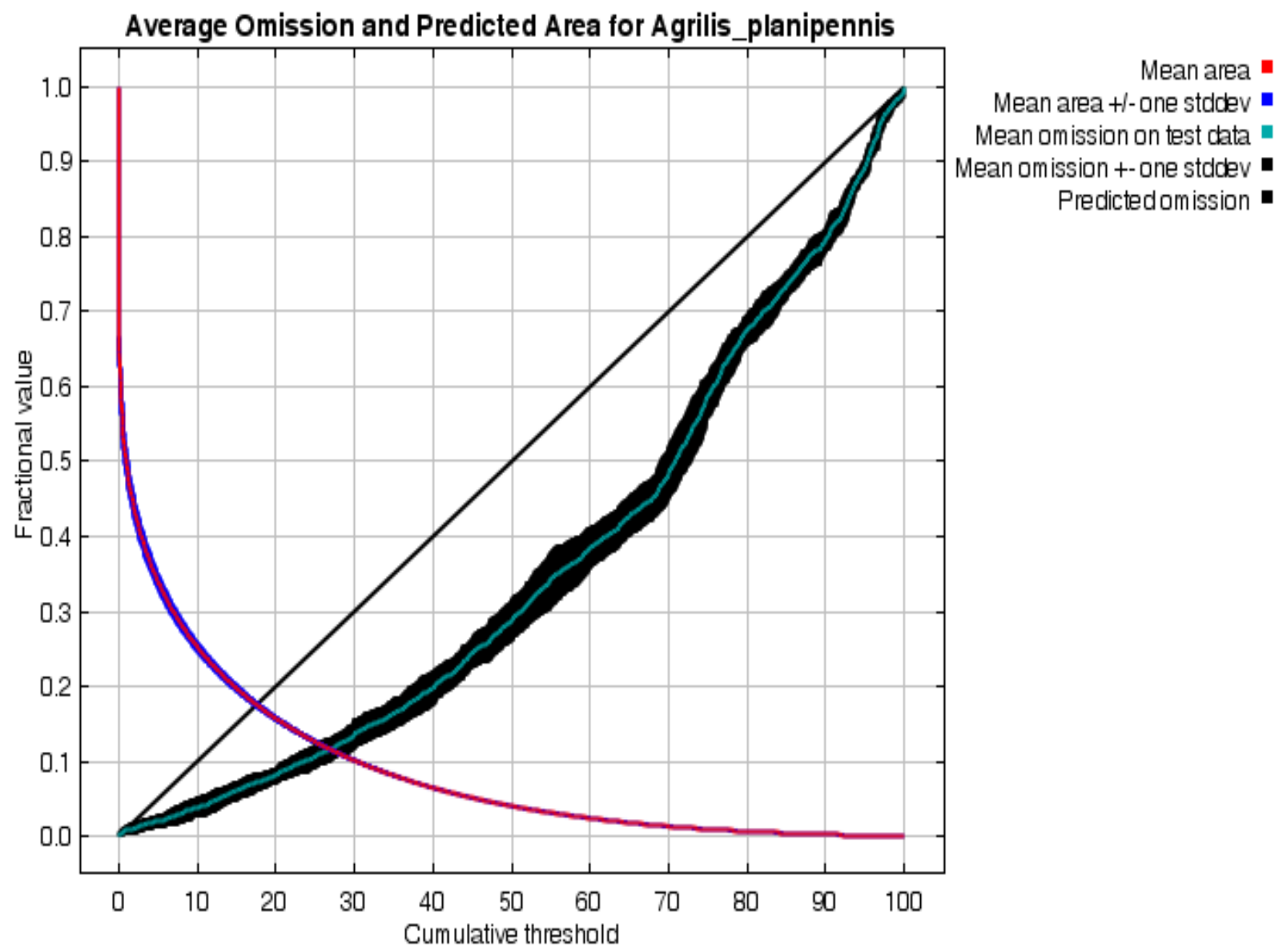

Figure 17. Omission and commission errors in Maxent model for EAB.

The next graph gives the results for the ROC curve (Fig. 18). This curve is derived from the same data as the omission and predicted area graph. The $\mathrm{x}$-axis represents the commission error from the Fig. 17 while the y-axis represents sensitivity or the absence of omission error (aka true positive rate). In this graph, the turquoise line depicts the chance of yielding a random prediction or the outcome of the model that was no better than random. Falling below this line indicates that the model performs very poorly resulting in a model that is worse than a random model. Thus, any model with an AUC greater than 0.5 is considered to have better predictive 
power than a randomly generated model would. The red line in Fig. 18 shows the average "fit" of the model to the test data for EAB within one standard deviation. This is the indicator of the model's real predictive power. The closer this line is to 1 , the better the model is at predicting probability of presence. As shown, the EAB model has an average AUC of 0.952, which signifies that the model achieves a high predictive power. In addition, the standard deviation (0.007) for the AUC is very low indicating low variance which strengthens the model's predictive power as well.

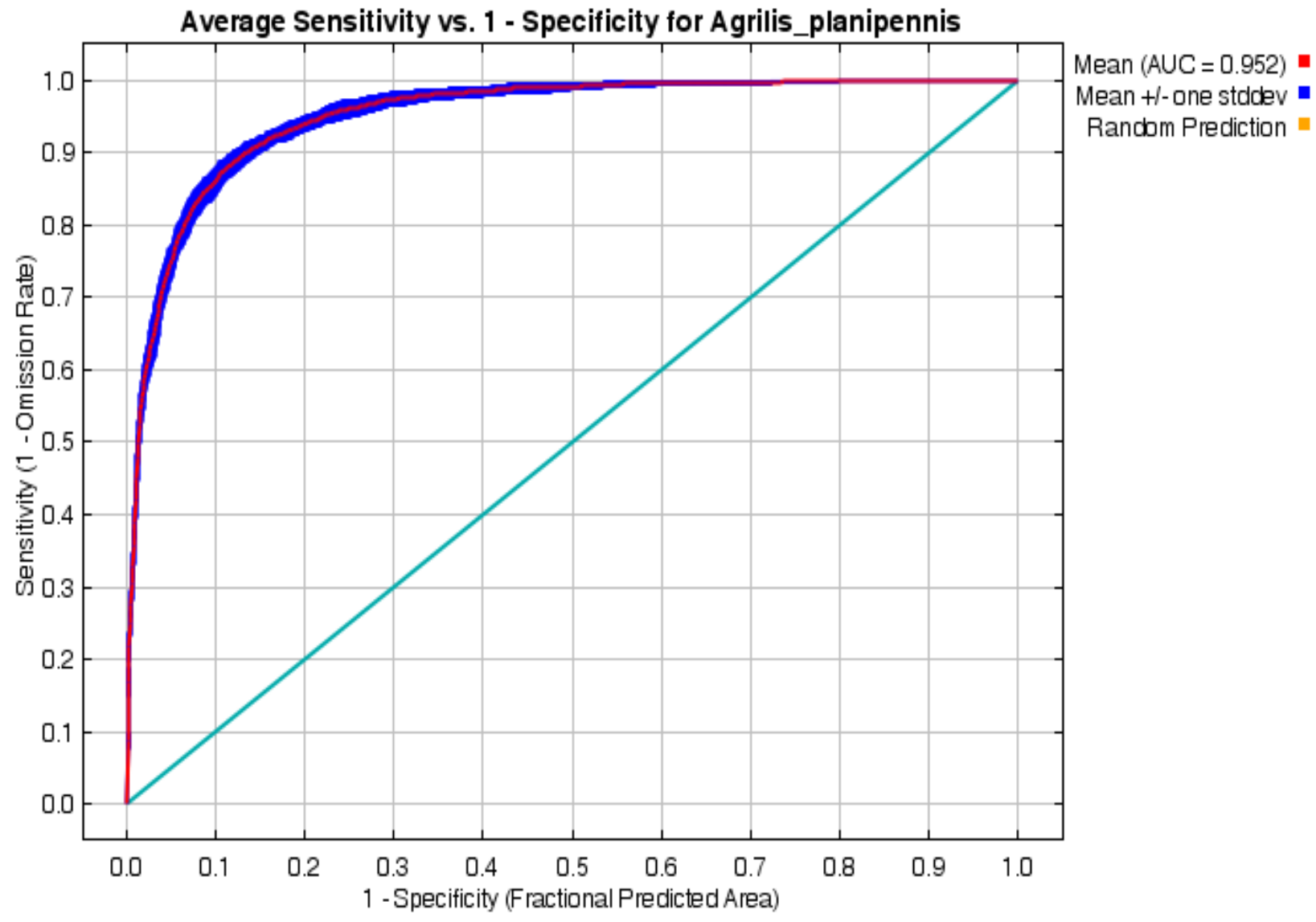

Figure 18. Receiver operating curve (ROC) representing area under the curve (AUC) justifying the model's predictive power for probability of EAB presence.

It is important to mention that AUC values are tied to study area size. Therefore, AUC values will generally be higher for studies with a smaller or narrow range. For example, this 
study uses the Mid-Atlantic region of the Unites States as a study boundary, which can seem quite large. However, many Maxent models will have data representing whole continents and sometimes, the whole world. AUC values for these particular study sizes will be much lower because the amount of error will undoubtedly increase, ultimately decreasing the predictive power of the model. As Phillips et al. (2006) explain, this is just an artifact of the AUC statistic and does not mean the models are less relevant.

\section{Predictive Probability of Presence Map}

As a part of the Maxent outputs, an image was generated to provide a visual interpretation of areas with probabilities. In addition to probabilities, the amount of area at risk by EAB was also calculated in ArcMap (Fig. 19). The map properly predicts high EAB risk in western Ohio because most of the observation points were confined to that part of the study area. This study was particularly interested in predicting new areas of risk to EAB. The output map has accomplished this goal. The map has clearly defined new high risk areas locations in northern New Jersey as well as western Pennsylvania. Parts of central Maryland are also predicted at high risk to EAB. The Ohio River valley along the border of Ohio and West Virginia has predicted greater than a $50 \%$ probability of presence for EAB.

Under the current model, the majority of the study area was at very low risk $(0-10 \%)$ to EAB establishment. The output predicted only $3,221 \mathrm{~km}^{2}$ of very high risk areas and 11,160 $\mathrm{km}^{2}$ of high risk areas $(50.1-75 \%)$. It is crucial to note that just because an area has reported a very low risk does not necessarily mean it is immune to establishment. For instance, one infestation in West Virginia was reported in a very low risk area. A few colonies in Ohio were also reported in low risk areas. 


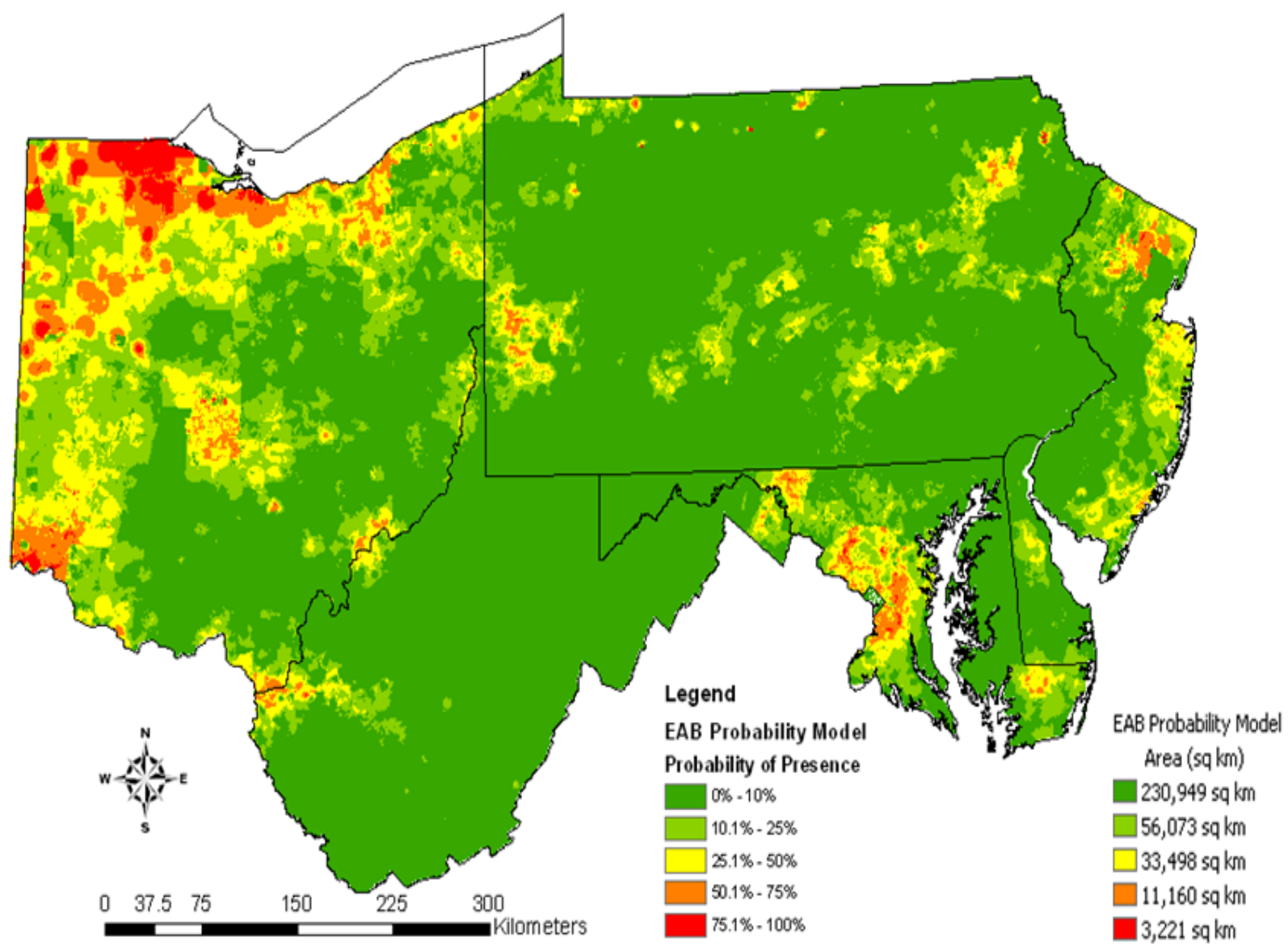

Figure 19. Predicted potential probability of presence for EAB in the Mid-Atlantic.

\section{Statistical Significance of the Prediction}

Since the model was provided with test data, Maxent automatically calculates statistical inference. This information is useful for depicting when the model yields significant values. Fig. 20 is only produced in each replicate simulation instead of the average of the 10 replicates. It is possible to select a threshold in which to apply for the model after a preliminary test has been run. Again, the contents of this table coincide with the other figures. Maxent allows for thresholds described in the description column of the table to be chosen in model simulations. By choosing a particular threshold, the model uses the value in calculating the final model. Determining which threshold to use and when to use them is still a newer concept in Maxent 
modeling. It is also important to note that choosing a threshold is completely up to the user and is not required to run the model.

To provide an example of the threshold interpretations, the test sensitivity and specificity threshold is first selected which resulted in a cumulative threshold value of 25.900 in Fig. 17. The logistic threshold column is the value in which all numbers of greater value are significant. In this case, values that are greater than 0.298 were considered significant in the logistic output, which is displayed in the next subsection. In terms of the EAB model, all cells with values larger than the 0.298 value signify that there was "significant" risk of EAB presence. Omission rates and predicted area are also derived. Fractional predicated area represents the

\begin{tabular}{|c|c|c|c|c|c|c|}
\hline Cunnulative threshold & Logistic threshold & Description & Fractional predicted area & Training omission rate & Test omission rate & P-value \\
\hline 1.000 & 0.027 & Fixed cumulative value 1 & 0.476 & 0.002 & 0.010 & OEO \\
\hline 5.000 & 0.082 & Fixed cumulative value 5 & 0.327 & 0.011 & 0.023 & OEO \\
\hline 10.000 & 0.135 & Fixed cumulative value 10 & 0.241 & 0.022 & 0.043 & OEO \\
\hline 0.031 & 0.002 & Minimum training presence & 0.674 & 0.000 & 0.007 & $1.837 \mathrm{E}-32$ \\
\hline 31.986 & 0.353 & 10 percentile training presence & 0.091 & 0.100 & 0.150 & OEO \\
\hline 30.950 & 0.344 & Equal training sensitivity and specificity & 0.095 & 0.096 & 0.150 & OEO \\
\hline 30.819 & 0.342 & Maximum training sensituity plus specificity & 0.095 & 0.091 & 0.147 & OEO \\
\hline 25.900 & 0.298 & Equal test sensitivity and specificity & 0.117 & 0.080 & 0.117 & OEO \\
\hline 26.727 & 0.308 & Maximum test sensitvity plus specificity & 0.113 & 0.084 & 0.117 & OEO \\
\hline 3910 & 0.069 & Balance training omission, predicted area and threshold value & 0.354 & 0.004 & 0.020 & OEO \\
\hline 13.125 & 0.168 & Equate entropy of thresholded and oniginal distributions & 0.205 & 0.038 & 0.077 & OEO \\
\hline
\end{tabular}

Figure 20. Common threshold values from one simulation of the replications for the Maxent EAB model.

percentage of the study area at risk meaning the percentage of the study area with a logistic value greater than 0.298 . This informs the user that roughly $30 \%$ of the study area was at "significant" risk to EAB according to the selected threshold (equal test sensitivity and specificity). For 
omission rates, a smaller value indicates less error. A value close to zero acknowledges that there was little omission error for the model. The last column in the table shows the standard pvalue for determining significance at the 0.05 level. For a more detailed explanation of Maxent output option statistics, see Phillips et al. (2006).

\section{Variable Contribution}

As with most studies, it is common to determine how the variables in the model were used. Upon completed simulations, Maxent outputs provide a table to analyze how each variable was used while the program was being trained. Maxent keeps track of how each variable's contribution and adjusts the coefficients accordingly. Then, after the simulation, Maxent tallies the contributions of each variable into a percentage. Maxent found that wood transportation by sawmill or firewood (43.7\%) had the most contribution to the probability of EAB presence over

the 10 replications (Table 3). Tree production (nurseries) and seasonal homes were the next most used variables in the model. It is important to note that even though variable contribution is minimal for some variables (i.e. human pop and road_rest) this does not mean that they are less significant. This only indicates the path that Maxent has chosen in order to provide the best outcome for maximum entropy. If another variable had been added or the datasets were represented differently, there could have been a completely different outcome. Therefore, variable contribution should be interpreted with caution, especially when variables are correlated (Phillips et al. 2006). 
Table 3. Selected environmental variables and their percent contribution (average of 10 simulations) in Maxent model for EAB in the Mid-Atlantic study region.

\section{Environmental Variable (Maxent code) Percent Contribution}

Wood Transport (woodtrans)

Tree Production (treeproduct5)

Seasonal Homes (seasonal)

11.8

Distance to Harbors (dist2harbor)

10.7

Total Homes with Firewood Usage by county (wooduse_raw) 7.9

Distance to Urban Areas (dist2urban)

5.6

Campground Density (campdens5)

1.7

Housing Density (housinggrid)

Ash Basal Area (ashgrid)

Human Population (humanpop)

Road Intersections and Rest Areas (road_rest)

1.6

1.5

\section{Response Curves}

Maxent produces response curves to explain how each variable affects the probability prediction. These response curves are created from a selection of features in the Maxent interface. For instance, Maxent provides five different options for displaying the response curves: linear, quadratic, product, threshold and hinge. Each of these different options will change the look of the response curves. Since Maxent utilizes a machine-learning process, two different sets of response curves are created. The first set contains the logistic probability of presence (y-axis) of suitable conditions with all other variables fixed at their average value (marginal response curves). This requires Maxent to assess how each variable interacts with all others during the model simulations. For marginal response curves, it should be noted that if the variables are correlated, then the curves can be misleading. To counteract this, Maxent produces a second set of response curves using only a particular variable and disregarding all other variables. As a result, some curves can look drastically different or look very similar to the first 
set. Curves with only the corresponding variables may be easier to interpret because of this reason.

It is important to point out that when comparing response curves that the y-axis scale will be different. When evaluating the graphs, caution must be taken to avoid inaccurate interpretation. In general, the standard deviation of the marginal response curves will be higher than those of the corresponding variable response curves, although this is not always the case. This is mostly attributed to the different variances, through multiple simulations, when the particular variable interacts with the others.

This section will analyze each variable (in no particular order) and their response curves to evaluate their interactions. The ash grid was included into the model because it is the preferred host species of EAB. The $\mathrm{x}$-axis in these response curves represents the amount of basal area with 0 being the lowest and 100 the highest. The marginal response curve (all variables) on the left with the corresponding variable (only variable used) is on the right. From each of the response curves, the amount of ash was not really a "good" determinant of EAB spread, especially when it is the only variable (Fig. 21). Probability of EAB risk was low even at its highest peak. An increase of ash basal area does not mean that EAB has a higher likelihood of establishment. One reason this could be true is that ash, itself, it just not a good indicator. The ash variable seems to be highly dependent on other variables for EAB spread. Another possible factor could be the representation of ash in urban areas, since it was so limited. With most of the presence points being in very low ash areas, the model does not accurately depict the ash grid as a contributing factor because the model was not including them properly in the analysis. 

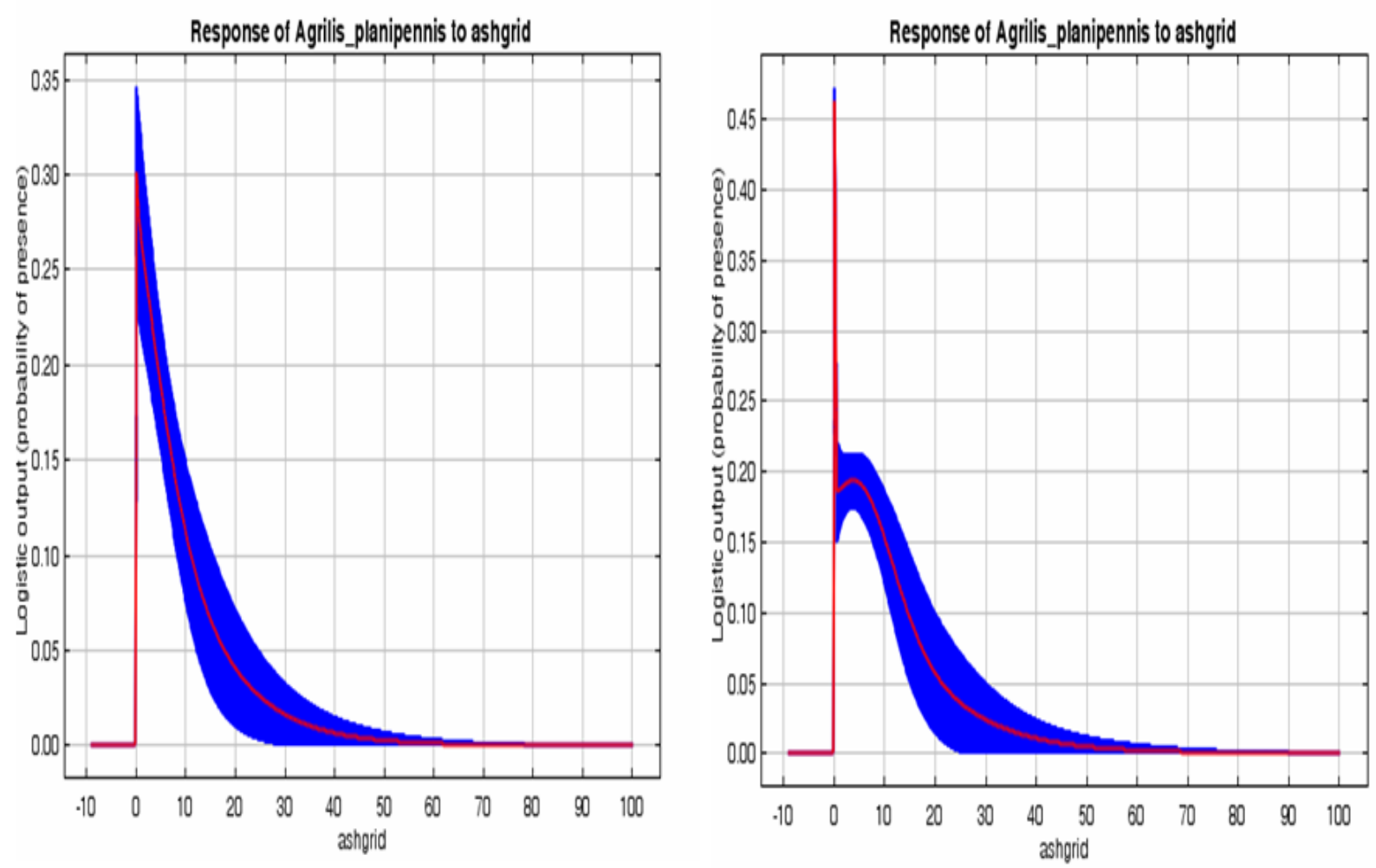

Figure 21. Response curves for ash basal area grid for the Maxent EAB model. The left curve represents the marginal response curve and the corresponding variable curve located on the right. The $x$-axis represents the amount of basal area while the $y$-axis is probability of presence.

Campgrounds were one of the most studied variables for EAB spread since they have interactions with the general public during the movement of firewood. This model used a variable as a density grid with a five mile search radius. The marginal response curve (left) predicts of $40 \%$ probability of presence at its highest point when interacting with other variables. This was a good indicator that EAB spread could be connected to campgrounds. The corresponding variable curve (right) tends to reinforce that concept with a high probability of occurrence when campgrounds were the only variable at 65\% (Fig. 22). Although the actual probabilities can be somewhat deceiving, the higher density amounts show no increasing risk of EAB presence. The variance of the marginal response curve provides an interesting output. A 
large difference in variation decreases the strength of this variable because it was not consistent in any simulation. This was especially true in higher density areas.
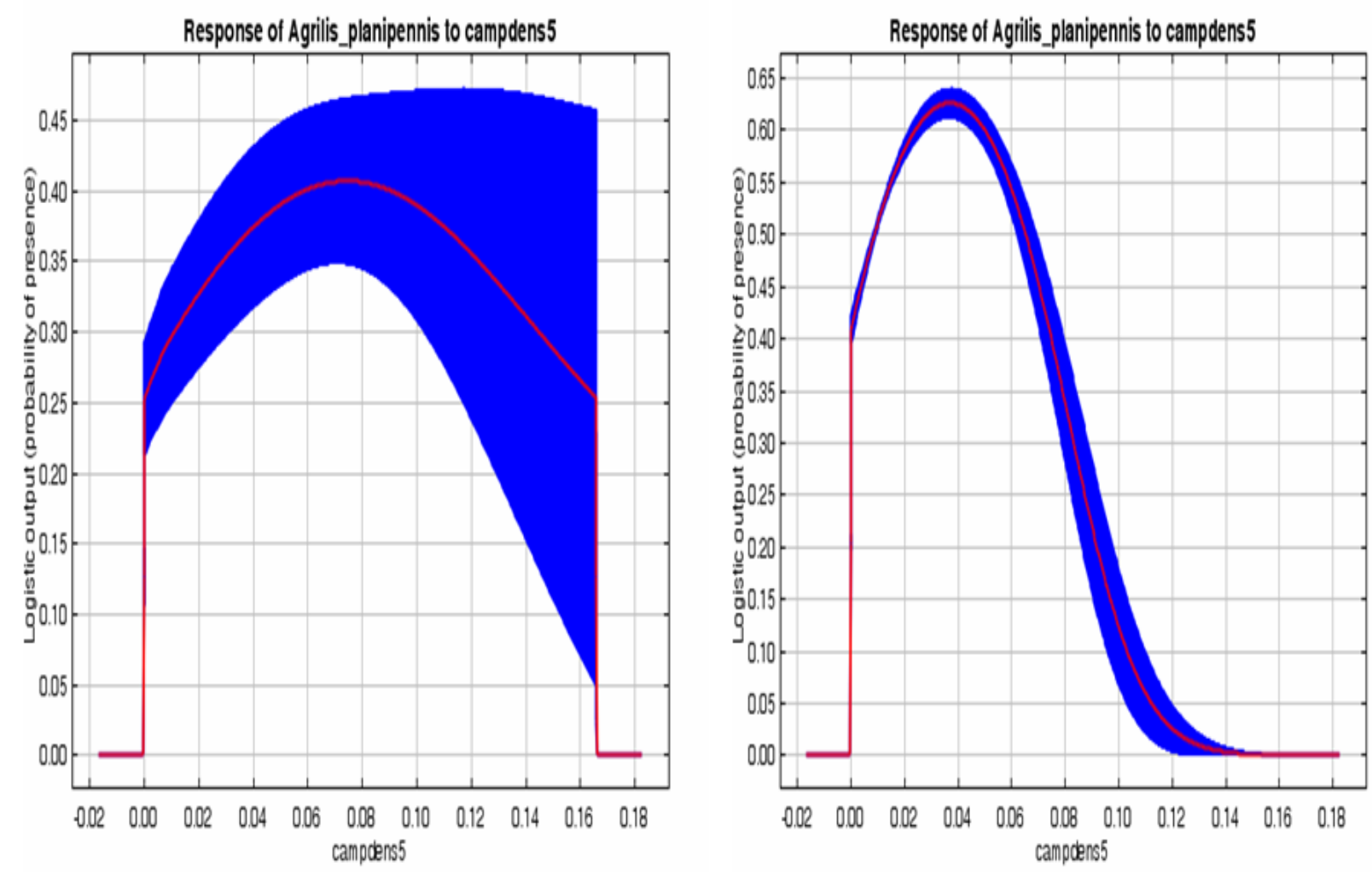

Figure 22. Response curves for campground density for the Maxent EAB model. The left curve represents the marginal response curve and the corresponding variable curve located on the right. The $x$-axis represents density within a five mile search radius using kernel density. The y-axis is probability of presence.

The distance to harbors grid was included to model the risk of introduction from sources outside the study area, most notably foreign countries. EAB was originally introduced into the U.S. by wood crating. Both response curves indicate that this variable is highly connected to EAB risk. Low variances in each curve signify that this variable was consistent throughout all simulations. The highest probabilities were located closest to the harbor and show a decreasing trend as distance increases (Fig. 23). The secondary peak in the middle of both graphs was an interesting artifact. Possibly, product distribution could be the factor producing this result. The initial probability of establishment occurs near the harbor. Products are generally shipped away 
by some transportation means. Therefore, the probability of risk would decrease because, while being transported, EAB establishment would be difficult to achieve. Consequently, products shipped to local distribution centers would increase the risk of EAB establishment, hence the increase in the middle of the graphs.
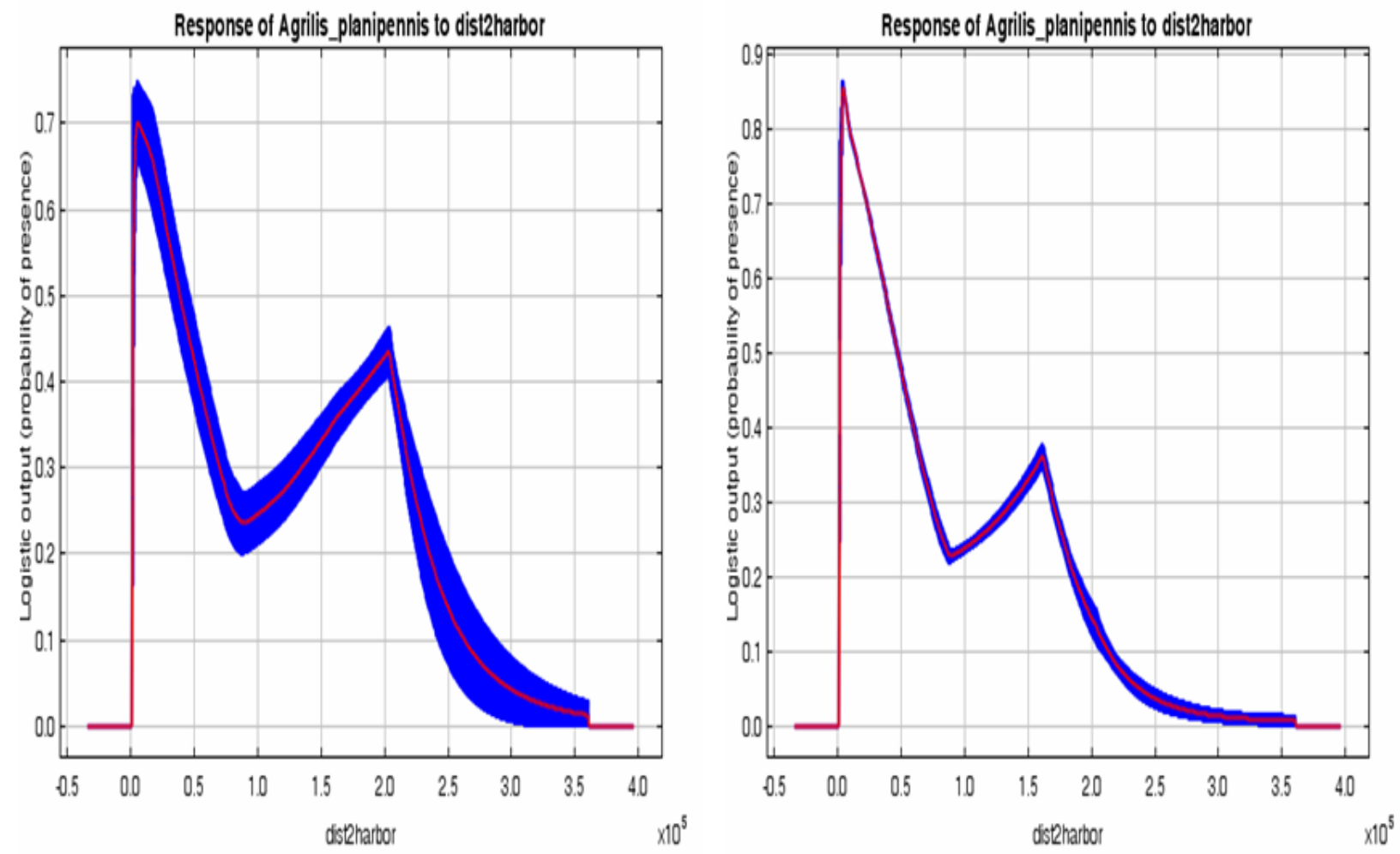

Figure 23. Response curves for the distance to harbors grid for the Maxent EAB model. The left curve represents the marginal response curve and the corresponding variable curve located on the right. The $x$-axis represents distance (meters) from the closest harbor. The y-axis is probability of presence.

Urban areas are often a source for invasive insects due to likelihood of spread by humans and product distribution centers. Maxent considers this variable as a decent indicator of EAB probability risk from the response curves. As expected, increased distance from urban areas decreases the chance of EAB presence (Fig. 24). This would be true with urban-forest interfaces. Natural EAB spread is slow, but increases rapidly with human involvement. Moving away from 
urbanized regions usually means less human interaction as human populations disperse rather than cluster.
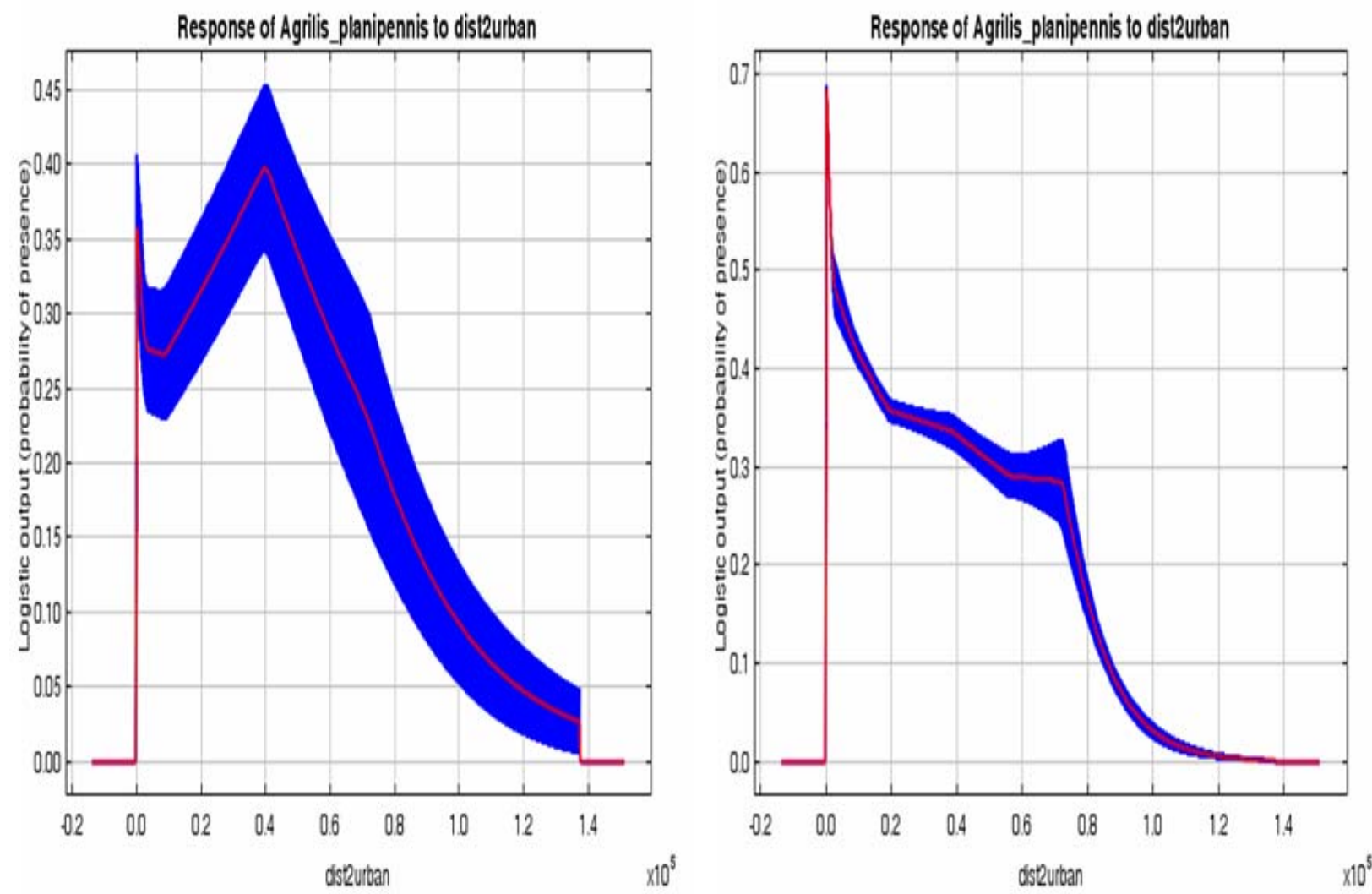

Figure 24. Response curves for the distance to urbanized areas grid for the Maxent EAB model. The left curve represents the marginal response curve and the corresponding variable curve located on the right. The $x$-axis represents distance (meters) from the urban area boundary. The y-axis is probability of presence.

Housing density was a new variable introduced in this EAB model. This variable was somewhat tied to urban areas, but differs due the recent trend of housing complexes being built outside of urbanized boundaries. These response curves are intriguing because both show a high probability of presence even though this variable did not have a high percent contribution (Fig. 25). One explanation for this could be that current EAB established colonies interact with the data layer, which indicated a high probability. Simply put, EAB may have already been present 
in these areas before housing density increased since this data layer has an increment of ten years. Nonetheless, the variance on both curves represents consistent usage over all simulations.
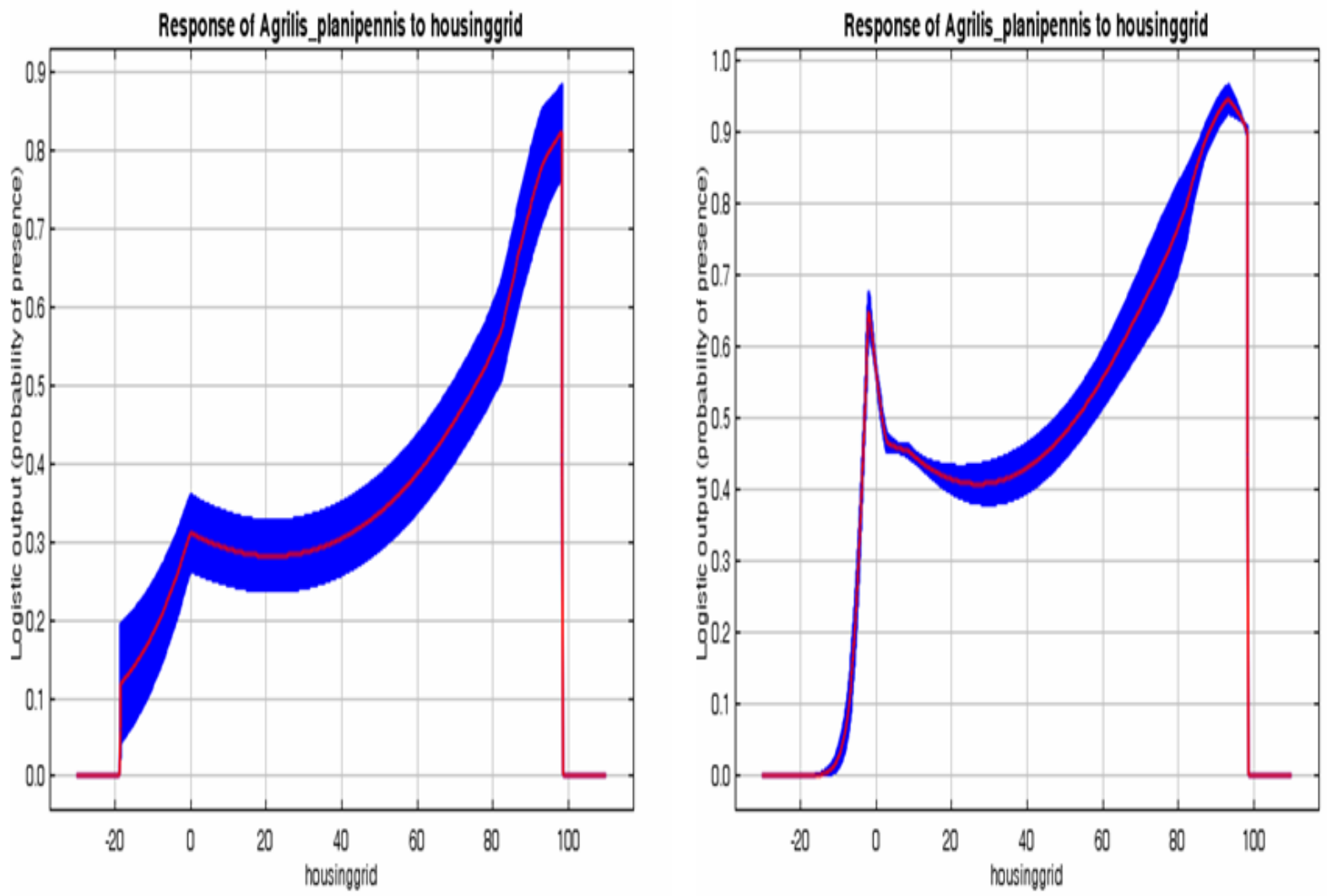

Figure 25. Response curves for the housing density grid in the Maxent EAB model. The left curve represents the marginal response curve and the corresponding variable curve located on the right. The $x$-axis represents housing units per square kilometer. The y-axis is probability of presence.

Overall, both response curves for total human population decrease as population increases (Fig. 26). Most likely, this means that human population was not correlated with risk of EAB spread above approximately 3000-4000 per census block group. Therefore, anything above this range does not increase the probability of EAB present based on this variable. With the increased standard deviation, the variable was not consistent at high population levels which means it could be a good indicator or serve almost no use at all. 

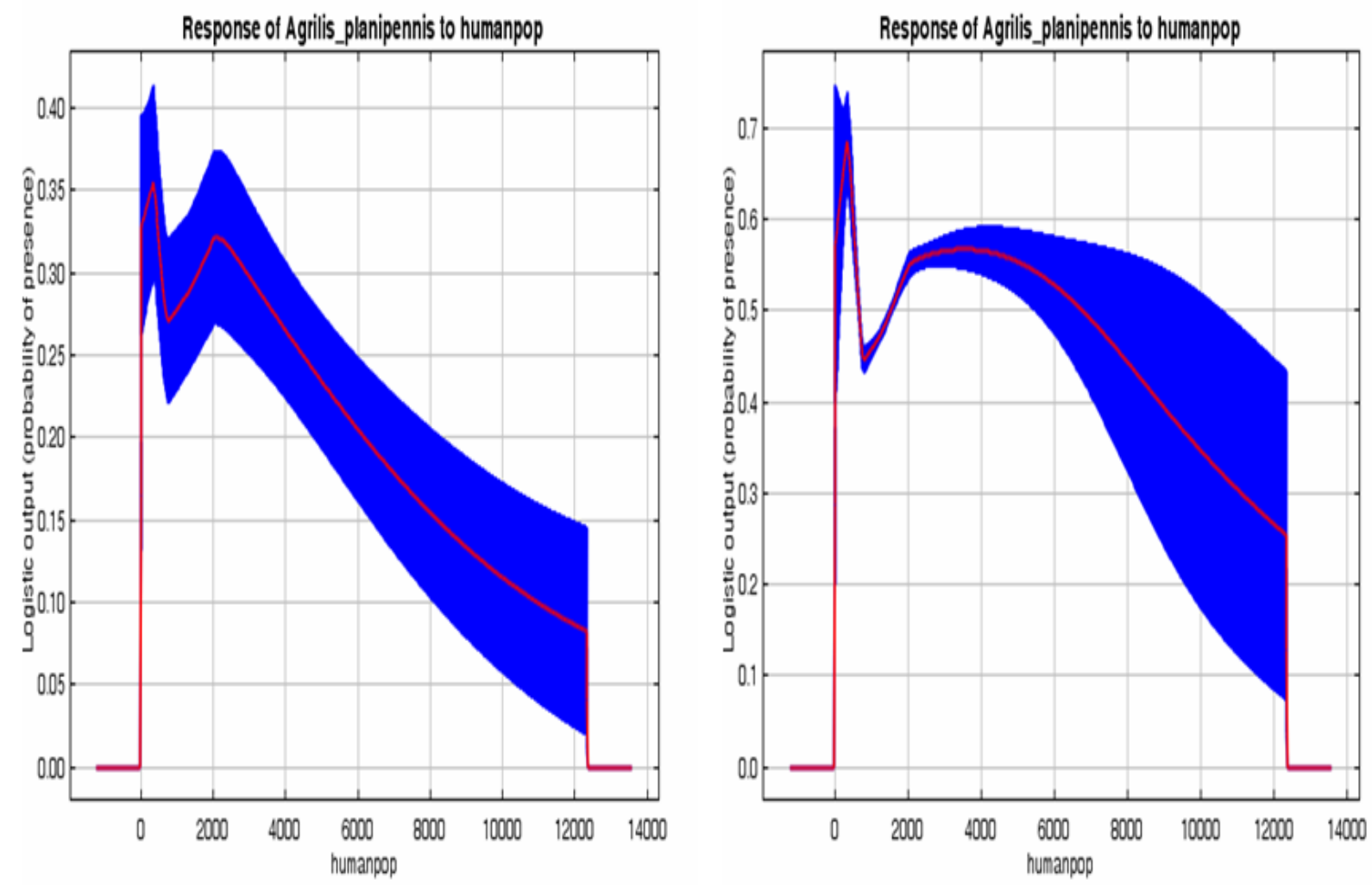

Figure 26. Response curves for the human population for the Maxent EAB model. The left curve represents the marginal response curve and the corresponding variable curve located on the right. The $x$-axis represents the total human population per block group from the 2000 census. The $y$-axis is probability of presence.

Major road intersections and rest areas provided interesting response curves. When interacting with other variables, the probability was rather low compared to when it was the only variable (Fig. 27). However, such a large standard deviation hinders the value of this information. The general trends decrease with distance, which was expected. From the curves, it appears that a distance greater than 600-800 meters has a negative effect on EAB establishment. 

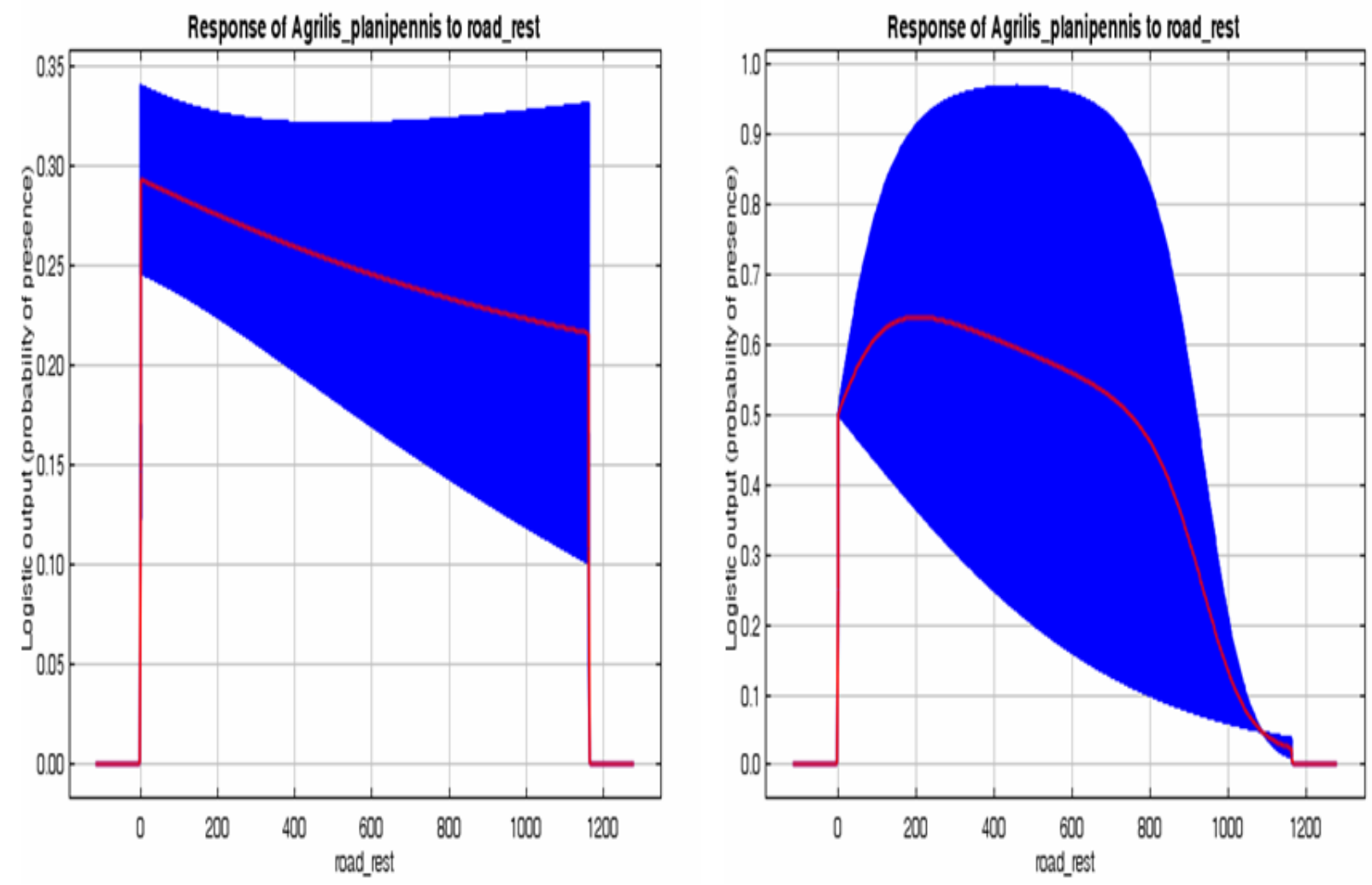

Figure 27. Response curves for the major (i.e. interstates and U.S. highways) road intersections and rest areas for the Maxent EAB model. The left curve represents the marginal response curve and the corresponding variable curve located on the right. The $x$-axis represents the distance (meters) from each intersection or rest area. The $y$-axis is probability of presence.

The number of seasonal or secondary homes does not appear to increase the probability of EAB presence even though it was one of the top three variables that Maxent used to create the model (Fig. 28). Any census block group with more than 500 secondary homes has a zero percent probability of EAB presence. Maxent could have possibly interpreted this variable by assuming anything block group with over 500 secondary homes does not increase the risk leaving the probability at zero rather than pick a random number of homes and finding a probability for that amount. This outcome was perplexing and does not seem to have a logical explanation. 

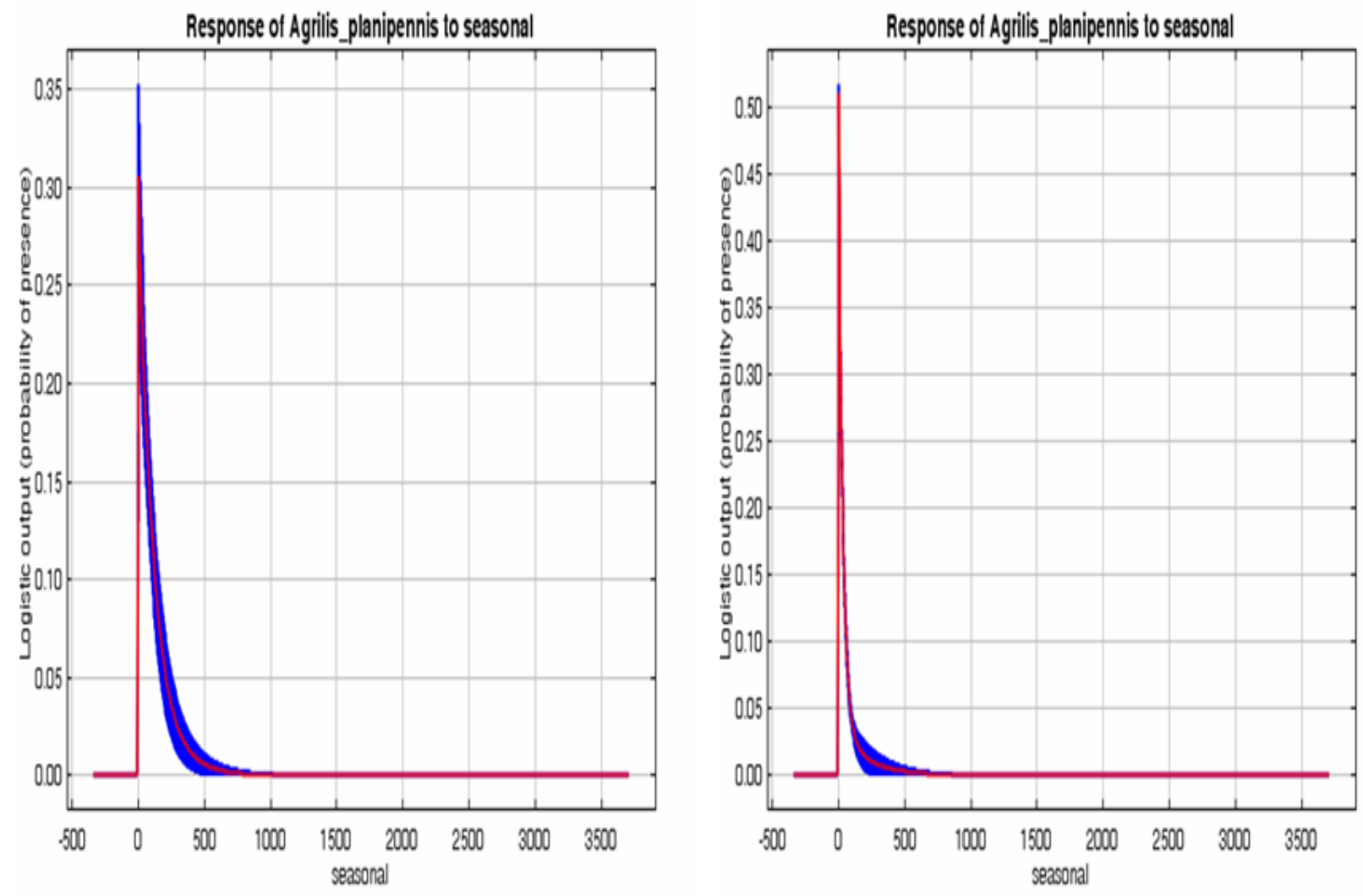

Figure 28. Response curves for the seasonal homes for the Maxent EAB model. The left curve represents the marginal response curve and the corresponding variable curve located on the right. The $x$-axis represents the total number of seasonal homes (secondary homes) per block group from the 2000 census. The $y$-axis is probability of presence.

When combined with other variables, nurseries seemed to be a good indicator of EAB presence (Fig. 29). The probability shows a positive trend when all variables were included. As the only variable, this was partly true because of the high probability with low variance on the left part of the curve. Once it reaches a value of 0.06 , the probability decreases drastically indicating that, upon the given density, nurseries are less likely to contribute to EAB spread. Its seems that nurseries, as well as a number of other variables, have a saturation point as any value greater than that point does not increase risk. 

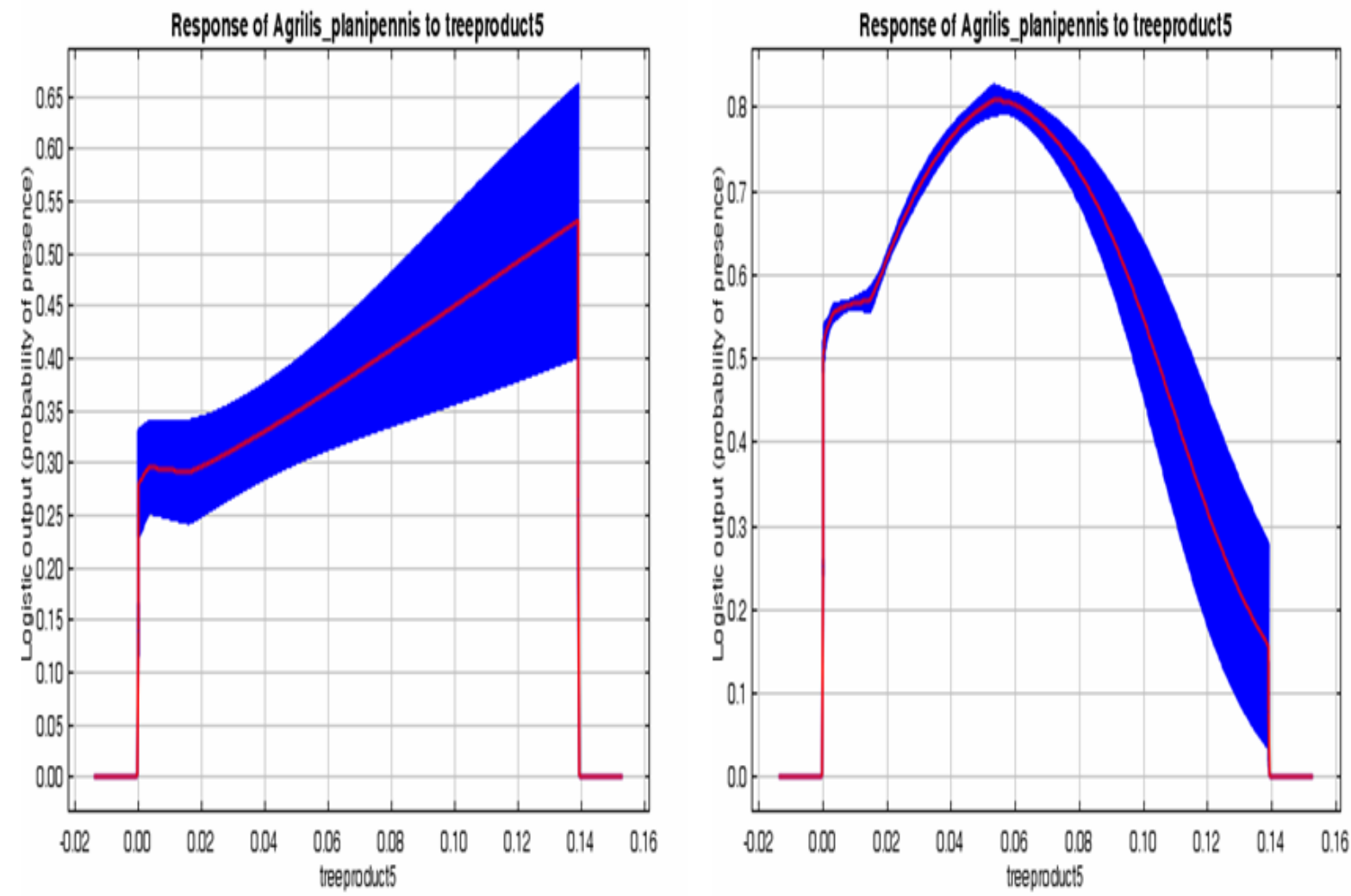

Figure 29. Response curves for tree production (nurseries) density within a five mile radius for the Maxent EAB model. The left curve represents the marginal response curve and the corresponding variable curve located on the right. The $x$-axis represents the density of tree production. The $y$-axis is probability of presence.

Wood transport was the main variable in terms of percent contribution for the Maxent model. Conversely, the response curves do not indicate a high probability when this variable was included (Fig. 30). Low variances strengthen the variable because of minimal deviation from multiple simulations. Wood transport remains a strong indicator of EAB spread because the small amount of variance. 

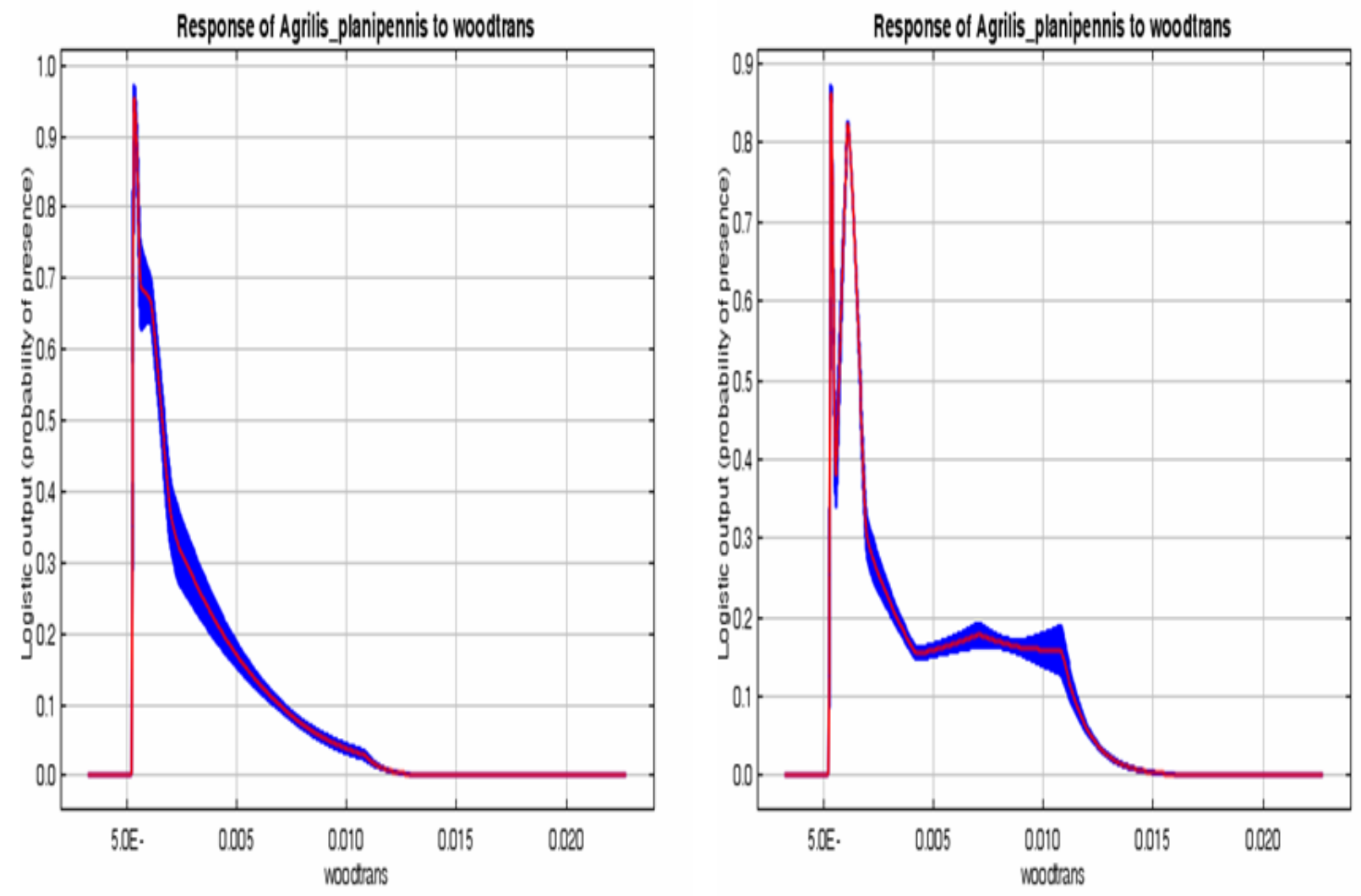

Figure 30. Response curves for the wood transportation (i.e. sawmills, logging, and firewood) density with a search radius of 50 miles for the Maxent EAB model. The left curve represents the marginal response curve and the corresponding variable curve located on the right. The $x$-axis represents the density of available businesses that transport wood. The $y$-axis is probability of presence.

The response curves for homes that reported using firewood as their main source of heat throughout the winter show a possible correlation to EAB risk. When included with other variables, the response curve peaks at $30 \%$ probability of presence (Fig. 31). That value is much higher when this was the only variable used proving that EAB has an increased risk in areas with greater amounts of firewood usage. Relatively low variances for both curves indicate that the variable was represented consistently throughout the models making it a good indicator of EAB risk. 

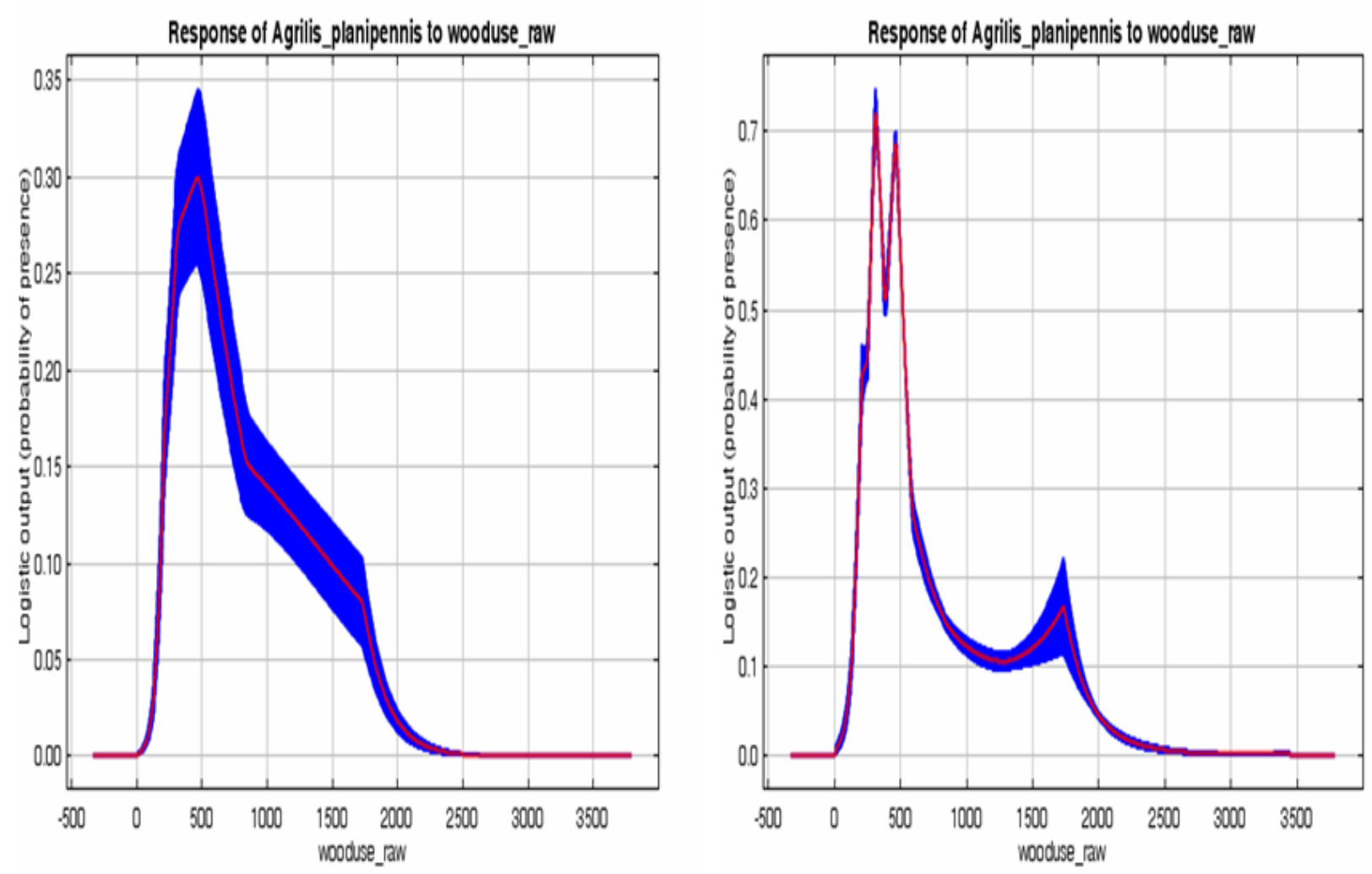

Figure 31. Response curves for the homes that use firewood by county for the Maxent EAB model. The left curve represents the marginal response curve and the corresponding variable curve located on the right. The $x$-axis represents the total homes per county. The $y$-axis is probability of presence.

\section{Jackknife Analysis of Environmental Variables}

While the percent contribution and response curves are useful for variable analysis, they have some inherent flaws. Another method to examine variables was to use a jackknife procedure. Maxent creates a model where each variable is excluded one at a time and then used to create a model using the rest of the variables. It then generates a model using each variable as a single model. As a result, each variable was analyzed with all variables and then again by itself. This process was the same as the response curves. Maxent creates three different jackknifes: regularized training gain, test gain, and AUC gain. Each jackknife has its own meaning and provides insight into how the model was generated using the variables. 
The first jackknife plot represents the regularized training gain. This jackknife was used for analysis because it utilizes the whole model. From the plot, the environmental variable with the highest gain was "woodtrans" (dark blue line). This indicates that "woodtrans" appears to contain the most useful information when it was the only variable used in the model (Fig. 32). Generally speaking, the dark blue lines that provide the highest gain provide the most information when they are used in isolation. From this model, "wooduse_raw," "dist2harbor," and "seasonal" all contain other useful information. Conversely, humanpop and road_rest provide almost no gain to the model indicating that they provide no useful information when used as the only variable.

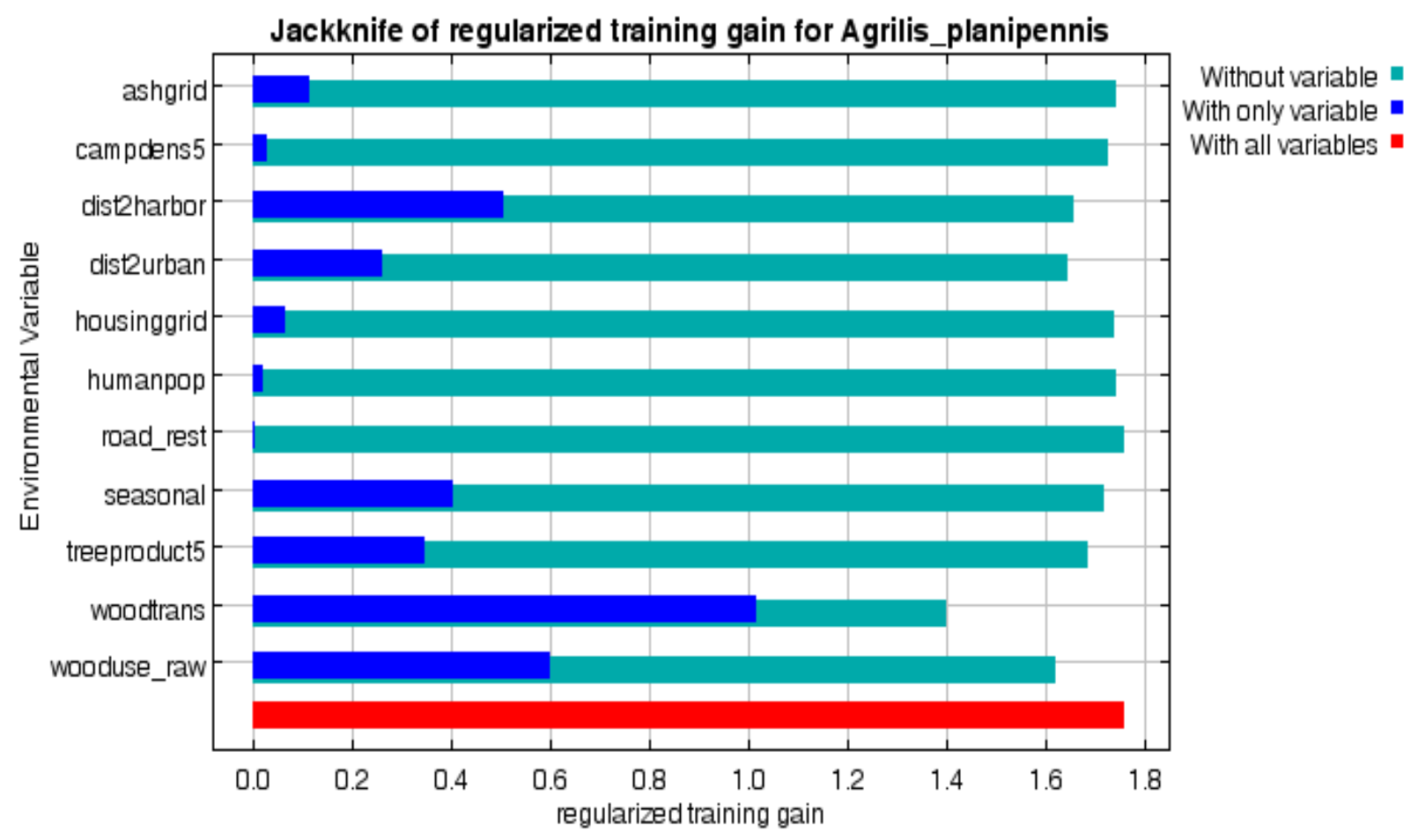

Figure 32. Results of jackknife evaluations of relative importance of environmental variables for EAB Maxent model using training data. For non abbreviated variables reference Table 2.

The light blue lines characterize the overall gain of the model when a particular variable was excluded. In this case, "woodtrans" decreases the model gain the most, therefore, it seems 
to have the most information that was not contained in the other variables. Analysis of the plot also reveals that "wooduse_raw," "dist2urban," and "dist2harbor" are parameters that decrease the overall gain. Therefore, these variables could be considered as the most important ones to include in the model because they have the greatest effect.

The next jackknife analyzes the test data that was set aside for the statistical analysis. The gain from this jackknife test will be different because the training data was not included. Conclusions drawn from this plot will be different and the most important values can change (Fig. 33). Although this plot can differ from the training data, it shows little disparity in terms of variable importance.

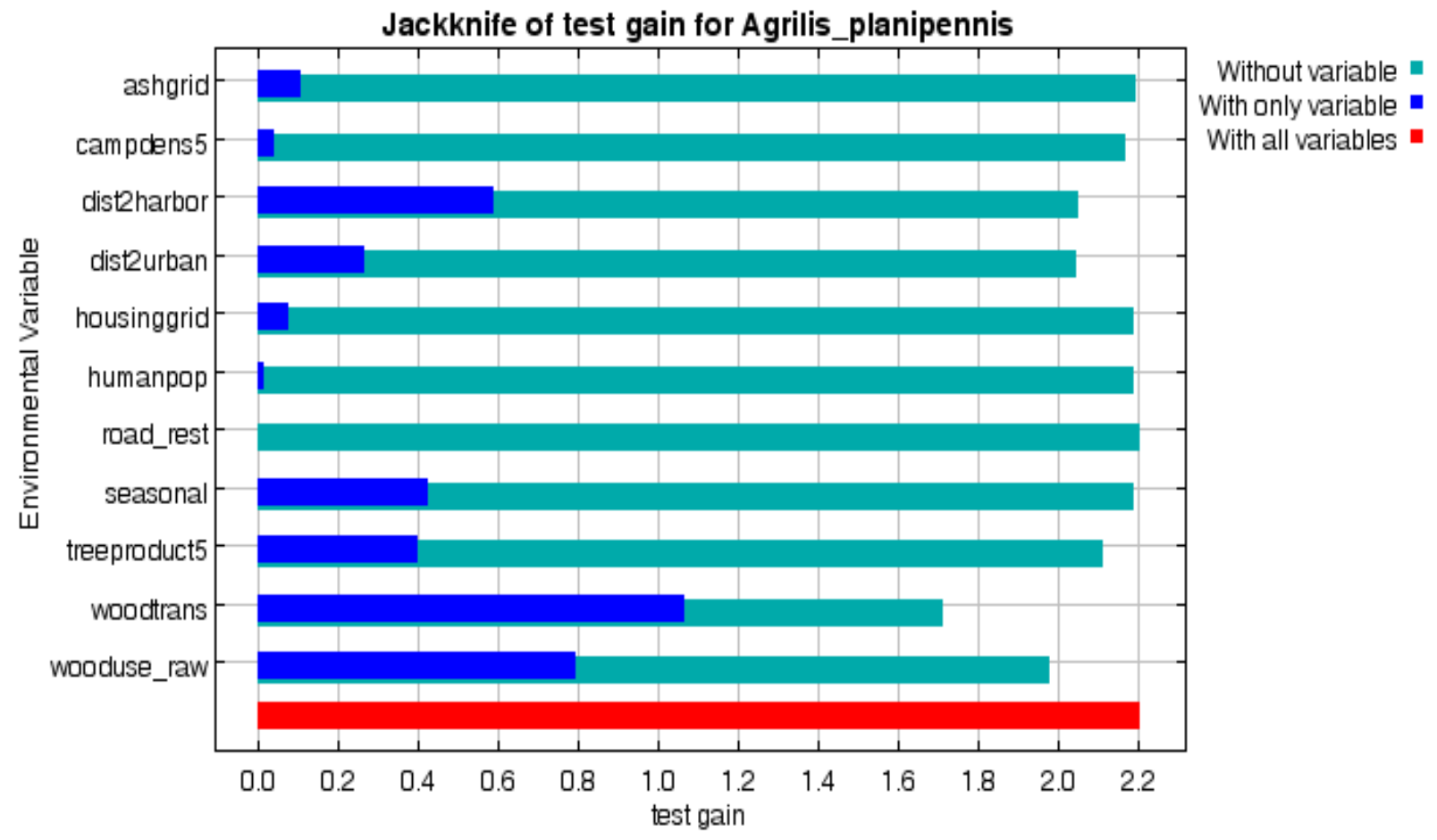

Figure 33. Results of jackknife evaluations of relative importance of environmental variables for EAB Maxent model using test data. For non abbreviated variables reference Table 2.

The last plot (Fig. 34) represent the jackknife used to created the AUC plot. It is essential to note that the red line only increases to the amount of the AUC previously mentioned in Fig. 18 
as opposed to the training and test gains in the other two jackknife plots. Here we see that the variables have changed drastically in appearance when they are represented as the only variable in the model.

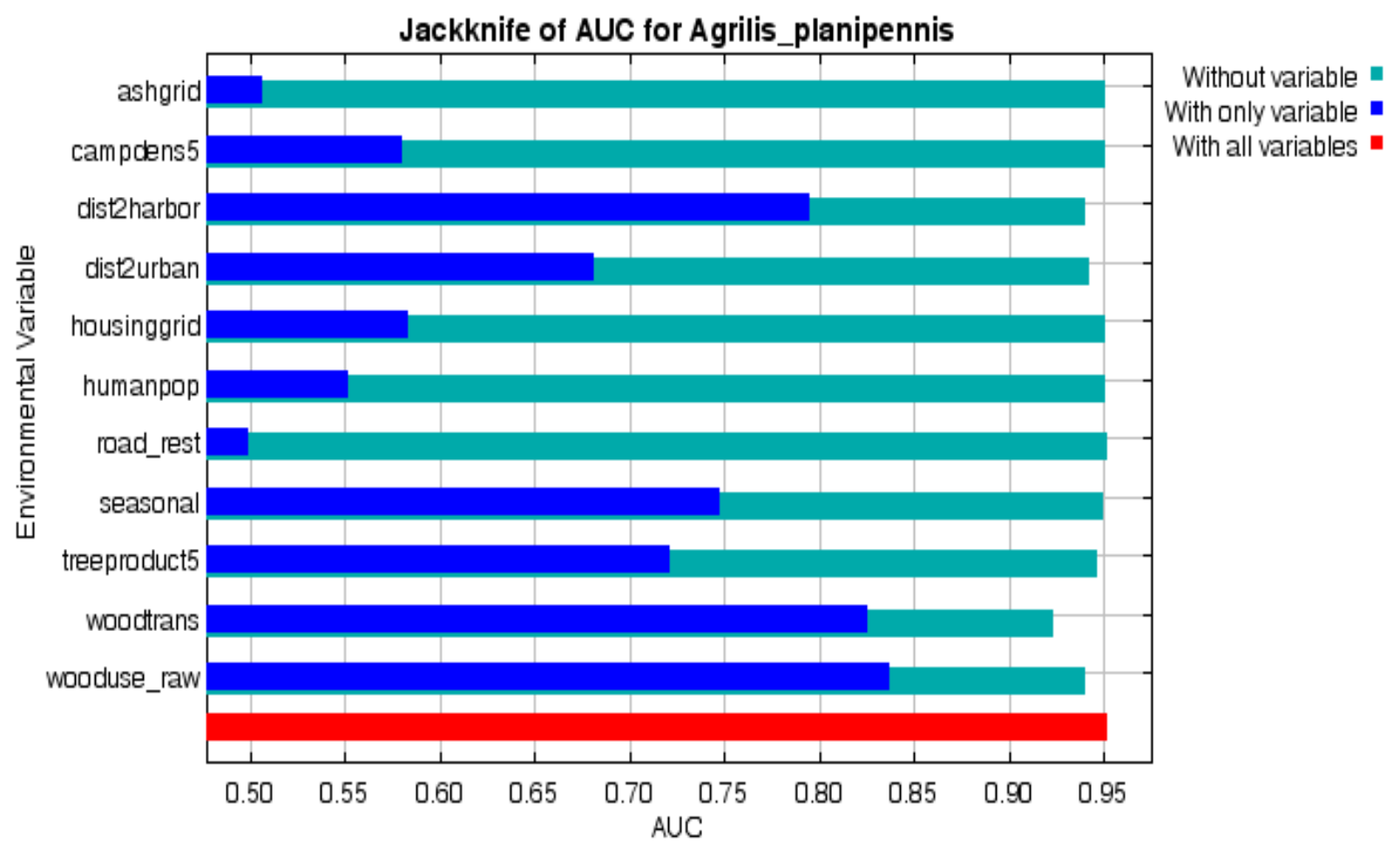

Figure 34. Results of jackknife evaluations of relative importance of environmental variables for EAB Maxent model using AUC data. For non abbreviated variables reference Table 2.

Comparing these jackknifes can offer very useful information. For instance, total homes with firewood usage (wooduse_raw) were only used marginally when data was set aside for testing. However, it was the single most effective environmental layer when predictive power of the model was measured. The same could be said for seasonal homes (seasonal) and nurseries (treeproduct5). In doing so, this allows these particular variables to be more transferable in the estimate of other models, which can be a good thing. Sometimes very detailed variables can actually hinder the overall model because they are more focused rather than generalized (Phillips et al. 2006). 


\section{Chapter 6: Discussion and Conclusions}

\section{Management Implications}

The Mid-Atlantic region of the United States was assessed for the risk of EAB spread through anthropogenic criteria using maximum entropy. While the majority of the study area (69\%) yielded less than a 10\% chance of presence, thousands of square kilometers were still at very high risk. Of the areas yet to be infested by EAB, northern New Jersey, northeastern Pennsylvania, parts of the Ohio River Valley and central Maryland appear to be the most susceptible to risk. All locations have sizable areas with a probability of $50 \%$ or greater. These areas were found to have the best likelihood of infestation based on the environmental factors from the current EAB colonies.

\section{Contiguous High Risk Areas}

High risk areas were defined as locations with a probability of presence $50 \%$ or greater. These areas were selected because they incur the most interaction associated with anthropogenic induced spreading. The Maxent model produced some noticeable large contiguous areas throughout the Mid-Atlantic, most of which occurred in Ohio. These locations were helpful but do not accomplish some of the goals for this study. This study wanted to find new locations where EAB was most likely to spread or have a high risk of spreading. Based on the results, the model can be used to identify areas of interest.

Determining a size threshold feasible enough for management can be somewhat complicated. Although it was useful to identify every high risk location, it was not economically feasible to manage all areas. The model identifies both forested and urban setting in which risk was high, but management practices would differ greatly between the two. Forested settings 
provide the challenge of accessibility when implementing management procedures. Since individual tree applications were not achievable, treatments for ash trees in this environment would be difficult. Aerial pesticide application could be a possibility, but the high overhead costs of the application could quite possibly hinder this solution. Consequently, ash species generally do not dominate in a forested landscape, so aerial application would possibly be a wasted attempt because the treatment would not just target the ash trees. Planned timber harvests would also be a challenge because ash was not a major timber species for most loggers and sawmills. The daunting task of finding a company to harvest in these setting would be rare with the cost of road construction, finding a buyer, and low volumes of harvestable timber. In these conditions, the logger would most likely have to spend more money than they would make, which would be a reason to not be involved in the transaction. Forested settings would have to include large contiguous high risk areas (possibly greater than 5,000-10,000 acres) before active management would even be considered due to inferring costs.

Urban settings seem to offer better solutions than forested settings, mainly because of accessibility. Individual herbicide treatments for each tree could be more economically feasible assuming there were enough workers to apply treatments. In general, more high risk areas tend to be located within urban boundaries, which increase the need to be more proactive in these areas. Costs of herbicides and labor hours could be high, but they provide a more feasible option than trying to manage large forested areas. Other preventive measures such as public awareness and education would be more effective in urbanized areas because they would reach a larger audience than in rural areas.

\section{Ash Basal Area versus High Risk Areas}


Ash species are the only suitable host for EAB and without them EAB has virtually no chance to survive and establish colonies. Reviewing the ash response curve and basal area grid, a couple of conclusions can be reached: 1) high amounts of ash basal area does not necessarily indicate that EAB risk will be high, and 2) low amounts of ash basal area cannot be assumed to be low risk. Numerous locations with high basal area were predicted to have low risk to EAB. For example, ash basal area was present in large quantities throughout the mountainous regions of eastern West Virginia and the plateaus of north central Pennsylvania, but reported having risk below $10 \%$. This was due to the absence of many other environmental criteria. Conversely, ash basal area throughout western Ohio was very low in comparison, but currently has the highest risk areas as well as widespread infestations. The difference here was the presence of almost (if not all) human risk criteria. The lack of ash basal could be from sampling methods as the basal area grid does not sample in urbanized areas. Localized sampling and inventories from urban areas would have to be used to receive a more accurate depiction of basal area. Since the representation of the basal area grid was misleading, this could be one of the reasons Maxent did not use the ash grid as a major contributor to the predictive model. However, locations with high ash basal area volumes should still be considered important because any EAB infestation could be disastrous.

\section{Selection of Management Areas}

Pinpointing management areas can be subjective since management boundaries are difficult to delineate. County level summaries are a good starting point because they provide focal points for management on a reasonable scale. Although county boundaries cannot

realistically enforce policy and containment, they do enable land managers a proactive option of EAB management by preparing herbicide treatments and ash tree removal, if necessary. The 
counties listed in Table 4 note the most highly probable locations for EAB spread without a current known EAB established colony in the immediate vicinity. These counties listed in this table were considered at utmost importance. Counties that have reported infestations were not included in this list as preventing infestations were not possible. It should be noted that the current $\mathrm{EAB}$ infestations were based on a collaboration of data from each state as of December 2009; therefore, these counties were identified using that data. Of the counties listed in Table 4, all counties except Ashtabula (Ohio) and Wayne (Pennsylvania) contain urban areas. Extra precautions should be given to these counties because the risks associated with human spread were higher. For management purposes, these counties should be the focal point of treatments and public awareness.

Table 4. Counties by state that contain at least $26 \mathrm{~km}^{2}$ ( $\sim 500$ acres) of high risk area ( $>50 \%$ probability of presence).

\begin{tabular}{ll} 
State & Counties \\
\hline Maryland & Howard, Montgomery, Washington, Wicomico \\
New Jersey & Morris, Passaic \\
Ohio & Ashtabula, Brown, Lawrence, Washington \\
Pennsylvania & Lackawanna, Wayne \\
West Virginia & Berkeley, Cabell \\
\hline
\end{tabular}

The following table provides a list of counties that potentially could be affected by EAB based on their proximity and adjacency to higher risk counties (Table 5). In terms of management, these counties should be monitored for EAB, but not actively managed. Again, the counties in this table do not currently have any known EAB infestations, but do have considerable contiguous areas with probabilities upwards of $50 \%$. 
Table 5. Potential counties to be at risk for EAB. These counties have tens of thousands of acres with probabilities ranging from $25-50 \%$.

\begin{tabular}{ll} 
State & Counties \\
Delaware & Kent \\
New Jersey & Anne Arundel, Charles \\
Ohio & $\begin{array}{l}\text { Atlantic, Bergen, Cumberland, Monmouth, } \\
\text { Ocean }\end{array}$ \\
Pennsylvania & Clinton, Crawford, Darke \\
West Virginia & Blair, Cumberland, Lebanon, Luzerne \\
\hline
\end{tabular}

Spatially, these counties are distributed throughout the entire study area (Fig. 35), which corresponds to Tables 4 and 5. Counties that are not displayed on the map currently have EAB infestations or are currently not highly susceptible to EAB infestation at this time.

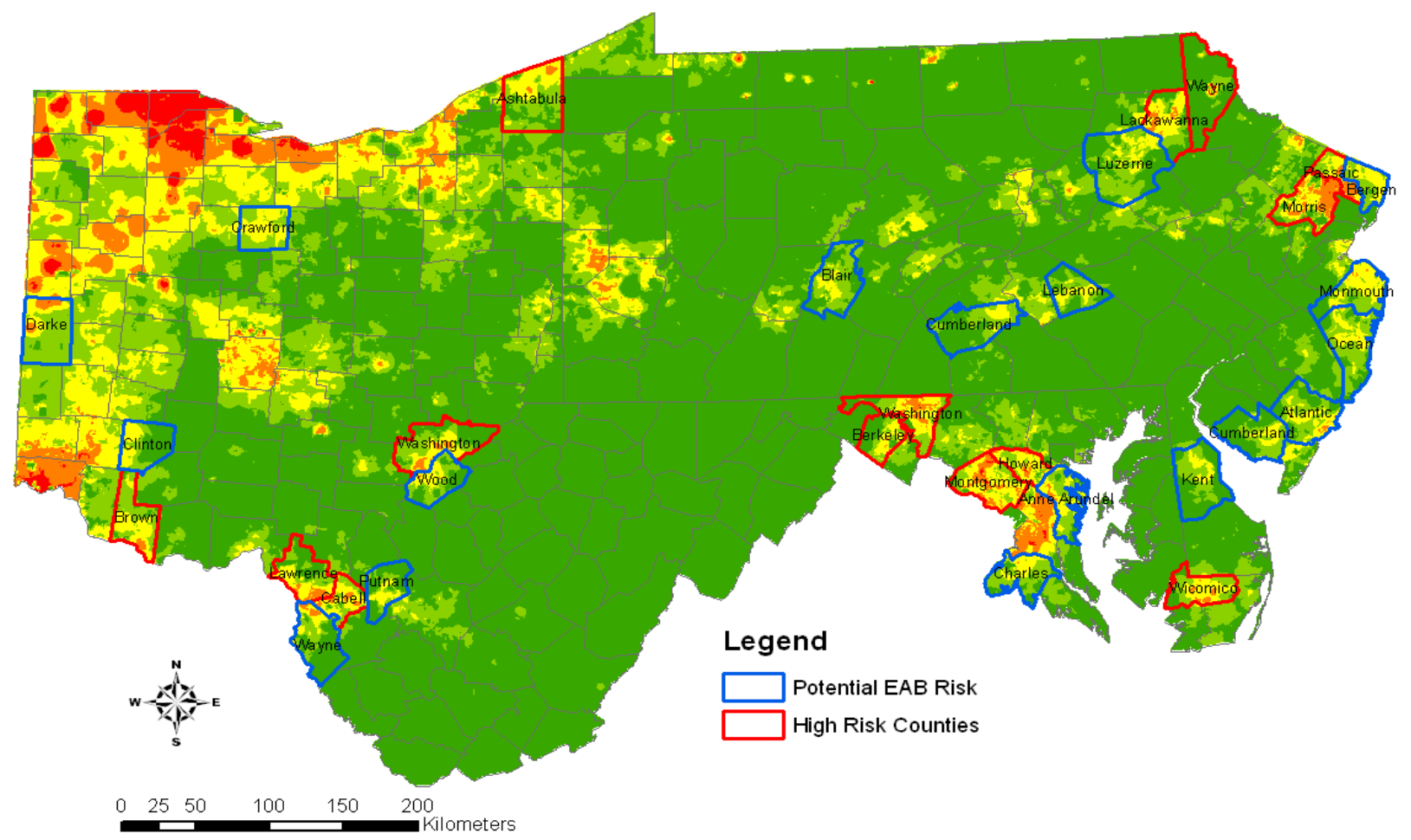

Figure 35. Spatial distribution of counties that have high risk or that could potentially be affected by EAB. 


\section{Presence versus Establishment}

The Maxent model revolves around the basis of potentially finding EAB based on probability. The model does not, however, predict the probability of establishment. This model was constructed on the premise of finding EAB at a given point, which could possibly lead to EAB establishment. Identifying just a few EAB individuals at one location does not insinuate establishment, but it does indicate presence. In order to find establishment probabilities, EAB density would have to be examined for each of the infestation points, and then, be included in the Maxent model. For colony establishment, hundreds, if not thousands, of EAB would have to be present with enough available ash resource to support the population.

\section{Management Options}

When assessing the risk map for management options, the key factors of risk probability and amount of ash are extremely important. For each county in the study area, the average probability of risk and the average amount of basal area within that county was tabulated. Instead of using raw averages, the values were normalized and then plotted as a scatter plot (Fig. 36). Different areas of the scatter plot will have conceptually different management strategies. For instance, counties with high probability of risk but have low amounts of ash could be considered quarantine areas. Conversely, areas with high amounts of ash but low probability of risk could plan harvests to avoid wasted materials. Ultimately, counties with low risk and ash could be counties with public outreach and occasional monitoring.

To understand up-to-date county quarantines, Fig. 36 has also indicated where each of these quarantines would lay on the scatter plot. Interesting enough, most quarantines are within the public outreach and monitoring sector. This is somewhat misleading because most of these counties are located in Ohio, where the main EAB infestations are in full force. 


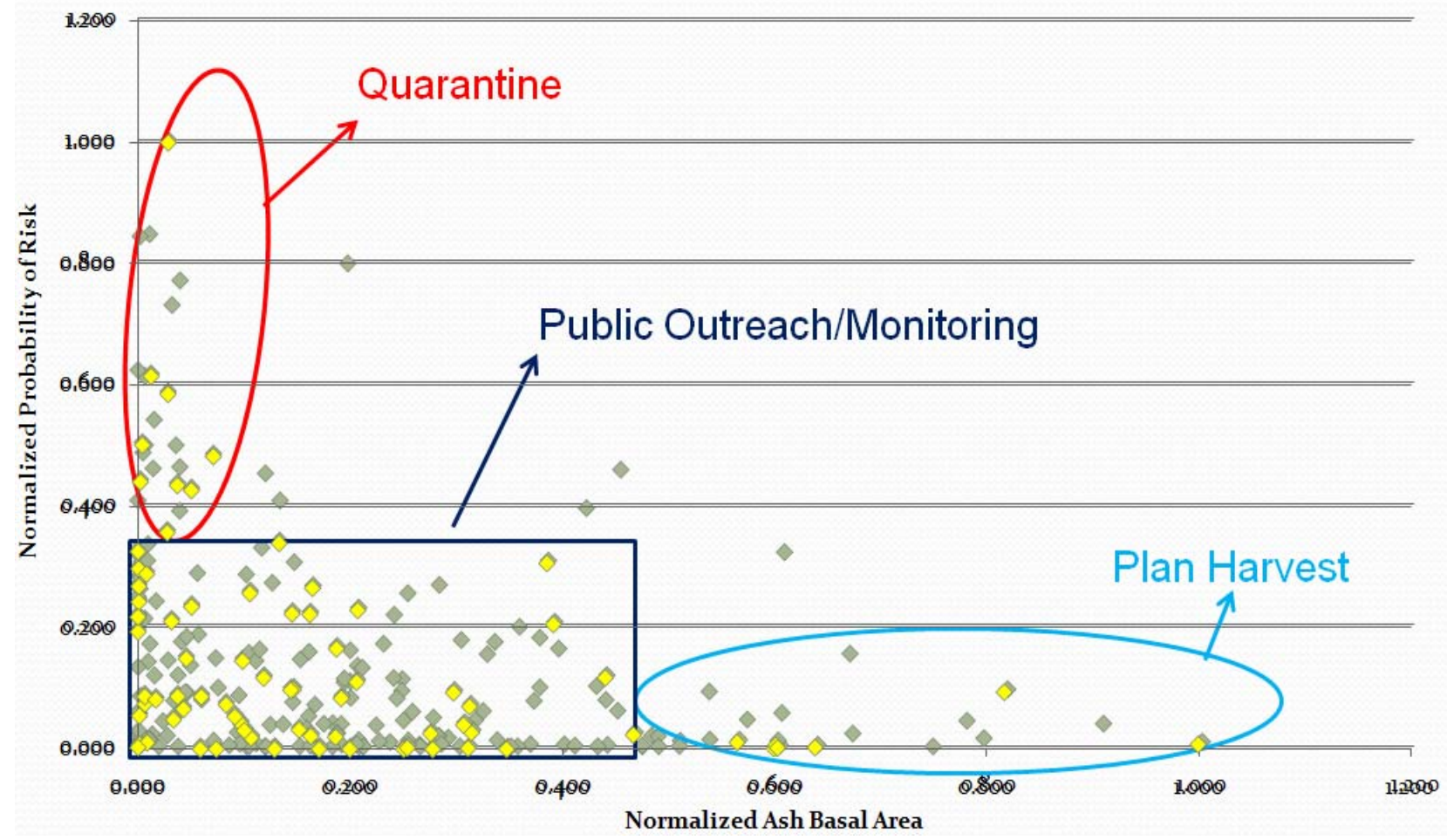

Figure 36. Scatter plot of management options for the EAB study area. The green marks indicate all counties within the study area while the yellow dots indicate the counties that are currently quarantined.

\section{Recommendations}

The following management recommendations should be implemented to save ash trees and prevent further EAB damages:

1) Areas with $50 \%$ or greater probability should take extreme caution by pre-treating ash trees or begin preparations for ash harvests, if feasible, to avoid wasted material.

Extensively surveying for and surrounding areas for EAB should also be highly considered.

2) Areas with $25-50 \%$ probability should be cautious of possible EAB infestations.

Surveying and monitoring should be completed but not to the extent of the higher probability areas. 
3) Areas with less than $25 \%$ probability should still be aware of EAB by informing landowners and land managers about the EAB risks. No pre-treatment or further surveying necessary.

4) Sawmills and nurseries that utilize ash should be monitored regularly.

5) Public awareness methods should be tailored to areas with over $50 \%$ probability by utilizing newspaper adds, billboards, or television as well as public outreach notices and education.

6) Avoid managing counties not listed in Tables 4 and 5 because they have little risk or poor accessibility. Forested landscapes are normally in remote areas making them somewhat immune to $\mathrm{EAB}$ infestations.

7) Concentrated efforts should be focused on the counties that contain urbanized areas from Tables 4 and 5.

\section{Limitations and Assumptions}

\section{Management Limitations}

While management attempts to contain and slow the spread of EAB, it must be understood that completely stopping the spread is simply not possible. EAB has many means of being moved by the general public. Too many in which can be controlled. Management tries to contain EAB but has limited options. Public awareness and education only works to a certain extent and treatments can only be applied to accessible locations. Harvesting ash timber is fundamentally a good idea, but comes with large costs and potentially low interest from loggers. 


\section{Data Limitations}

Data limitations are a natural part of research because they exist in almost all types of studies. Not all data is perfect, in fact, most data have inherent flaws that must be discovered by the user before the data can be used accurately. Therefore, data-mining is necessary to uncover relationships and explore data.

Finding the appropriate amount of basal area without rigorous sampling is difficult to obtain. Because the study area was large in size, inventories could not be done for this study. Instead, Forest Inventory and Analysis (FIA) data had to be used as an alternative which is the best representation of basal area to date. This is the accepted method when using basal area data in research studies when individual inventories cannot be completed. Unfortunately, FIA sampling methods are somewhat limited and their accuracy for local applications is questionable. Under the current sampling design, one FIA plot is established every 6,000 acres and measured every three years. In addition, only forested landscapes are used in the design grid. Plots are not placed in urban areas under the current established sampling criteria. With these regulations, parts of the EAB study area are not sampled by FIA data. This will not accurately depict ash populations in those areas.

Collecting data for every campground, nursery, sawmill, and firewood dealer is virtually impossible to accomplish. Representing the total number of these businesses was at utmost importance for this study because they symbolize the most common human transportation vectors. Assumptions were also made for these datasets due to time constraints. For sawmills, ash was automatically assumed to be one of the timber species that was used. Transportation of ash was understood to be less than 50 miles from each sawmill location because of travel costs. Campgrounds were assumed to be actual field locations or campsites and not a main office or 
headquarters location. It was also assumed that firewood was used at each camp location. Each nursery was assumed that ash was grown and sold. Distribution from the nurseries was also an assumption because of unknown shipment routes.

Harbors are used in this analysis as risk factors that could be brought into the U.S. from foreign sources. Since EAB was noted to be brought to this country in wood crating and pallets, this human vector was important. Harbors are much more likely to transport cargo by wood crating so there existence in the datasets was justified.

New housing development was a new variable of EAB modeling introduced in this project. Actual representation of this variable is unknown and use is questionable. New developments are assumed to have ash being planted in the landscaped areas for aesthetic reasons. However, ash is not always planted as a shade tree. Also, for the housing density data, housing units were by building but can include multiple units such as apartments.

\section{Future Research}

This study to find the probability of presence and the risk of EAB was conducted on a broad scale. Many factors associated with the business features such as sawmill size, amount of ash consumed, and number of campground visitors could not be directly obtained because they were so abundant. This extra detailed information could go a long way in assessing risk for EAB. By decreasing the actual study area, information can be more accurately gathered on a local scale. Sawmills could be weighted by their size or the amount of ash used as well as identifying if they are being regulated. Inventories of ash could be conducted to predict and provide their current abundance and distribution instead of relying on sparse FIA data. Campground size could be weighted for risk by how many visitors they serve per year or by the number of campsites. Examining the zip code of travelers to campsites could also be a 
possibility to find how far they travel and where they are traveling from. For individual cities wishing to assess risk, distribution of ash could be studied throughout the city to provide areas where $\mathrm{EAB}$ could potential have an effect.

In future analysis and model updates, the values within each variable will change. With more research, how the variables were used in this project will also change. By using sensitivity analysis, determining each variables contribution in the model and how it reacts when manipulating the other variables is an important future step. Currently, the values in this model are fixed in time, but in the future these variables will change. For instance, adjusting the search radius on the density grids could become more vital in analysis than it currently is today. Variables with major contributions now may be hardly used at all in the future. However, if variables remain at a static contribution regardless of time, then the selection of those variables would seem most justified because no matter what else changes, those criteria will always have a major impact on EAB spread. 


\section{Literature Cited}

Anulewicz, A.C., D.G. McCullough, D.A Cappaert, T.M. Poland, D.L. Miller. 2007. Host range of the emerald ash borer (Agrilus planipennis) (Coleoptera: Burprestidae): choice and no-choice tests In: Gottschalk, Kurt W., ed. Proceedings, 17th U.S. Department of Agriculture interagency research forum on gypsy moth and other invasive species 2006; Gen. Tech. Rep. NRS-P-10. Newtown Square, PA: U.S. Department of Agriculture, Forest Service, Northern Research Station: 16.

Barnd, B.D., P.M. Pijut, M.D. Ginzel. 2008. Insects affecting hardwood tree plantings. In: Pijut, P.M., ed. Planting and care of fine hardwood seedlings. FNR-227-W. West Lafayette, IN: U.S. Department of Agriculture, Forest Service, Northern Research Station, Hardwood Tree Improvement and Regeneration Center, and Purdue University, Extension. 17p.

Bauer, L.S., R.A. Haack, D.L. Miller., T.R. Petrice, H. Liu. 2003a. Emerald ash borer life cycle. In: Mastro, Victor; Reardon, Richard, comps. Emerald ash borer research and technology development meeting; 2003 September 30 - October 1; Port Huron, MI. FHTET 2004-03. Morgantown, WV: U.S. Forest Service, Forest Health Technology Enterprise Team: 8.

Bauer, L.S., D.L. Miller, R.A.J. Taylor, R.A. Haack. 2003b. Flight potential of the emerald ash borer In: Mastro, Victor; Reardon, Richard, comps. Emerald ash borer research and technology development meeting; 2003 September 30 - October 1; Port Huron, MI. FHTET 2004-03. Morgantown, WV: U.S. Forest Service, Forest Health Technology Enterprise Team: 9.

BenDor, T., S. Metcalf, L. Fontenot, B. Sangunett, B. Hannon. 2006. Modeling the spread of the emerald ash borer. Ecological Modelling. 197: 221-236.

Burns, R.M., B.H. Honkala. 1990. Silvics of North America: 1. Conifers; 2. Hardwoods. Agriculture Handbook 654. U.S. Department of Agriculture, Forest Service, Washington, DC. 2: 877.

Cappaert, D., D.G. McCullough, T.M. Poland, N.W. Siegert. 2005. Emerald ash borer in North America: A research and regulatory challenge. American Entomologist. 51: 152-163.

Carreiro, M.M., W.C. Zipperer. 2008. Urban forestry and the eco-city: today and tomorrow. In: Ecology, Planning, and Management of Urban Forests: 435-456.

Carter, G.A. 1994. Ratios of leaf reflectances in narrow wavebands as indicators of plant stress. International Journal of Remote Sensing. 15: 697-703.

Cook, S., S. Cherry, K. Humes, J. Guldin, C. Williams. 2007. Development of a satellite-based hazard rating system for Dendrctonus frontallis (Coleoptera: Scolytidae) in the Ouachita Mountains of Arkansas. Journal of Economic Entomology. 100(2): 381-388. 
Crowl, T.A., T.O Crist, R.R. Parmenter, G. Belovsky, A.E. Lugo. 2008. The spread of invasive species and infectious disease as drivers of ecosystem change. Front Ecology Environment. 6(5): 238-246.

Elith, J., C.H. Graham, R.P. Anderson, M. Dudı'k, S. Ferrier, A. Guisan, R.J. Hijmans, F. Huettmann, J.R. Leathwick, A. Lehmann, J. Li, L.G. Lohmann, B.A. Loiselle, G. Manion, C. Moritz, M. Nakamura, Y. Nakazawa, J.M. Overton, A.T. Peterson, S.J. Phillips, K.S. Richardson, R. Scachetti-Pereira, R.E. Schapire, J. Sobero'n, S. Williams, M.S. Wisz, N.E. Zimmermann. 2006. Novel methods improve prediction of species' distributions from occurrence data. Ecography. 29: 129-151.

Environmental Systems Research Institute (ESRI). 2003. ArcGIS ArcMap Version 9.2. Redlands, CA.

Fitzpatrick, M.C., A.D. Gove, N.J. Sanders, R.R. Dunn. 2008. Climate change, plant migration, and range collapse in a global biodiversity hotspot: The Banksia (Proteaceae) of Western Australia. Global Change Biology. 14(6): 1337-1352.

Flint, H.L. 1985. Plants showing tolerance of urban stress. Journal of Environmental Horticulture. 3: 85-89.

Frieswyk, T.S., D.M. DiGiovanni. 1988. Forest statistics for Maryland--1976 and 1986. Resour. Bull. NE-107. Broomall, PA: U.S. Department of Agriculture, Forest Service, Northeastern Forest Experiment Station. 157p.

Gibbs, J.N. 1978. Intercontinental epidemiology of Dutch elm disease. Annual Review of Phytopathology. 16: 287-307.

Gitelson, A.A., M.N. Merzlyak. 1996. Signature analysis of leaf reflectance spectra: algorithm development of remote sensing of chlorophyll. Journal of Plant Physiology. 148: 494-500.

Goebel, C., M. Bumgardner, D. Herms. 2008. Phytosanition of emerald ash borer infested firewood. Ohio Agricultural Research and Development Center. September 2008.

Goodchild, M.F. 1993. The state of GIS for environmental problem-solving. In: Environmental Modelling with GIS. In: Goodchild MF, Parks BO, Steyaert LT, Eds. New York: Oxford University Press, 8-15.

Griffin, G.J. 2000. Blight control and restoration of the American chestnut. Journal of Forestry. 98: 22-27.

Griffith, D.M., D.M. DiGiovanni, T.L. Witzel, E.H. Wharton. 1993. Forest statistics for Ohio, 1991. Resour. Bull. NE-128. Radnor, PA: U.S. Department of Agriculture, Forest Service, Northeastern Forest Experiment Station. 169p. 
Griffith, D.M., R.H. Widmann. 2003. Forest statistics for West Virginia: 1989 and 2000. Resour. Bull. NE-157. Newtown Square, PA: U.S. Department of Agriculture, Forest Service, Northeastern Research Station. 119p.

Gustafson, E., J. Nestler, L. Gross, K.M. Reynolds, D. Yaussy, T.P. Maxwell, V.H. Dale. 2002. Evolving approaches and technologies to enhance the role of ecological modeling in decision making. In: Dale, Virginia H., ed. Ecological Modeling for Resource Management. New York, NY: Springer-Verlag: Chapter 8: 135-164.

Hao, C., C. Lijun, T. Albright. 2007. Predicting the potential distribution of invasive exotic species using GIS and information-theoretic approaches: A case of ragweed (Ambrosia artemisiifolia L.) distribution in China. Chinese Science Bulletin. May 2007. 52(9): 1223-1230.

Haack, R.A., E. Jendek, H. Liu, K.R. Marchant, T.R. Petrice, T.M. Poland, H. YE. 2002. The emerald ash borer: A new exotic pest in North America. Newsletter Michigan Entomology Society. 47(3,4): 1-5. Michigan Entomological Society, East Lansing, MI. 24p.

Hammer, R.B., S.I. Stewart, R. Winkler, V.C. Radeloff, P.R. Voss. 2004. Characterizing spatial and temporal residential density patterns across the U.S. Midwest, 1940-1990. Landscape and Urban Planning. 69: 183-199.

Heimlich, J., T.D. Sydnor, M. Bumgardner, P. O'Brien. 2008. Attitudes of residents toward street trees on four streets in Toledo, Ohio, U.S. before removal of ash trees (Fraxinus spp.) from emerald ash borer (Agrilus planipennis). Aboriculture \& Urban Forestry. 34(1): 47-53.

Herlihy, A.T., J.L. Stoddard, C.B. Johnson. 1998. The relationship between stream chemistry and watershed land cover data in the Mid-Atlantic region. U.S. Water, Air, \& Soil. 105: 377-386

Herms, D.A., D.G. McCullough, D.R. Smitley, C. Sadof, R.C. Williamson, P.L. Nixon. 2009. Insecticide options for protecting ash trees from emerald ash borer. North Central IPM Center Bulletin 12p.

Heyd, R. 2005. Ash (Fraxinus sp.) management guidelines. Emerald ash borer response strategy. Draft report, Michigan Department of Natural Resources, March 2005. Michigan Department of Natural Resources, Lansing, MI. 24p.

Holcombe, T., T. Stohlgren, C. Jarnevich. 2007. Invasive species management and research using GIS. USDA National Wildlife Research Center Symposium. Website:

http://digitalcommons.unl.edu/cgi/viewcontent.cgi article $=1017 \&$ context $=$ nwrcinvasive

Hunter, R.D., R.K. Meentemeyer, D.M. Rizzo, C.A. Gilligan. 2008. Predicting the spread of sudden oak death in California: spatial-temporal modeling of susceptible-infectious transitions. In: Frankel, Susan J.; Kliejunas, John T.; Palmieri, Katharine M., tech. coords. 2008. Proceedings of the sudden oak death third science symposium. Gen. Tech. Rep. PSW-GTR-214. Albany, CA: U.S. Department of Agriculture, Forest Service, Pacific Southwest Research Station. p. 277. 
Hutchinson, G.E. 1957. Concluding remarks. Cold Spring Harbor Symposium on Quantitative Biology. 22: 415-457.

Iverson, L., A. Prasad, J. Bossenbroek, D. Sydnor, E. Schwartz. 2006. Modeling potential movements of the emerald ash borer in Ohio and Michigan. Proceedings of the 2006 Society of American Foresters National Convention.

Jaynes, E.T. 1957. Information theory and statistical mechanics. Physics Review. 106: 620-630.

Keena, M.A. 2006. Effects of temperature on Anoplophora glabripennis (Coleoptera: Cerambycidae) adult survival, reproduction, and egg hatch. Environmental Entomology. 35(4): 912-921.

Koch, F.H., W.D. Smith. 2008. Spatio-Temporal analysis of Xyleborus glabratus (Coleoptera: Cicculionidae: Scolytinae) invasion in eastern U.S. forests. Environmental Entomology. 37(2): 442-452.

Krist, F.J., F.J. Sapio, B.M. Tkacz. 2006. A multi-criteria framework for producing local, regional, and national insect and disease risk maps (DRAFT).

Kumar, S., T.J. Stohlegren. 2009. Maxent modeling for predicting suitable habitat for threatened and endangered tree Canacomyrica monticola in New Caledonia. Journal of Ecology and Natural Environment. 1(4): 94-98.

Loarie, S.R., B.E. Carter, K. Hayhoe, S. McMahon, R. Moe, C.A. Knight, D.D. Ackerly. 2008. Climate change and the future of California's endemic flora. PLOS ONE 3(6): e2502.

Lui, H., L.S. Bauer, T. Zhao, R. Gao. 2008. Population biology of emerald ash borer and its natural enemies in China. In: Mastro, Victor; Lance, David; Reardon, Richard; Parra, Gregory, comps. Emerald ash borer research and development meeting; 2007 October 23-24; Pittsburgh, PA. FHTET 2008-07. Morgantown, WV: U.S. Department of Agriculture, Forest Service, Forest Health Technology Enterprise Team: 59-60.

Lui, H., L.S. Bauer. 2008. Emerald ash borer microbial control with the Entomopathogen Beauveria bassiana GHA formulated as Botanigard®. In: Mastro, Victor; Lance, David; Reardon, Richard; Parra, Gregory, comps. Emerald ash borer research and development meeting; 2007 October 23-24; Pittsburgh, PA. FHTET 2008-07. Morgantown, WV: U.S. Department of Agriculture, Forest Service, Forest Health Technology Enterprise Team: 48-49.

Maryland Department of Agriculture. 2008. Emerald ash borer in Maryland. Website: http://www.mda.state.md.us/plants-pests/eab (Last Accessed 09 March, 2009).

Mastro, V., D. Lance, R. Reardon, G. Parra. 2007. Emerald ash borer and asian longhorned beetle research and technology development meeting. Cincinnati, OH, October 29-November 2, 2006. USDA Forest Service FHTET-2007-04. 
McCullough, D.G., S.A. Katovich. 2004. Emerald ash borer. NA-PR-02-04. Newtown Square, PA: U.S. Dept. of Agriculture, Forest Service, Northeastern Area, State \& Private Forestry. 2p.

McCullough, D.G., T. Poland, D. Cappaert. 2003. Dispersal of emerald ash borer: a case study at Tipton, Michigan In: Mastro, Victor; Reardon, Richard, comps. Emerald ash borer research and technology development meeting; 2003 September 30 - October 1; Port Huron, MI. FHTET 2004-03. Morgantown, WV: U.S. Forest Service, Forest Health Technology Enterprise Team: 67.

McRoberts, R.E., R.J. Barbour, K.M. Gebert, G.C. Liknes, M.D. Nelson, D.M. Meneguzzo. 2006. Using basic geographic information systems functionality to support sustainable forest management decision making and post-decision assessments. Journal of Sustainable Forestry. 23(4): 13-34.

McWilliams, W.H., S.P. Cassell, C.L. Alerich, B.J. Butler, M.L. Hoppus, S.B. Horsley, A.J. Lister, T.W. Lister, R.S. Morin, C.H. Perry, J.A. Westfall, E.H. Wharton, C.W. Woodall. 2007. Pennsylvania's Forest 2004. Resour. Bull. NRS-20. Newtown Square, PA: U.S. Department of Agriculture, Forest Service, Northern Research Station. 86p.

Minnesota Department of Agricuture. 2006. Emerald ash borer introduction risk model for Minnesota. Plant Protection Division. December, 2006.

Mora, F., L. Iverson. 2002. A spatially constrained ecological classification: rationale, methodology and implementation. Plant Ecology. 158: 153-160.

Nowak, D.J., R.E. Hoehn, J. Wang, A. Lee, V. Krishnamurthy, G. Schwetz. 2009. Urban forest assessment in northern Delaware. Resour. Bull. NRS-40. Newtown Square, PA: U.S. Department of Agriculture, Forest Service, Northern Research Station. 50.

Nowak, D.J., R. Hoehn, J.T. Walton, D.E. Crane, J.C. Stevens, D. Twardus, A. Cumming, M. Mielke, B. Smith. 2006. Urban Forest Health Monitoring in the United States. In: AguirreBravo, C.; Pellicane, Patrick J.; Burns, Denver P.; and Draggan, Sidney, Eds. 2006. Monitoring Science and Technology Symposium: Unifying Knowledge for Sustainability in the Western Hemisphere Proceedings RMRS-P-42CD. Fort Collins, CO: U.S. Department of Agriculture, Forest Service, Rocky Mountain Research Station. p. 181-187.

Nzokou, P., T.R. Petrice, R.A. Haack, D.P. Kamdem. 2006. Borate and imidacloprid treatment of ash logs infested with emerald ash borer. Forest Products Journal. 56(5): 78-81.

Ohio Department of Agriculture. 2009. Emerald ash borer. Website: http://www.agri.ohio.gov/eab (Last Accessed 10 March, 2009).

Omernik, J.M., R.G. Bailey. 1997. Distinguishing between watersheds and ecoregions. Journal of the American Water Resources Association. 33(5): 935-949.

Park, Y.L. Personal Interview. April 2009. West Virginia University. 
Pearson, R.G. 2007. Species' Distribution Modeling for Conservation Educators and Practitioners. Synthesis. American Museum of Natural History. Available at http://ncep.amnh.org

Pennsylvania DCNR. 2008. Emerald Ash Borer. Website: http://www.dcnr.state.pa.us/forestry/fpm invasives EAB.aspx (Last Access 10 March, 2009).

Perry, C.H., V.A. Everson, I.K. Brown, J. Cummings-Carlson, S.E. Dahir, E.A. Jepsen, J. Kovach, M.D. Labissoniere, T.R. Mace, E.A. Padley, R.B. Rideout, B.J. Butler, S.J. Crocker, G.C. Liknes, R.S. Morin, M.D. Nelson, B.T. Wilson, C.W. Woodall. 2008. Wisconsin's forests, 2004. Resour. Bull. NRS-23. Newtown Square, PA: U.S. Department of Agriculture, Forest Service, Northern Research Station. 104p.

Peterson, A.T., M. Papes, M. Eaton. 2007. Transferability and model evaluation in ecological niche modeling: a comparison of GARP and Maxent. Ecography. 30: 550-560.

Phillips, S.J., R.P. Anderson, R.E. Schapire. 2006. Maximum entropy modeling of species geographic distributions. Ecological Modelling. 190: 231-259.

Phillips, S.J., M. Dudik. 2008. Modeling of species distribution with Maxent: new extensions and a comprehensive evaluation. Ecography. 31: 161-175.

Poland, T.M., D.G. McCullough. 2006. Emerald ash borer: invasion of the urban forest and the threat to North America's ash resource. Journal of Forestry: April-May, 2006: 118-124.

Pontius, J., M. Martin, L. Plourde, R. Hallett. 2008. Hyperspectral remote sensing for early detection of invasive pests In: Mastro, Victor; Lance, David; Reardon, Richard; Parra, Gregory, comps. Emerald ash borer research and development meeting; 2007 October 23-24; Pittsburgh, PA. FHTET 2008-07. Morgantown, WV: U.S. Department of Agriculture, Forest Service, Forest Health Technology Enterprise Team: 66.

Rock, B.N., T. Hoshizaki, J.R. Miller. 1988. Comparison of in situ and airborne spectral measurements of the blue shift associated with forest decline. Remote Sensing of Environment. 24: $109-127$.

Schroeder, H.W., S.R. Ruffolo. 1996. Householder evaluations of street trees in a Chicago suburb. Journal of Arboriculture. 22: 35-43.

Shamilov, A., Y.M. Kantar, I. Usta. 2008. Use of MinMaxEnt distributions defined on basis of MaxEnt method in wind power study. Energy Conversion and Management. 49: 660-677.

Sharma, B.D., J. Wang, G. Miller. 2008. A GIS-based approach to stand visualization and spatial pattern analysis in a mixed hardwood forest in West Virginia. In: Jacobs, Douglass F.; Michler, Charles H., eds. 2008. Proceedings, 16th Central Hardwood Forest Conference; 2008 April 8-9; West Lafayette, IN. Gen. Tech. Rep. NRS-P-24. Newtown Square, PA: U.S. Department of Agriculture, Forest Service, Northern Research Station: 356-365. 
Siegert, N.W., D.G. McCullough, A.M. Liebhold. 2008. Dendrochronoloical reconstruction of the establishment and spread of emerald ash borer. In: Mastro, Victor; Lance, David; Reardon, Richard; Parra, Gregory, comps. Emerald ash borer research and development meeting; 2007 October 23-24; Pittsburgh, PA. FHTET 2008-07. Morgantown, WV: U.S. Department of Agriculture, Forest Service, Forest Health Technology Enterprise Team: 4-5.

Smith, A., D.A. Herms, R.P. Long. 2007. Impact of emerald ash borer on forests within the Huron River watershed of southeast Michigan. In: Gottschalk, Kurt W., ed. Proceedings, 17th U.S. Department of Agriculture interagency research forum on gypsy moth and other invasive species 2006; Gen. Tech. Rep. NRS-P-10. Newtown Square, PA: U.S. Department of Agriculture, Forest Service, Northern Research Station: 92.

Smith, J., B. Haack, L. Bauer. 2003. Genetic analysis of emerald ash borer (Agrilus planipennis, Fairmaire) to determine point of origin in North American infestations. In: Mastro, Victor; Reardon, Richard, comps. Emerald ash borer research and technology development meeting; 2003 September 30 - October 1; Port Huron, MI. FHTET 2004-03. Morgantown, WV: U.S. Forest Service, Forest Health Technology Enterprise Team: 12.

Strazanac, J.S., J.R. Gould, R.A. Haack, I. Fraser. 2008. Field host range testing of Spathius agrili, a parasitoid of emerald ash borer: evaluating nontarget impacts. In: Mastro, Victor; Lance, David; Reardon, Richard; Parra, Gregory, comps. Emerald ash borer research and development meeting; 2007 October 23-24; Pittsburgh, PA. FHTET 2008-07. Morgantown, WV: U.S. Department of Agriculture, Forest Service, Forest Health Technology Enterprise Team: 6162.

Storer, A.J., J.A. Metzger, I. Fraser, D.G. McCullough, T.M. Poland, R.L. Heyd. 2007. Detection and monitoring of emerald ash borer populations: trap trees and the factors that may influence their effectiveness. In: Gottschalk, Kurt W., ed. Proceedings, 17th U.S. Department of Agriculture interagency research forum on gypsy moth and other invasive species 2006; Gen. Tech. Rep. NRS-P-10. Newtown Square, PA: U.S. Department of Agriculture, Forest Service, Northern Research Station: 93.

Swearingen, J., K. Reshetiloff, B. Slattery, S. Zwicker. 2002. Plant invaders of Mid-Atlantic natural areas. National Park Service and U.S. Fish \& Wildlife Service, 82p.

Sydnor, T.D., M. Bumgardner, A. Todd. 2007. The potential economic impacts of emerald ash borer (Agrilus planipennis) on Ohio, U.S., communities. Arboriculture \& Urban Forestry. 33(1): 48-54.

Taylor, R.A., L.S. Bauer, D.L. Miller, R.A. Haack. 2005. Emerald ash borer flight potential. In: Mastro, Victor; Reardon, Richard, comps. Proceedings of the emerald ash borer research and technology development meeting; 2004 October 5-6; Romulus, MI. FHTET 2004-15.

Morgantown, WV: U.S. Forest Service, Forest Health Technology Enterprise Team: 15-16.

Thorn, J.S., V. Nijman, D. Smith, K.A.I. Nekaris. 2009. Ecological niche modelling as a technique for assessing threats and setting conservation priorities for Asian slow lorises (Primates: Nycticebus). Diversity \& Distributions 15(2): 289-298. 
Thuiller, W., D.M. Richardson, P. Pysek, G.F. Midgley, G.O. Hughes, M. Rouget. 2005. Nichebased modelling as a tool for predicting the risk of alien plant invasions at a global scale. Global Change Biology. 11: 2234-2250.

Timms, L.L., S.M. Smith, P. De Groot. 2006. Patterns in the within-tree distribution of the emerald ash borer (Agrilus planipennis, Fairmaire) in young, green-ash plantations of southwestern Ontario, Canada. Agricultural and Forest Entomology. 8: 313-321.

Tinoco, B.A., P.X. Astudillo, S.C. Latta, C.H. Graham. 2009. Distribution, ecology and conservation of an endangered Andean hummingbird: The violet-throated metaltail (Metallura baroni). Bird Conservation International. 19(1): 63-76.

Turcotte, R. Personal Interview. February 2009. USDA Forest Service Morgantown, WV.

Ueckert, D.N., H.A. Wright. 1974. Wood boring insect infestations in relation to mesquite control practices. Journal of Range Management. 27(5): 383-386.

USDA APHIS. 2006. Invasive species and forest health. October 2006.

USDA APHIS. 2008. Emerald ash borer background. Last Modified 8 October, 2008. Website: http://www.aphis.usda.gov/plant_health/plant_pest_info/emerald_ash_b/background.shtml (Last Accessed 11 March 2009).

US Forest Service. 2009. Control and management. Last Modified 14 September 2009. Website: http://nrs.fs.fed.us/disturbance/invasive_species/eab/control_management/ (Last Accessed 1 December 2009).

USGS. 2003. A tapestry of time and terrian: the union of two maps - geology and topography. US Dept. of Interior. Last Modified 17 April 2003. Website:

http://tapestry.usgs.gov/physiogr/physio.html (Last Accessed 30 November 2009).

Vogelmann, J.E., B.N. Rock, D.M. Moss. 1993. Red edge spectral measurements from sugar maple leaves. International Journal of Remote Sensing. 14: 1563-1575.

Walton, J.T., D.J. Nowak, E.J. Greenfield. 2008. Assessing urban forest canopy cover using airborne or satellite imagery. Arboriculture \& Urban Forestry. 34(6): 334-340.

Ward, K.T., G.R. Johnson. 2007. Geospatial methods provide timely and comprehensive urban forest information. Urban Forestry \& Urban Greening. 6: 15-22.

Wei, X., Y. Wu, R. Reardon, T. Sun, M. Lu, J. Sun. 2007. Biology and damage traits of emerald ash borer (Agrilus planipennis, Fairmaire) in China. Insect Science. 14(5): 367-373. Biological Abstracts 1969 - Present, EBSCOhost (accessed December 17, 2008).

West Virginia Division of Forestry. 2008. Emerald ash borer found in Fayette County quarantine placed on forest-related products. Website: http://www.wvforestry.com/eab.cfm (Last Accessed 10 March, 2009). 
Whitesell, C.D., D.S. DeBell, T.H. Schubert, R.F. Strand, T.B. Crabb. 1992. Short-rotation management of Eucalyptus: guidelines for plantations in Hawaii. Gen. Tech. Rep. PSW-GTR137. Albany, CA: Pacific Southwest Research Station, Forest Service, U.S. Department of Agriculture; 30p.

Widmann, R.H. 2005. Forests of the Garden State. Resour. Bull. NE-163. Newtown Square, PA: U.S. Department of Agriculture, Forest Service, Northeastern Research Station. 20p.

Williams, J.N., C. Seo, J. Thorne, J.K. Nelson, S. Erwin, J.M. O'Brien, M.W. Schwartz. 2009. Using species distribution models to predict new occurrences for rare plants. Diversity \& Distributions. 15(4): 565-576.

Wilson, M., E. Rebek. 2005. Extension Bullentin E-2938 Signs and symptoms of the emerald ash borer. Michigan State University. Reprinted December 2005.

Wisconsin DNR. 2008. Identification and Biology - Emerald ash borer. Website: http://dnr.wi.gov/forestry/FH/Ash/eab-symptoms.htm (Last Accessed 04 March, 2009).

Wollan, A.K., V. Bakkestuen, H. Kauserud, G. Gulden, R. Halvorsen. 2008. Modelling and predicting fungal distribution patterns using herbarium data. Journal of Biogeography. 35: 22982310.

Wolter, P.T., P.A. Townsend, B.R. Sturtevant, C.C. Kingdon. 2008. Remote sending of the distribution and abundance of host species for spruce budworm in Northern Minnesota and Ontario. Remote Sensing of Environment. 112: 3971-3982.

Yost, A.C., S.L. Petersen, M. Gregg, R. Miller. 2008. Predictive modeling and mapping sage grouse (Centrocercus urophasianus) nesting habitat using Maximum Entropy and a long-term dataset from southern Oregon. Ecological Informatics. 3(6): 375-386. 